UNIVERSIDADE DE SÃO PAULO

FACULDADE DE SAÚDE PÚBLICA

Tendência secular da alimentação de crianças brasileiras menores de cinco anos nas três últimas décadas

Ana Elisa Madalena Rinaldi

Tese apresentada ao Programa

de Pós-graduação em Nutrição

em Saúde Pública para obtenção

do título de Doutor em Ciências

Nível: Doutorado

Orientador: Prof. Dr. Wolney Lisboa Conde

São Paulo-SP

2015 


\title{
Tendência secular da alimentação de crianças brasileiras menores de cinco anos nas três últimas décadas
}

\author{
Ana Elisa Madalena Rinaldi \\ Tese apresentada ao Programa \\ de Pós-graduação em Nutrição \\ em Saúde Pública para obtenção \\ do título de Doutor em Ciências
}

Nível: Doutorado

Orientador: Prof. Dr. Wolney Lisboa Conde

São Paulo-SP

2015 
É expressamente proibida a comercialização deste documento, tanto na sua forma impressa como eletrônica. Sua reprodução total ou parcial é permitida exclusivamente para fins acadêmicos e científicos, desde que na reprodução figure a identificação do autor, título, instituição e ano da tese/dissertação. 
Dedicatória

Dedico esta tese, com muito carinho, aos meus pais e a minha irmã, pessoas queridas, que representam meu porto seguro, que respeitam e compreendem minhas escolhas e decisões. 


\section{Agradecimentos}

Ao Prof Wolney Conde, meu querido orientador, pelo prazer de poder partilhar do seu conhecimento, pela excelente orientação, pelo incentivo constante na tese e também na minha carreira profissional, pelos inúmeros cafés permeados por conhecimento científico e cultural, pela amizade e por ter acreditado no meu trabalho.

Ao Prof. José Maria Pacheco pelas diversas contribuições no meu trabalho, pelos questionamentos desde o exame de qualificação, que foram de grande valia para meu aprendizado e crescimento profissional;

À Dra. Sônia Venâncio pelos questionamentos e contribuições neste trabalho desde o exame de qualificação e pelo prazer de compartilhar dos seus conhecimentos da temática desta tese;

À Profa. Maria Antonieta Carvalhaes pelas contribuições e questionamentos no trabalho e também na minha formação acadêmica desde a graduação;

Ao Prof Pedro Lira pelas contribuições e avaliação deste trabalho;

À Profa Elsa Giugliane por contribuir no aprimoramento deste trabalho no exame de qualifição;

À Universidade Federal de Uberlândia, em nome do magnífico Reitor Elmiro Rezende e do Diretor da Faculdade de Medicina Ben Hur Braga Taliberti pela aprovação do pedido de afastamento para cursar o doutorado;

Ao Flávio, meu companheiro, pelo amor, carinho, respeito, cumplicidade, companhia, amizade, incentivo e compreensão nos momentos de alegria e de tensão;

Aos pais do Flávio, Noriko e Kazuo, por me acolher tão respeitosamente em São Paulo durante o doutorado;

À Profa. e amiga Daurea de Souza pelo incentivo constante na minha carreira acadêmica, pela amizade, trocas de ideia e ensinamentos;

À Profa. e amiga Catarina Azeredo por dividir desde 2010 o mesmo espaço de trabalho, as mesmas disciplinas do doutorado, as mesmas análises estatísticas, as mesmas agonias e alegrias desta fase especial que passamos juntas. Os aprendizados pelo convívio ultrapassaram os acadêmicos e vão valer para a vida;

A todos os colegas do Curso de Nutrição da Universidade Federal de Uberlândia pela amizade e incentivo durante o doutorado;

À Profa. e amiga Érika Tassi pelo prazer da sua amizade, pelas mensagens de carinho, apoio e incentivo;

Às amigas que tive o prazer de conhecer no Lanpop e poder compartilhar momentos tão agradáveis, em especial Márcia Pedroso, Regismeire Lima, Natalia Utikava, Giulia Mainardi, Natalia Altoé.

À Profa. Betzbeth Slater pela amizade nestes quatro anos e por compartilhar momentos tão agradáveis.

Às antigas e valiosas amigas, Cintia Diniz, Ana Paula Clemente, Vanessa Peresi, Helena Vassimon e Thalia Martins pelos incentivos durante estes quatro anos e pelos agradáveis momentos de convívio. 


\section{Epígrafe}

"A ciência será sempre uma busca, jamais uma descoberta. É uma viagem, nunca uma chegada"

"Acho que só há um caminho para a ciência - ou para a filosofia: encontrar um problema, ver a sua beleza e apaixonarmo-nos por ele; casarmo-nos com ele até que a morte nos separe - a não ser que encontremos outro problema ainda mais fascinante..." 


\section{RESUMO}

Rinaldi, AEM. Tendência secular da alimentação de crianças brasileiras menores de cinco anos nas três últimas décadas [tese de doutorado]. São Paulo: Faculdade de Saúde Pública da USP; 2015.

INTRODUÇÃO: As recomendações alimentares na infância são a exclusividade do leite materno $(L M)$ até o 6ำ mês, sua extensão mínima até o 24ำ mês e introdução programada de alimentos semissólidos e sólidos até os dois anos. O padrão alimentar na infância influencia preferências sensoriais e indicadores de saúde nos ciclos de vida subsequentes. OBJETIVO: Analisar a tendência secular da alimentação de crianças brasileiras menores de cinco anos entre 1986 e 2006. MÉTODOS: Os dados foram provenientes da amostra de crianças menores de cinco anos das três Pesquisas de Demografia e Saúde realizadas no Brasil em 1986, 1996 e 2006. O aleitamento materno (AM) foi descrito segundo indicadores propostos pela Organização Mundial da Saúde (2008). As medianas do AM e do aleitamento materno exclusivo (AME) e os seus fatores preditores foram estimadas por modelo de regressão de Cox. Os padrões alimentares (PA) foram identificados por análise de componentes principais (ACP) e, em seguida, foram calculados os escores de cada PA. Estes PA foram incluídos como desfechos em modelos de efeitos mistos cujos fatores preditores associados foram aqueles referentes à saúde maternoinfantil e sociodemográficos. RESULTADOS: Entre 1986 e 2006, o percentual de crianças expostas ao LM foi de 91 para $97 \%$ e a duração mediana, de 6 para 12 meses. Entre 1996 e 2006 a mediana do AME aumentou de 0,7 para 2 meses. A amamentação na $1^{\text {a }}$ hora de vida foi fator protetor para a duração do AME e do AM. A duração mediana do AME foi homogênea entre as regiões, associada de forma direta com relação de pré-natal, escolaridade materna e índice de riqueza. A duração mediana do AM foi associada de forma inversa com nascimento por parto cesáreo em hospital privado, intervalo interpartal inferior a 24 meses e difere segundo região geográfica, sendo superior no Norte brasileiro. Foram identificados quatro padrões alimentares para as crianças com idade entre 6 e 59 meses: PA1(iogurte, carnes, tubérculos, hortaliças, frutas), PA2(líquidos, leites nãomaternos, carnes e carga fatorial negativa para leite materno e papas à base de farinhas enriquecidas), PA3(líquidos, sucos de frutas, papas à base de amido industrializado, papas à base de farinha enriquecida, iogurte e carga fatorial negativa para carnes vermelhas) e PA4(leite não-materno, fórmulas e carga fatorial negativa 
papas à base de farinhas enriquecidas e ovopeixefrango). A prática dos padrões PA1 e PA3 foi superior entre crianças que recebiam leite materno. O padrão PA1 foi distribuído de forma homogênea entre as regiões enquanto os outros padrões alimentares apresentaram comportamento distinto entre as regiões. A mudança mais expressiva no período analisado foi a virtual substituição do PA4 pelo PA3, cuja composição de alimentos se aproxima mais das recomendações para faixa etária. CONCLUSÃO: O quadro pró-aleitamento materno é centrado principalmente na exposição universal ao $L M$ e na sustentação desta exposição, refletida no incremento da sua duração mediana. Entretanto, o avanço na duração do AME é menos expressivo no período. $O$ aumento da exposição aos alimentos sólidos entre as crianças menores de 12 meses representa a principal alteração dos padrões alimentares entre 1996 e 2006. Três padrões alimentares das crianças menores de cinco anos são influenciados regionalmente e um deles socialmente.

Descritores: padrões alimentares, aleitamento materno, alimentação infantil, tendência secular, análise de sobrevida. 


\section{ABSTRACT}

Rinaldi, AEM. Secular trend of Brazilian young child feeding practices in last three decades [Thesis]. São Paulo (BR): Faculdade de Saúde Pública da USP; 2015.

INTRODUCTION: The infant and recommendations are exclusive breastfeeding (EBF) at six months, breastfeeding at least $24^{\text {th }}$ months and the programmed introduction of solid, semi-solid or soft foods with breast milk until 24 months. Early dietary patterns can explain the sensory preferences and the health indicators throughout the life course. OBJECTIVE: To analyze the secular trend of Brazilian young child feeding practices between 1986 and 2006. METHODS: The under five children sample was from three probabilistic Brazilian Demographic Health Surveys carried out in 1986, 1996 and 2006. The breastfeeding (BF) was described according to the indicators from World Health Organization (WHO, 2008). The BF and exclusive breastfeeding (EBF) medians and the predictor factors were estimated using Cox regression model. The dietary patterns (DP) were identified by principal component analysis (PCA) and the dietary pattern scores were included as outcome variables in logistic mixed model. The predictive variables were sociodemographic, maternal and infant health. The complex design sample was considered in statistical analysis. RESULTS: In the period between 1986 and 2006, the percentage of children exposed to breast milk increased from 91 to $97 \%$ and the BF median increased from 6 to 12 months and the EBF increased from 0.7 to 2.0 months. Early initiation of breastfeeding was a protective factor for BF and EBF length. The EBF length was uniform among geographic regions and it was directly associated with antenatal care, maternal schooling and wealth index. The EF median was inversely associated with cesarean delivery in private hospital, birth interval less than 24 months and it was different among regions (higher in North). Four DP were identified for children age 6 to 59 months: PA1(composed of yogurt, red meat, chicken, eggs, tubers, vegetables and fruits), PA2(composed of liquids, non-breast milk, red meat, chicken, eggs and negative loadings for breast milk and enriched starch porridge), PA3(composed of liquids, fruit juices, industrialized starch porridge, yogurt and negative factor loadings for red meat) and PA4( composed of non-breast milk, formula and negative factor loadings for enriched starch porridge and egg/fish/chicken). The PA1 and PA3 practices were higher among breastfed children. The PA1 dietary pattern was uniform among geographic regions otherwise, another patterns were differently distribute. The most important DP change was the virtual replacement PA4 for PA3, 
that was more appropriated for children aged higher than 12 months. CONCLUSION: The pro-breastfeeding scenarium is focused mainly in children universally exposed to $\mathrm{BF}$ and the upkeeping of BF, assessed by BF median duration. However, in this survey periods, the increase of EBF duration is lower than the BF duration. The increased solids exposure in children under 12 months expresses the main dietary pattern change between 1996 and 2006. Three dietary patterns of under five children are predicted by geographic region factors and one of them by socioeconomic factors.

Key words: dietary patterns, breastfeeding, infant feeding, secular trend, survival analysis 
Sumário

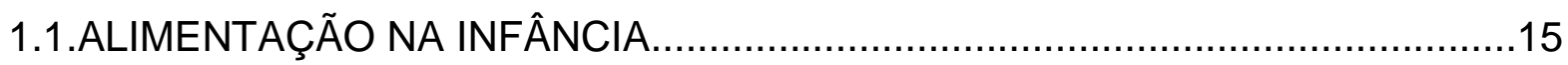

1.2.ALEITAMENTO MATERNO: BENEFÍCIOS E TENDÊNCIA TEMPORAL .........16

1.3.ALIMENTAÇÃO APÓS O SEXTO MÊS.......................................................21

1.4.PROGRAMAS E AÇÕES DIRECIONADAS À ALIMENTAÇÃO NA

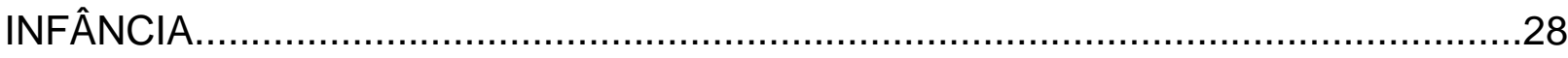

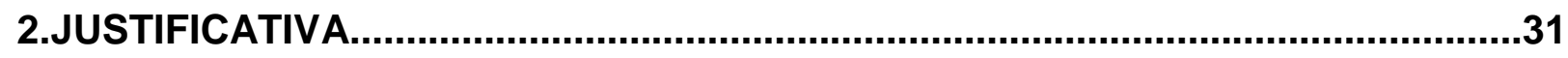

3.OBJETIVOS

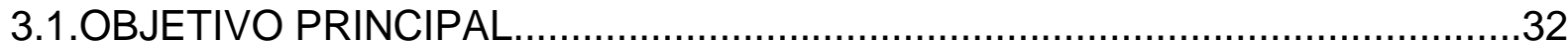

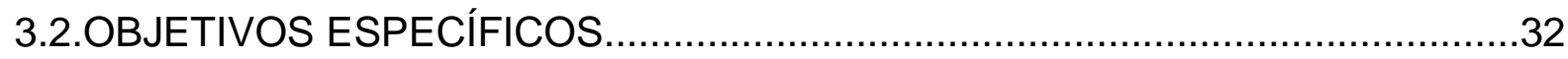

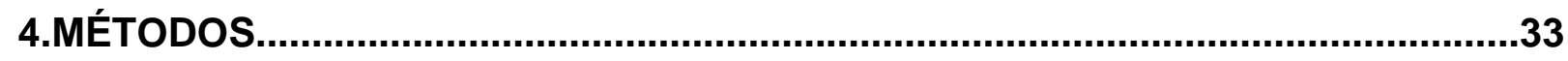

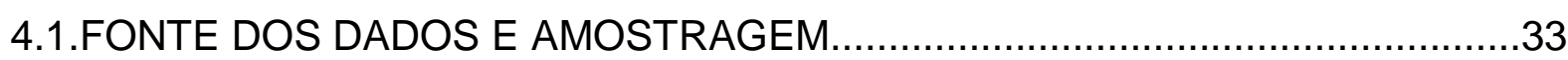

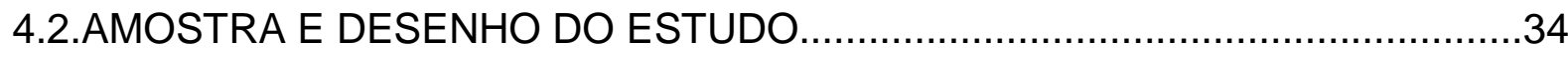

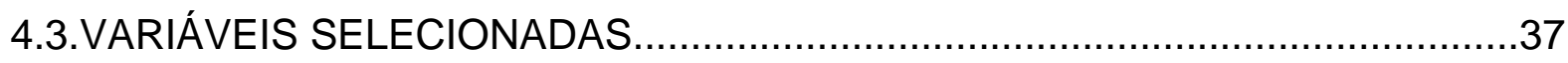

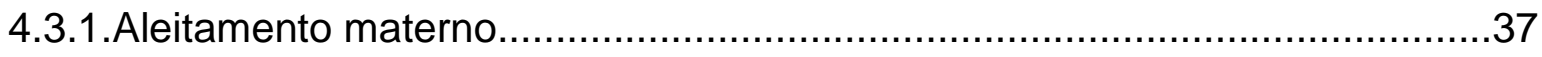

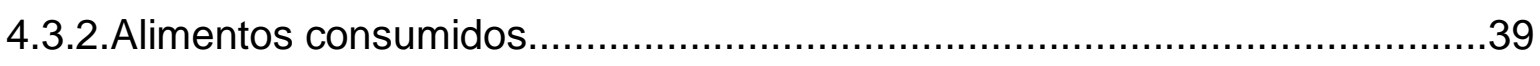

4.3.3. Variáveis referentes à criança...............................................................

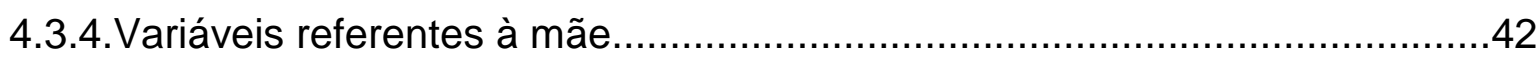

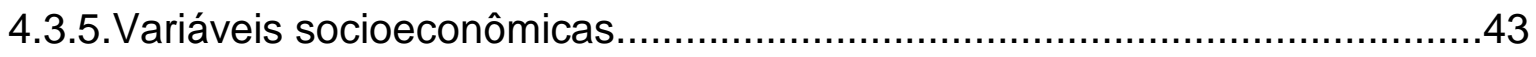

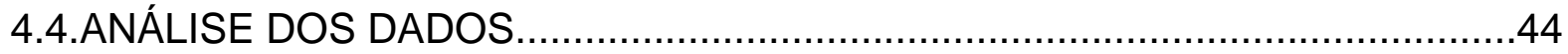

4.4.1. Descrição dos indicadores e da duração do aleitamento materno.................44

4.4.2.Descrição dos alimentos consumidos.......................................................

4.4.3.Definição dos padrões alimentares e fatores associados.............................47

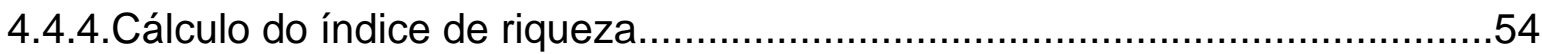


5.RESULTADOS.

5.1.DESCRIÇÃO E TENDÊNCIA TEMPORAL DOS INDICADORES SOCIODEMOGRÁFICOS E DE SAÚDE MATERNO-INFANTIL.................................62

5.2.DESCRIÇÃO DOS INDICADORES DO ALEITAMENTO MATERNO. .66

5.3.ALIMENTOS CONSUMIDOS ENTRE CRIANÇAS MENORES DE DOIS ANOS

5.4.PADRÕES ALIMENTARES NA INFÂNCIA EM TODO O ESPECTRO ETÁRIO

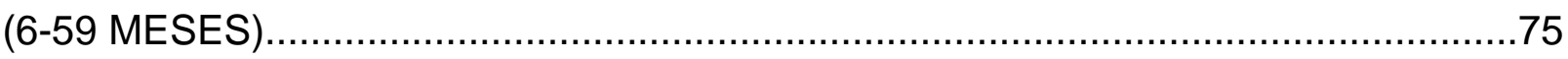

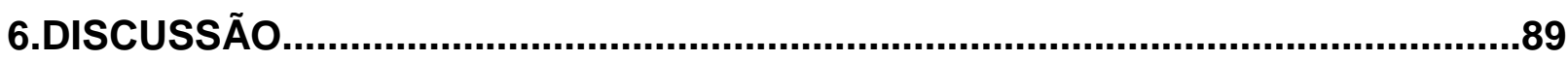

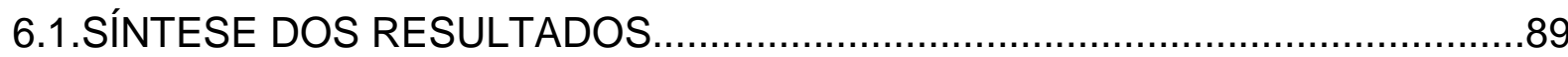

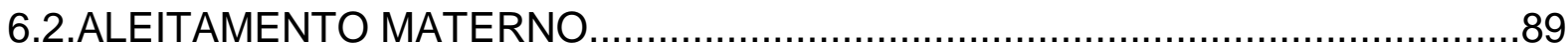

6.3.ALEITAMENTO E ALIMENTAÇÃO INFANTIL............................................100

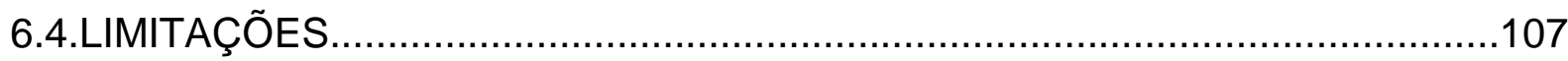

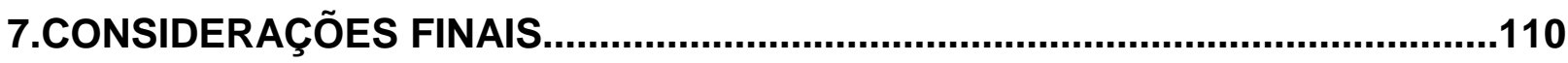

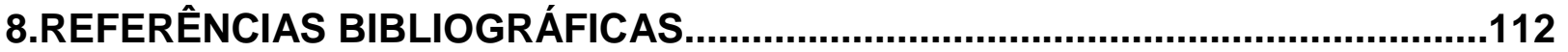

\section{ANEXOS}

ANEXO 1

ANEXO 2

ANEXO 3

ANEXO 4

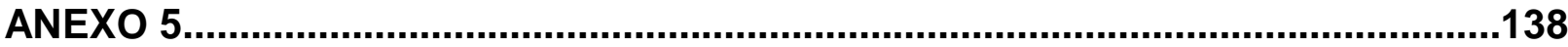

ANEXO 6

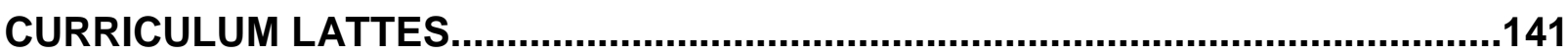




\section{Lista de Quadros e Tabelas}

Quadro 1. Descrição dos estudos sobre padrões alimentares infantis e fatores associados

Quadro 2. Indicadores selecionados da alimentação infantil e seus respectivos grupos etários de referência, tal como propostos pela Organização Mundial da Saúde 38

Quadro 3. Base populacional investigada e variáveis sobre alimentação nas três Pesquisas Nacionais de Demografia e Saúde .41

Quadro 4. Conteúdo dos grupos de alimentos segundo grupo etário.

Tabela 1. Características demográficas, socioeconômicas e de saúde infantil e materna. Brasil, 1986-2006

Tabela 2. Frequência e razão de prevalência dos indicadores do aleitamento materno de crianças menores de dois anos segundo ano do inquérito. Brasil, 19862006 67

Tabela 3. Efeitos dos fatores sociodemográficos e materno-infantil sobre a duração do aleitamento materno e aleitamento materno exclusivo modelados por regressão de Cox. Brasil, 1996-2006. .71

Tabela 4. Razão de prevalência e intervalo de confiança (95\%) para o registro mais precoce de água, líquidos, leite e fórmulas infantis e alimentos semissólidos e sólidos para crianças menores de seis meses segundo idade da criança e ano da pesquisa. Brasil, 1996-2006 .73

Tabela 5. Descrição dos padrões alimentares de crianças entre 6 e 59 meses. Brasil, 1996

Tabela 6. Distribuição percentual dos padrões alimentares segundo fatores sociodemográficos. Brasil, 1996. 78 
Tabela 7. Descrição dos padrões alimentares de crianças entre 6 e 59 meses. Brasil, 2006 80

Tabela 8. Distribuição percentual dos padrões alimentares segundo fatores sociodemográficos. Brasil, 2006. 82

Tabela 9. Descrição dos padrões alimentares de crianças entre 6 e 59 meses nas duas últimas décadas.

Brasil, $1996-$ 2006 83

Tabela 10. Descrição dos padrões alimentares de crianças entre 6 e 59 meses nas duas últimas décadas. Brasil, 1996-2006. 85

Tabela 11. Fatores sociodemográficos e materno-infantis e os escores dos padrões alimentares em modelo de efeitos mistos. Brasil, 1996-2006. .87 


\section{Lista de Figuras}

Figura 1. Sumário da cronologia das ações de promoção, apoio e proteção ao aleitamento materno.

Brasil, $1980-$ 2014 30

Figura 2. Sumário do desenho amostral das Pesquisas Nacionais de Demografia e Saúde (1986, 1996 e 2006) 34

Figura 3. Desenvolvimento cronológico da alimentação infantil e indicadores correspondentes segundo grupo etário entre crianças menores de cinco anos. .36

Figura 4: Representação simplificada da estrutura das variáveis na análise principais componentes. .48

Figura 5. Síntese das etapas de padronização das variáveis do consumo alimentar em 1996 e 2006 para a realização da estimativa multivariada dos padrões alimentares. .52

Figura 6. Modelo conceitual da duração do aleitamento materno e do aleitamento materno exclusivo. 56

Figura 7. Modelo conceitual dos padrões alimentares na infância. 59

Figura 8. Síntese das análises dos dados no estudo 61

Figura 9. Curvas de sobrevida modeladas por regressão de Cox para a duração do aleitamento materno (9A) e do aleitamento materno exclusivo (9B) nas três últimas décadas. Brasil, 1986-2006 69

Figura 10. Frequência relativa (\%) do consumo de leite materno e outros alimentos entre crianças brasileiras ao longo do período recomendado para amamentação. Brasil, 1986-2006 
Figura 11. Frequência dos cinco padrões alimentares de crianças entre 6 e 59 meses segundo

faixa

etária.

Brasil,

1996

Figura 12. Prevalência dos cinco padrões alimentares de crianças entre 6 e 59 meses segundo faixa etária. Brasil, 2006 81

Figura 13. Prevalência dos cinco padrões alimentares de crianças entre 6 e 59 meses segundo

ano

do

inquérito.

Brasil,

1996-

2006 


\section{INTRODUÇÃO}

\subsection{ALIMENTAÇÃO NA INFÂNCIA}

As práticas alimentares constituem elemento essencial no cuidado das crianças menores de cinco anos. A alimentação e o status de doenças nesta fase do ciclo de vida são os determinantes diretos do crescimento e desenvolvimento(WHO,1998). As repercussões biológicas da alimentação inadequada na infância são o aumento da morbi-mortalidade e o atraso no desenvolvimento motor e cognitivo. Entretanto, as repercussões sociais da inadequação da alimentação não se limitam a este ciclo de vida, sendo extrapoladas para a vida adulta marcando prejuízos no desempenho intelectual, capacidade de trabalho e desfechos reprodutivos, perpetuando o ciclo intergeracional da pobreza e da desnutrição. Desta forma, a qualidade da alimentação infantil começa com a garantia do estado nutricional e saúde maternos, que irão impactar os ciclos de vida subsequentes(WHO,2000). As práticas alimentares inadequadas constituem o maior obstáculo para o desenvolvimento econômico sustentável e a redução da pobreza, sendo que os esforços para acelerar o desenvolvimento econômico não serão bem sucedidos caso não haja investimento nas condições sociais que garantam a alimentação adequada(WHO,2003a).

As evidências científicas que embasaram as recomendações atuais da alimentação infantil foram o período crítico para o crescimento adequado do nascimento até os 24 meses (mais recentemente este período inclui a gestação), a duração adequada da oferta exclusiva do leite materno, a idade oportuna para introdução dos alimentos complementares ao leite materno, a quantidade e qualidade adequadas destes alimentos, expressas em necessidades energéticas e de micronutrientes, respectivamente. Adicionalmente, as bases fisiológicas da sucção, mastigação e deglutição permitiram estabelecer a consistência apropriada dos alimentos para cada idade(WHO,1998).

As recomendações para alimentação adequada foram compiladas pela Organização Mundial da Saúde em 10 diretrizes (Guiding principles for complementary feeding of the breastfeeding child), destacando o leite materno como o primeiro e único alimento a ser oferecido de forma exclusiva nos primeiros seis 
meses, a introdução subsequente de alimentos semissólidos e sólidos e a extensão do aleitamento materno até a idade mínima de 24 meses(WHO,2003b).

Diante da relevância da alimentação adequada para a saúde infantil, a OMS elaborou a Estratégia Global para a Alimentação Infantil(WHO,2003b) com o objetivo principal de melhorar a saúde, o estado nutricional, o crescimento e desenvolvimento e a sobrevivência nos primeiros cinco anos de vida. Os objetivos específicos da Estratégia englobam a sensibilização dos órgãos de saúde de cada país para elaboração de ações que promovam a alimentação infantil, assim como a criação de um ambiente favorável às mães e cuidados para a seleção e garantia de alimentação saudável às crianças(WHO,2003b).

Apesar das evidências serem bem organizadas e devidamente apoiadas na literatura científica, a forma mais consistente para implementá-las e avaliá-las no nível populacional esbarra em dificuldades metodológicas. A dificuldade e a complexidade se concentram no diagnóstico objetivo da qualidade da alimentação e no desenvolvimento e implantação das ações. A fim de superar estas dificuldades, os indicadores da alimentação infantil propostos em 1991, foram revisados e publicados em 2008. Estes indicadores são produtos de uma ampla revisão de estudos disponíveis e da análise de validade, precisão e consistência, testados a partir de uma base de dados de países em desenvolvimento. A aplicação dos indicadores é direcionada ao nível populacional com objetivos de descrever tendências temporais e comparações entre subgrupos populacionais; identificar o público alvo para intervenções e alocação de recursos, monitorar o progresso de implementação das metas e avaliar o impacto das intervenções(WHO,2008).

\subsection{ALEITAMENTO MATERNO: BENEFÍCIOS E TENDÊNCIA TEMPORAL}

O período que compreende os noves meses de gestação e os dois primeiros anos de vida - 1000 dias - é considerado atualmente uma janela de oportunidades para a implementação de ações que visam o crescimento e o desenvolvimento infantis adequados $e$, consequentemente, o desenvolvimento de uma nação(http://www.thousanddays.org/)(VICTORA et al., 2010). A oferta exclusiva do leite materno é a melhor forma de iniciar a alimentação da criança após o nascimento(WHO,2000). 
O leite humano é considerado o alimento mais adequado para o bebê pela especificidade de sua composição nutricional, presença de imunoglobulinas, células de defesa e compostos bioativos(STAM; SAUER; BOEHM, 2013). A composição nutricional do leite humano se ajusta à idade da criança e suas necessidades nutricionais, além de sofrer alterações intra e entre-mamadas, tornando-o superior a quaisquer fórmulas ou leite não-humano. O leite materno é um veículo dos odores e sabores dos alimentos consumidos pela mãe à criança e que fazem parte da sua cultura, sensibilizando-a precocemente aos alimentos que serão introduzidos posteriormente(MENNELLA; JAGNOW; BEAUCHAMP, 2001)(STAM; SAUER; BOEHM, 2013). Desta forma, a aceitabilidade de novos alimentos, de frutas e hortaliças é maior quando a criança é exposta ao sabor destes alimentos via leite materno. As crianças que são alimentadas com fórmulas infantis não vivenciam esta experiência sensorial precocemente e perdem a volatilidade dos sabores da alimentação da mãe(STAM; SAUER; BOEHM, 2013).

Outra vantagem do aleitamento materno é a preservação do ajuste fino dos sinais de fome e saciedade a partir da quantidade de energia consumida pela criança, principalmente quando a exposição ao leite materno ocorre por no mínimo 12 meses(MENNELLA; JAGNOW; BEAUCHAMP, 2001). A mudança de composição do leite materno ao longo do dia e a dificuldade das mães de controlar a quantidade de leite em cada mamada fazem com que a criança regule o seu consumo respeitando seus sinais de saciedade. Em contrapartida, a composição da fórmula é constante ao longo do dia e a quantidade diária é padronizada e determinada pela mãe e há o estímulo materno para que a criança consuma a quantidade oferecida. Este ajuste do consumo energético seria um dos possíveis mecanismos pelos quais o leite materno previne a obesidade(BARTOK; VENTURA, 2009).

As práticas alimentares nos primeiros dois anos de vida incluem o leite materno e são resumidas em três recomendações globais: amamentação na $1^{\underline{a}}$ hora de vida, o aleitamento materno exclusivo até o sexto mês e o aleitamento materno complementado até os 24 meses ou mais(WHO,2008).

O leite materno isoladamente pode evitar $13 \%$ das mortes por causas preveníveis em crianças menores de cinco anos, sendo que nenhuma outra estratégia isolada alcança tal magnitude(JONES et al., 2003). A proteção conferida pelo leite materno é maior quanto menor for a idade da criança e o nível 
socioeconômico(WHO,2000). Outra vantagem a ser destacada é a econômica, pois a amamentação poupa gastos com fórmulas infantis e alimentos.

A duração subótima do aleitamento materno, exclusivo ou não, ocupa a 14aㅗ posição no ranking geral de 43 fatores de risco para a carga global de doenças e é o segundo fator de risco para os anos de vida perdidos ajustados por incapacidade (Disability Adjusted Life Years - DALY) entre crianças menores de cinco anos. A África Subsaariana é o único local onde a duração subótima do aleitamento materno ainda ocupa a $3^{\text {a }}$ posição dentre todas as causas nas crianças menores de cinco anos. As mudanças no perfil de aleitamento materno retiraram o Brasil do ranking dos países com maior frequência absoluta e relativa de anos de vida perdidos por incapacidade (DALY) em função de condições subótimas do aleitamento materno(ROBERTS; CARNAHAN; GAKIDOU, 2013).

O aleitamento materno vigora como uma das recomendações centrais para a prevenção e o manejo da desnutrição e também para a prevenção da obesidade infantil. Dentre as seis Metas Globais para melhora da Saúde Materno-infantil elaboradas em 2012 pela Organização Mundial da Saúde, está o aumento de 50\% nas taxas do aleitamento materno exclusivo( http://www.thousanddays.org/). O Plano de Ação para a prevenção da obesidade na infância e na adolescência elenca a promoção, proteção e apoio às práticas do aleitamento materno e alimentação complementar como ação efetiva na prevenção da obesidade infantil(OPAS,2014).

Os estudos sobre os efeitos do aleitamento materno na saúde infantil tiveram início a partir da década de 70 possivelmente em função do baixo percentual de crianças amamentadas e da curta duração do aleitamento materno associados à elevada mortalidade infantil. Leonardo Mata e colaboradores verificaram que a flora intestinal de bebês amamentados protegia-os da diarreia(MATA; WYATT, 1971). Posteriormente, Feachem e Koblinsky (1984) publicaram a primeira meta-análise que mostrava proteção contra a morte por doenças infecciosas nas crianças que recebiam exclusivamente leite materno até 0 4ํ-으 mês de vida(FEACHEM; KOBLINSKY, 1984). A partir destas evidências, diversos estudos sobre o tema foram realizados. No Brasil, Victora e colaboradores (1987) em estudo de caso-controle, após ajuste dos fatores de confusão e construção do modelo epidemiológico causal, verificaram menor risco de morte por diarreia e outras infecções nas crianças aleitadas exclusivamente(VICTORA et al., 1987). Kramer e Kakuma (2004) constataram que crianças amamentadas exclusivamente até o sexto mês de vida 
não apresentaram déficit de crescimento em comparação àquelas que receberam outros alimentos além do leite materno(KRAMER; KAKUMA, 2004). Este estudo de revisão sistemática embasou a recomendação da prática do aleitamento materno exclusivo até o $6^{\circ}$ mês de vida.

Os benefícios do aleitamento materno para diferentes morbidades são consideradas como de curto e de longo prazo. Entre as morbidades a curto prazo estão a doenças respiratórias e a diarreia, que são consideradas as principais causas da mortalidade infantil(WHO,2013b). As evidências biológicas do efeito protetor do leite materno recaem principalmente na presença de substâncias com propriedades imunológicas e antimicrobianas, oligossacarídeos, fatores antimicrobianos e anti-inflamatórios. O leite materno em si contribui para o bom estado nutricional, condição necessária para manutenção da imunidade nãoespecífica e evita o consumo de alimentos que possam estar contaminados. $O$ aleitamento materno previne $80-90 \%$ e $50 \%$ da mortalidade e morbidade por diarreia, respectivamente, e $30 \%$ da morbidade por doenças respiratórias(WHO,2013b). Os efeitos isolados do aleitamento materno nestes dois desfechos foram verificados, após controle de todos os fatores de confusão.

Os efeitos a longo prazo do aleitamento materno estão associados às doenças crônicas e à inteligência (quociente de inteligência). A evidência biológica do efeito do aleitamento materno para estes desfechos é mais complexa em função da dificuldade de se estabelecer uma relação causal única, uma vez que estes desfechos têm múltiplas causas. Além disso, a estrutura da relação de confusão não se comportar de forma homogênea segundo o grau de desenvolvimento de um país(BRION et al., 2011). O efeito protetor do aleitamento materno na prevalência de excesso de peso ou obesidade é pequeno, 10\%, entretanto, é possível que haja efeito de confusão da renda e escolaridade materna. $O$ efeito do aleitamento materno nos desfechos pressão arterial, diabetes mellitus tipo 2 e colesterol total não é claro e possíveis associações indicariam efeitos residuais, sem relação causal efetivamente verificada. Entretanto, para a inteligência, a relação causal foi estabelecida. As crianças que foram amamentadas apresentaram desempenho superior nos testes de inteligência $(+2,19$ pontos)(WHO,2013a).

Em um pequeno recorte do comportamento das práticas de amamentação durante o século $X X$, verificou-se intenso declínio do percentual de crianças que 
recebiam o leite materno até a década de 70, período no qual este percentual atinge seu máximo expoente no Brasil e em outros países da América Latina(FREIRE, 2005). Contudo, estudos anteriores a este período são escassos, pontuais e regionais(VENANCIO; MONTEIRO, 1998). No município de São Paulo, neste período, a duração mediana da amamentação foi de apenas um mês(SIGULEM; TUDISCO, 1980). No Brasil, os estudos com representatividade nacional sobre amamentação tiveram início na década de 80 , tornando possível a análise temporal da situação do aleitamento materno. Entre as décadas de 70 e 80, a duração mediana da amamentação subiu de 2,5 para 5,5 meses(VENANCIO; MONTEIRO, 1998). A duração mediana do aleitamento materno entre 1974 e 2008 aumentou de 2,5 para 11,9 meses e a taxa de aumento da prevalência do aleitamento materno exclusivo foi de 13,2 entre 1986 e 2008 (3,1\% e 41,0\%, respectivamente)(VENÂNCIO, 2013). Estes dados são provenientes de diferentes inquéritos nacionais e para torná-los compatíveis, foram selecionadas somente as crianças menores de 12 meses.

Em um pool de 140 países em desenvolvimento a prevalência do aleitamento materno aumentou 18\% no período de 1995 e 2010. A maior taxa de aumento foi observada na África $(+1,59)$ e a menor no sul da Ásia $(+1,08)$. O sul da Ásia, no entanto, já registra as prevalências mais elevadas da prática do aleitamento materno. Este estudo não apresenta estimativas para América Latina e Caribe(CAI; WARDLAW; BROWN, 2012).

Em relação aos fatores envolvidos à interrupção do aleitamento materno, estes são semelhantes nos países desenvolvidos e no Brasil. Wijndaele e colaboradores (WIJNDAELE et al., 2009) verificaram em amplo estudo de revisão que mães jovens, com baixo nível de escolaridade, baixa renda, fumantes, curta duração do aleitamento materno e falta de orientação nos serviços de saúde foram determinantes do desmame precoce. Os fatores psicossociais e culturais, como apoio do cônjuge, familiares, amigos e a própria disponibilidade materna para amamentar também interferem no início e duração da amamentação e no período de introdução da alimentação complementar(LANDE et al., 2003). A introdução precoce do leite de vaca e o uso de chupeta também são fatores que contribuem para a redução da duração do aleitamento materno(BUENO et al., 2002)(PARIZOTO et al., 2009). A dimensão continental brasileira implica em diversidades culturais, 
climáticas, de costumes e tradições que devem ser consideradas nos estudos sobre este tema. Entre as crianças brasileiras com idade inferior a seis meses residentes nas capitais, a introdução do chá destaca-se na região sul, sucos e outros leites no nordeste e sudeste e mingau no nordeste(SALDIVA et al., 2011).

\subsection{ALIMENTAÇÃO APÓS O SEXTO MÊS}

A alimentação na infância é considerada relevante exposição modificável que tem efeito na saúde e desenvolvimento a curso e longo prazo(SMITHERS et al., 2012). Concomitantemente ao aleitamento materno, as intervenções que melhoram a qualidade da alimentação complementar seriam responsáveis pela prevenção de $5 \%$ da mortalidade infantil causada por diarreia, pneumonia, sarampo e malária(JONES et al., 2003).

O termo alimento complementar (complementary foods) se refere aos alimentos que são oferecidos à criança em adição ao leite materno e o termo alimentação complementar (complementary feeding) se refere ao processo de oferta destes alimentos complementares à criança(WHO,2000). A alimentação complementar considerada adequada deve contemplar quatro aspectos: 1) adequação ao tempo de introdução (timely): quando a oferta é realizada a partir do sexto mês, pois nesta fase o leite materno não é mais suficiente para atender as necessidades energéticas e de nutrientes (a partir dos seis meses); 2) adequação às recomendações nutricionais (adequate): quando os alimentos são oferecidos em quantidade suficiente para garantir o crescimento; 3) adequação às normas de higiene (safe): quando os alimentos são preparados e armazenados em locais e recipientes devidamente higienizados; 4) adequação à forma de oferta (properly fed): quando os alimentos são oferecidos de acordo com os sinais de fome e saciedade da criança(WHO,2000).

Os indicadores para avaliação das práticas alimentares infantis(WHO, 1991) foram desenvolvidos em 1991 com o objetivo de sistematizar e uniformizar a forma de descrever e analisar a situação do aleitamento materno. A alimentação complementar foi abordada neste documento, porém com o objetivo de marcar a idade em que o leite materno deixou de ser avaliado de forma exclusiva. 
A ausência de indicadores válidos e reprodutíveis tanto no contexto de cada país como entre países dificultou o progresso nos estudos que analisem a adequação das práticas alimentares infantis, suas repercussões no estado nutricional e consequentemente à elaboração de recomendações consistentes e de estratégias de intervenção(WHO,2008).

Em 2008, a Organização Mundial da Saúde adicionou cinco indicadores da alimentação infantil aos indicadores do aleitamento materno, sendo este conjunto composto por oito indicadores principais (core) e sete opcionais (optional). Os indicadores sobre a alimentação infantil contemplam a idade apropriada de introdução dos alimentos semissólidos e sólidos, a frequência das refeições, a diversidade da dieta, o consumo de grupos alimentares que devem ser oferecidos à criança e consumo de alimentos fontes de ferro(WHO,2008).

A síntese de dados regionais brasileiros sobre consumo alimentar de crianças menores de cinco anos apontou a ingestão predominante de leite em pó, modificado ou de vaca sem diluição adequada, espessantes como amido de milho e farináceos, açúcar (adicionados em mingaus ou refrigerantes), embutidos/enlatados, doces e guloseimas e quantidade insuficiente de carnes, feijões, hortaliças e frutas(JÚNIOR; DE; OSÓRIO, 2005)(OLIVEIRA et al., 2005)(TUMA; COSTA; SCHMITZ, 2005)(CASTRO et al., 2009)(CORRÊA et al., 2009). O consumo de açúcar é acentuado nas classes socioeconômicas mais baixas(AQUINO; PHILIPPI, 2002). A consistência dos alimentos também apresenta inadequação uma vez que a introdução de papas é substituída por alimentos sólidos ou altamente liquidificados(GARCIA DE LIMA PARADA; DE BARROS LEITE CARVALHAES; JAMAS, 2007). A adição de sal além da quantidade recomendada também foi identificada por pesquisadores em amostra de lactentes em Belém-PA, especialmente, nas famílias de baixo nível socioeconômico. A quantidade de sódio excedeu o valor máximo considerado seguro em $51,4 \%$ e $31,7 \%$ das crianças de baixo e alto nível socioeconômico, respectivamente. A quantidade de ferro também estava insuficiente(PORTELLA; MORAIS; MORAIS, 2010). Esta informação é preocupante, pois provavelmente há a ingestão concomitante de alimentos industrializados, que também contém excesso de sódio. Em um município da região metropolitana de São Paulo, os fatores associados à introdução precoce de alimentos foram o uso de chupetas, mães que trabalhavam e mães com mais de 35 
anos. O risco para a introdução precoce foi menor entre as crianças atendidas nos serviços públicos de saúde(SILVA; VENÂNCIO; MARCHIONI, 2010).

Um dos grandes desafios na área da alimentação após os seis meses de idade é descrever o seu conjunto. A necessidade de lidar com muitos indicadores nutricionais torna o quadro mais complexo e exige conjuntos de dados amplos para permitir recortes mais detalhados da alimentação infantil. Uma das saídas é a utilização de técnicas multivariadas para a análise de dados da alimentação infantil por sua capacidade de produzir sínteses robustas a partir do grande número de variáveis disponíveis.

A aplicação desta técnica aos dados dietéticos é frequentemente empregada nos estudos de epidemiologia nutricional sendo que as variáveis latentes são nomeadas genericamente como padrões alimentares e, mais especificamente, o rótulo de cada padrão é atribuído com base no(s) alimento(s) com maiores cargas fatoriais. Nos estudos sobre consumo alimentar em adultos, esta técnica é amplamente utilizada para descrever os padrões mais prevalentes na população estudada e a sua associação com doenças crônicas não-transmissíveis(FUNG et al., 2001)(DEMETRIOU et al., 2012).

A análise de principais componentes (APC) é uma técnica multivariada, cuja principal aplicação é a redução da complexidade da interrelação entre um número potencialmente grande de variáveis observadas a um número relativamente menor de combinações lineares deles, denominados como componentes principais ou variáveis latentes. De maneira ampla, a interpretação dos componentes principais é guiada pelo grau no qual cada variável está associada com um componente particular. Aquelas variáveis que estão mais relacionados ao componente em questão são usadas como guia para estas interpretações. Nesta análise há a concentração da variância em um número reduzido de variáveis/componentes. Os principais componentes têm as propriedades de serem não correlacionados uns com os outros. Cada componente é obtido de forma a concentrar a variância no conjunto inicial dos dados (nos primeiros componentes). Na análise de APC a maior parte da variância possível deve ser concentrada nas variáveis iniciais. Nesta técnica, os componentes principais ou variáveis latentes são utilizadas de forma descritiva e também modeladas como desfechos e preditores em outras análises estatísticas(RAYKOV; MARCOULIDES, 2012). 
A aplicação desta técnica na infância é mais recente e o enfoque se concentra na análise da distribuição dos padrões segundo estratos sociais e demográficos e a modificação ou estabilidade dos padrões segundo faixas etárias(GATICA et al., 2012)(SMITHERS et al., 2012)(BELL et al., 2013)(KRISTIANSEN et al., 2013) (WEN et al., 2014)(Quadro 1). 
Quadro 1. Descrição dos estudos sobre padrões alimentares infantis e fatores associados.

\begin{tabular}{|c|c|c|c|c|}
\hline $\begin{array}{c}\text { Local } \\
\text { Autores(ano) }\end{array}$ & $\begin{array}{c}\text { Faixa } \\
\text { etária } \\
\text { (meses) }\end{array}$ & $\begin{array}{l}\text { Número de } \\
\text { grupos } \\
\text { alimentares }\end{array}$ & Padrões alimentares ${ }^{\star}$ & Fatores preditores \\
\hline $\begin{array}{l}\text { Brasil } \\
\text { (Pelotas-RS) } \\
\text { Gatica et al } \\
(2012)\end{array}$ & $\begin{array}{c}12,24 \mathrm{e} \\
48\end{array}$ & $\begin{array}{l}\text { 12-24 meses: } 19 \\
48 \text { meses: } 20\end{array}$ & $\begin{array}{l}5 \text { padrões alimentares (12 e } 24 \text { meses) } \\
\text { Milk: leite materno(+) e leite de vaca(-) } \\
\text { Staples: arroz(+), feijão(+), massas(-) } \\
\text { Meat and vegetables: carne, hortaliças, batata/mandioca(+) } \\
\text { Beverages: suco(+), água/chá(-) } \\
\text { Snack: café(+), pãobolacha(+), frutas(-), iogurte(-) } \\
5 \text { padrões alimentares (48 meses) } \\
\text { Milk: leite de vaca(+) e leite com chocolate }(+) \\
\text { Staples: arroz }(+), \text { feijão(+), carne }(+) \\
\text { Beverages: suco(+), refrigerante(-) } \\
\text { Snack: café(+), pão/bolacha }(+), \text { água }(+), \text { iogurte(-), refrigerante(-) } \\
\text { Treats: salgadinho(+), doces }(+), \text { chocolates }(+)\end{array}$ & $\begin{array}{l}\text { Milk (12 e 24): associação inversa com índice } \\
\text { de riqueza } \\
\text { Milk (48): associação direta com índice de } \\
\text { riqueza } \\
\text { Treats (48): associação inversa com } \\
\text { escolaridade materna e com índice de } \\
\text { riqueza } \\
\text { Snack: associação inversa entre café, pão e } \\
\text { bolacha com índice de riqueza e associação } \\
\text { direta entre frutas, iogurte e refrigerantes. }\end{array}$ \\
\hline $\begin{array}{l}\text { Avon } \\
\text { (Inglaterra) } \\
\text { Smithers et al } \\
(2012)\end{array}$ & 6 e 15 & $\begin{array}{l}6 \text { meses: } 43 \\
15 \text { meses: } 70\end{array}$ & 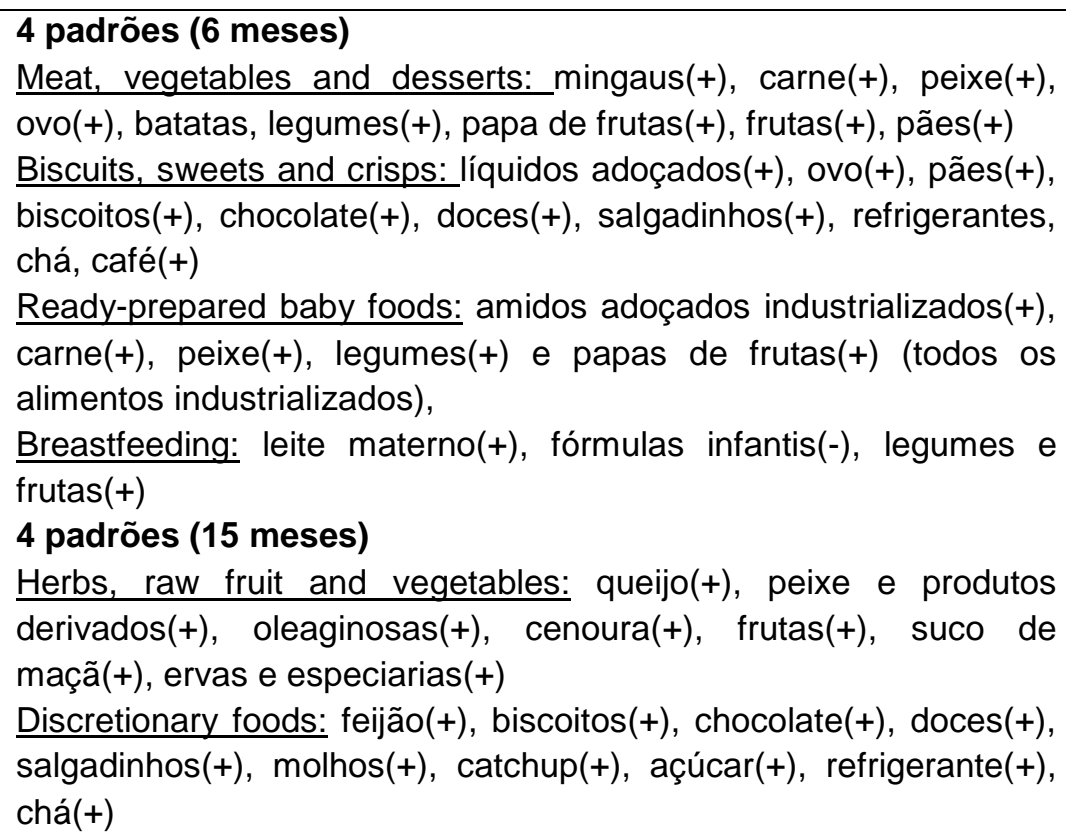 & $\begin{array}{l}\text { Breastfeeding e Meat, vegetables and } \\
\text { dessert: associação direta com a idade e } \\
\text { escolaridade maternal, número de crianças } \\
\text { na cada e associação inversa com o índice } \\
\text { de massa corporal materno } \\
\text { Discretionary foods: associação inversa com } \\
\text { idade e escolaridade materna e direta com } \\
\text { índice de massa corporal materno e número } \\
\text { de crianças na família } \\
\text { Ready-prepared baby foods: associação } \\
\text { inconsistente com os fatores } \\
\text { sociodemográficos }\end{array}$ \\
\hline
\end{tabular}




\begin{tabular}{|c|c|c|c|c|}
\hline & & & $\begin{array}{l}\text { Ready-prepared baby foods: alimentos para bebês industrializados } \\
\text { - mingaus(+), carnes(+), peixes }(+) \text {, legumes(+), papa de frutas }(+) \text {, } \\
\text { cereal de arroz }(+) \text {, torradas }(+) \\
\text { Reverse meats, vegetables and dessert: iogurte(-), mingau(-), } \\
\text { vísceras(-), peixes(-), ervilhas(-), batatas(-), papa de frutas(-), } \\
\text { molhos(-) }\end{array}$ & \\
\hline $\begin{array}{l}\begin{array}{l}\text { Australia } \\
\text { (nacional) }\end{array} \\
\text { Bell et al } \\
(2013)\end{array}$ & 14 e 24 & $\begin{array}{l}13 \text { a } 16 \text { meses } \\
(14 \text { meses): } 69 \\
22 \text { a } 25 \text { meses } \\
\text { (24 meses): } 73\end{array}$ & 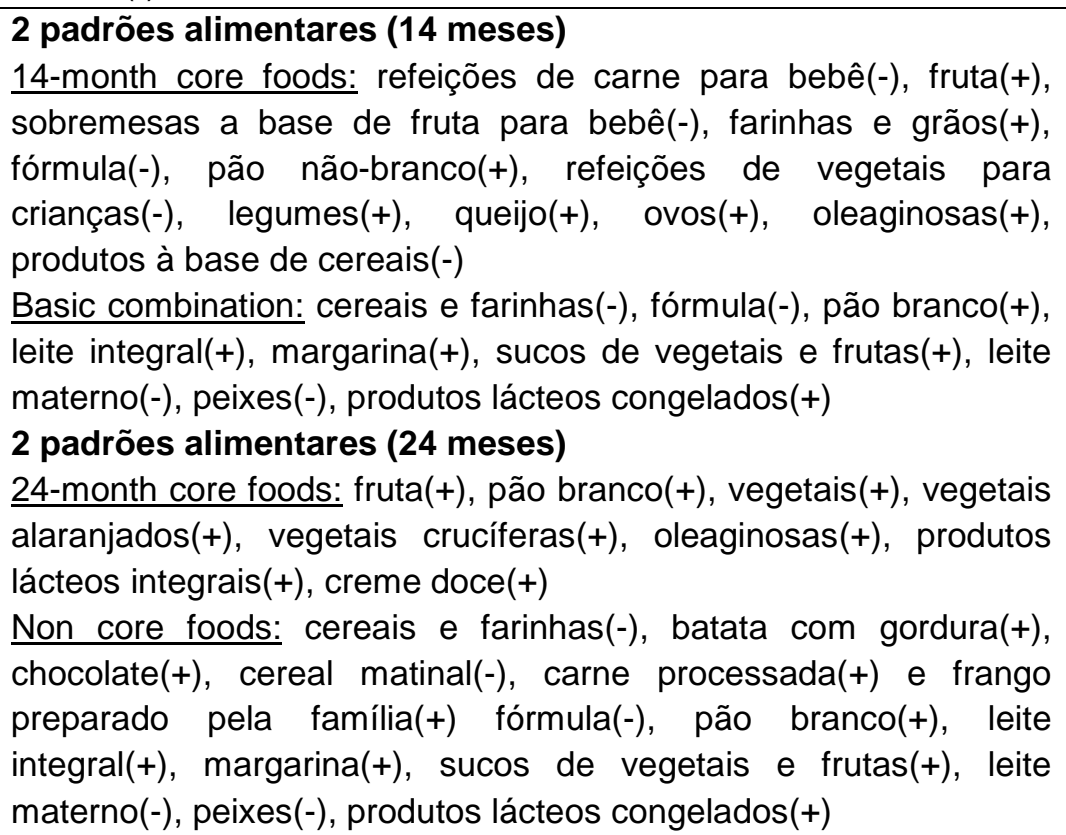 & $\begin{array}{l}14 \text { month core foods: associação inversa } \\
\text { com a escolaridade materna, idade da } \\
\text { criança e duração do aleitamento materno } \\
\text { Basic combination: associação inversa com a } \\
\text { idade materna no nascimento da criança e } \\
\text { duração do aleitamento materno e direta com } \\
\text { a idade da criança } \\
24 \text { month core foods: associação direta com } \\
\text { a introdução de sólidos } \\
\text { Non-core: associação inversa com a idade } \\
\text { materna de nascimento e duração do } \\
\text { aleitamento materno }\end{array}$ \\
\hline $\begin{array}{l}\text { Noruega } \\
\text { (nacional) } \\
\text { Kristiansen et } \\
\text { al (2013) }\end{array}$ & 24 & $\begin{array}{l}\text { 1999: } 131 \\
\text { 2007: } 151\end{array}$ & 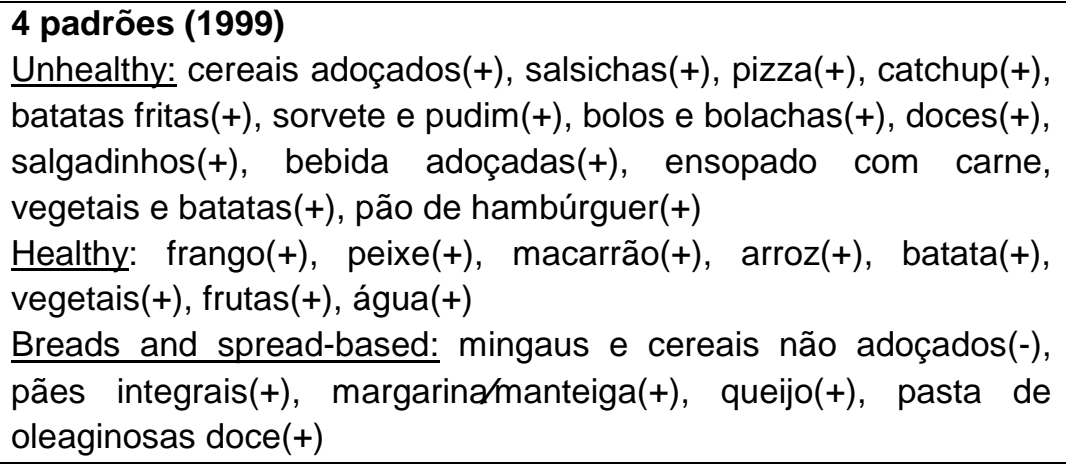 & $\begin{array}{l}\text { Unhealthy: associação direta com sexo } \\
\text { masculino, paridade e inversa com duração } \\
\text { aleitamento materno, escolaridade materna e } \\
\text { paterna }\end{array}$ \\
\hline
\end{tabular}




\begin{tabular}{|c|c|c|c|c|}
\hline & & & 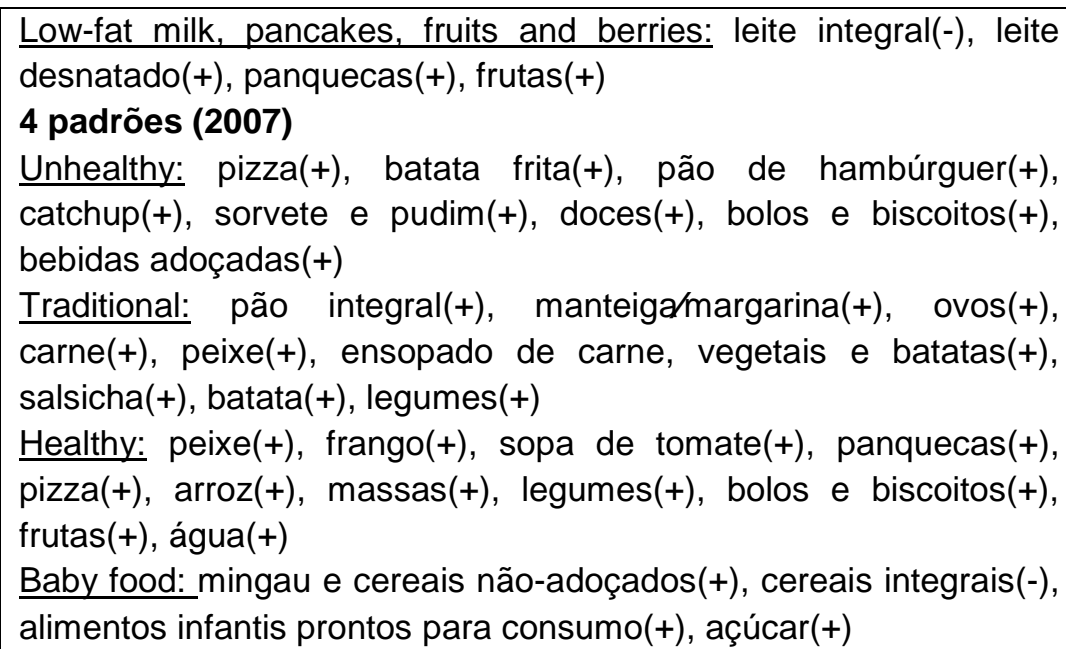 & \\
\hline $\begin{array}{l}\text { Estados } \\
\text { Unidos } \\
\text { Wen et al } \\
(2014)\end{array}$ & 6 e 12 & 6 e 12 meses: 18 & 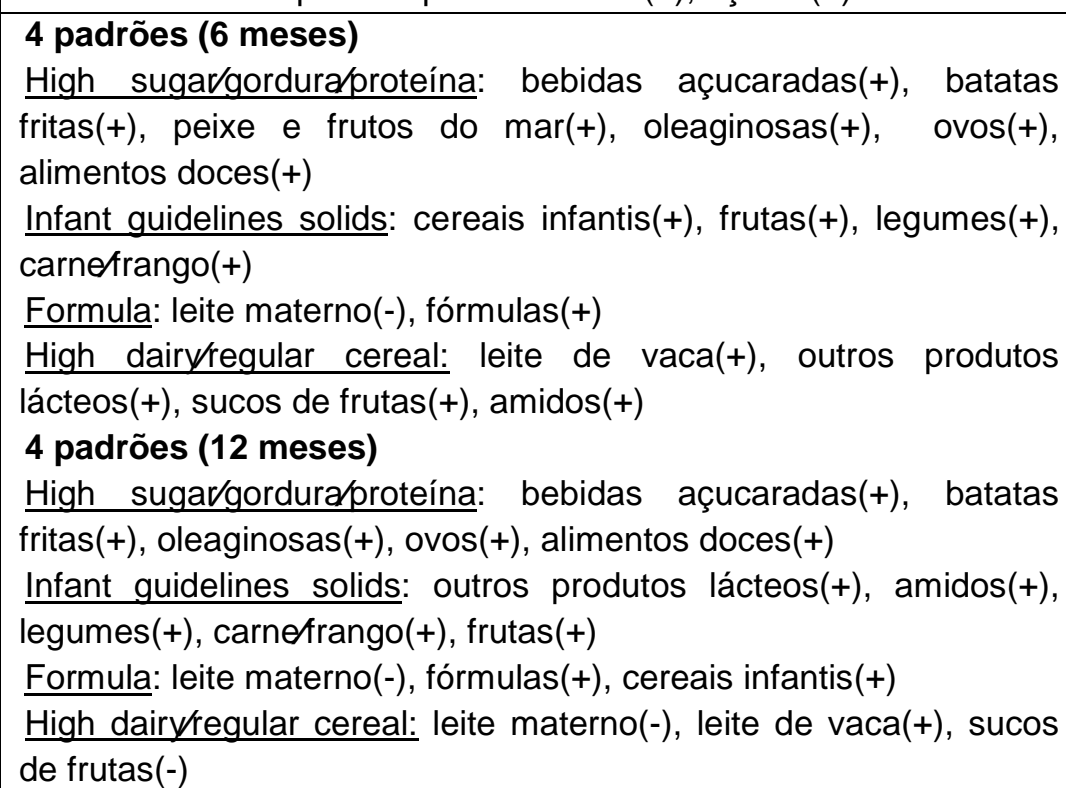 & $\begin{array}{l}6 \text { meses } \\
\text { High sugargordura/proteína e High } \\
\text { dairy/regular cereal: associação inversa com } \\
\text { o escore comprimento-para-idade, } \\
\text { associação direta com escore do índice de } \\
\text { massa corporal-para-idade } \\
\text { Formula: associação direta com escore do } \\
\text { índice de massa corporal-para-idade } \\
12 \text { meses } \\
\text { High sugavgordura/proteína: associação } \\
\text { inversa com a escolaridade materna }\end{array}$ \\
\hline
\end{tabular}

${ }^{*}(+)$ : carga fatorial positiva com o padrão alimentar; (-):carga fatorial negativa com o padrão alimentar 


\subsection{PROGRAMAS E AÇÕES DIRECIONADAS À ALIMENTAÇÃO NA INFÂNCIA}

Outro item importante na análise da alimentação infantil no Brasil é o conjunto de políticas públicas voltadas para a promoção ou regulação da alimentação saudável nesse grupo etário.

Dentre as diversas intervenções de saúde, o incentivo ao aleitamento materno e sua prática é uma das intervenções que exigem menor infraestrutura por parte dos órgãos públicos que não produzem desigualdades sociais(ROBERTS; CARNAHAN; GAKIDOU, 2013)(WHO, 2010).

No Brasil, a trajetória das ações de promoção do aleitamento materno iniciou em 1981 com a criação do Programa Nacional de Incentivo ao Aleitamento Materno (PNIAM)(MINISTÉRIO DA SAÚDE, 2011) (Figura 1). A primeira atividade desenvolvida em 1981 foi a veiculação maciça em emissora de rádio e televisão de que as crianças deveriam receber leite materno seguida pela produção de materiais educativos e treinamento de profissionais da saúde. Posteriormente, o Instituto Nacional de Alimentação e Nutrição (INAN) elaborou as primeiras Normas para Comercialização de Alimentos para Lactentes em 1988, atual Norma Brasileira de Comercialização de Alimentos para Lactentes e Crianças de Primeira Infância, Bicos, Chupetas e Mamadeiras(MINISTÉRIO DA SAÚDE, 2011).

Dentre as ações internacionais pró-amamentação da década de 90, destacase a Declaração de Innocenti (1990), enfatizando que todas as mulheres devem estar capacitadas para praticar o aleitamento materno exclusivo até o 4ํㅜ ou 6ํㅡês de vida.

Estas ações supracitadas ocorreram durante intensas modificações demográficas e socioeconômicas brasileiras, com destaque à crescente urbanização, contribuindo para aproximar as mulheres e crianças dos serviços de saúde e destas ações(IBGE,2010). No setor da saúde, a criação do Sistema Único de Saúde (SUS) na década de 90 possibilitou maior cobertura da assistência básica de saúde como a ampla cobertura vacinal, a criação do Programa de Saúde da Família juntamente com o Programa de Agentes Comunitários, garantindo, principalmente, os cuidados com a saúde materno-infantil(MONTEIRO et al., 2010). A composição e a organização da Rede de Atenção à Saúde do atual sistema de saúde brasileiro contribuem para 
aplicação das ações de promoção, proteção e incentivo ao aleitamento materno, por contemplar o aleitamento em todos os níveis de atenção.

As ações de incentivo à alimentação saudável e adequada concentram-se na elaboração do Guia Alimentar para Crianças Menores de dois anos(MINISTÉRIO DA SAÚDE, 2002), na Estratégia Nacional para Alimentação Complementar Saudável (ENPACS)(MINISTÉRIO DA SAÚDE, 2010a), cujo foco principal é incentivar a alimentação complementar como atividade de rotina dos serviços de saúde e mais recentemente na Estratégia Nacional para Promoção do Aleitamento Materno e Alimentação Complementar Saudável - Estratégia Amamenta e Alimentação Brasil(MINISTÉRIO DA SAÚDE, 2013). Esta Estratégia é resultante da integração de duas estratégias já existente que são a Rede Amamenta Brasil(MINISTÉRIO DA SAÚDE, 2008) e a ENPACS. Os objetivos centrais desta estratégia são qualificar as ações de promoção do aleitamento materno e da alimentação complementar saudável para crianças menores de dois anos e aprimorar as competências e habilidades dos profissionais da saúde para a promoção do aleitamento materno e da alimentação complementar como atividade de rotina das Unidades Básicas de Saúde. Os resultados esperados com a implementação de estratégia são o aumento da taxa de aleitamento materno exclusivo entre as crianças menores de seis meses, aumentar a taxa de aleitamento materno entre as crianças menores de 24 meses, reduzir a introdução precoce de fórmulas e alimentos que possam interromper o aleitamento materno, aumentar o consumo de frutas, hortaliças e reduzir o consumo de alimentos processados.

Em comparação com o aleitamento materno, estudos nacionais que tracem um perfil consistente das práticas alimentares infantis após o sexto mês de vida e que avaliem sua tendência temporal dentro da ótica das mudanças conjunturais socioeconômicas, demográficas e das políticas de saúde ainda são escassos e devem ser realizados. 


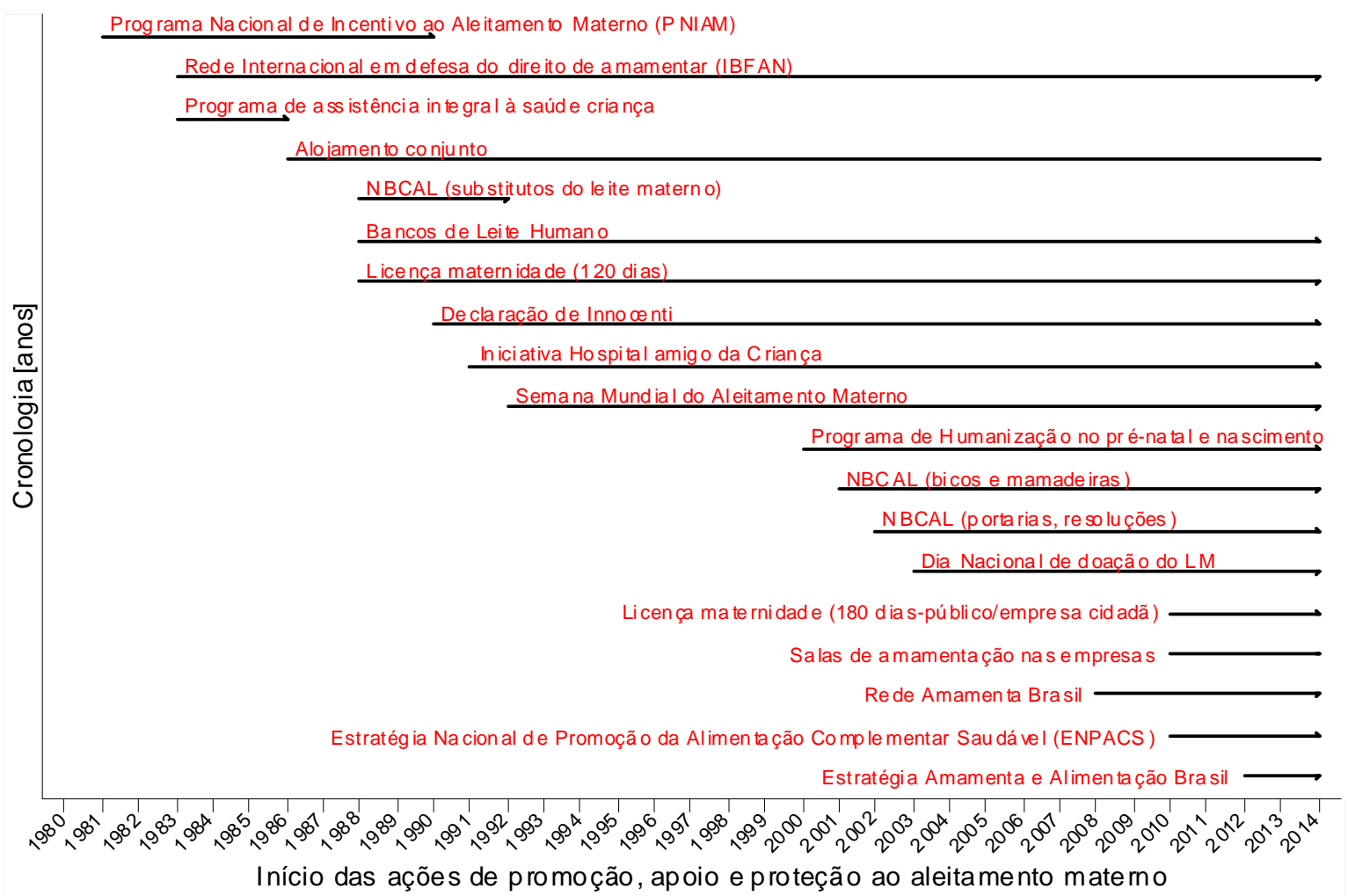

NBCAL: Norma Brasileira de Comercialização de Alimentos para Lactentes e Crianças de Primeira Infância, Bicos, Chupetas e Mamadeiras

Figura 1. Sumário da cronologia das ações de promoção, apoio e proteção ao aleitamento materno. Brasil, 1980-2014. 


\section{JUSTIFICATIVA}

Os resultados contemporâneos dos fatores preditores de saúde evidenciam os efeitos positivos do aleitamento materno em todos os ciclos de vida, seu papel relevante nos indicadores socioeconômicos de uma sociedade e no desenvolvimento do capital humano. Adicionalmente, estudos mais recentes sinalizam a contribuição do leite materno na formação de hábitos alimentares mais saudáveis. As experiências sensoriais no início da vida modelam as preferências sensoriais e alimentares na vida adulta. Os odores variados da alimentação materna são experimentados precocemente pela criança via leite materno.

O aumento das taxas de aleitamento após a implementação de ações de promoção, apoio e proteção foi descrito em recortes de estudos nacionais e, principalmente, regionais. Contudo, a descrição completa da trajetória da duração do aleitamento materno e aleitamento materno exclusivo e seus fatores associados não foram descritos anteriormente, em função de diferenças centradas na base amostral, nos recortes etários e nos métodos analíticos.

De forma distinta do aleitamento materno, a trajetória dos padrões alimentares associados ou não ao leite materno no contexto nacional é pouco descrita e compreendida. Esta lacuna é justificada pela ausência de indicadores robustos a serem utilizados na sua aferição e escassos estudos que tinham como propósito analisar os efeitos da alimentação infantil nos ciclos de vida.

A análise das práticas alimentares infantis deve englobar o aleitamento materno e os alimentos consumidos conjuntamente a fim de embasar ações que potencializem os benefícios individuais e contextuais e de forma a não causar iniquidades sociais e de saúde.

Deste modo, a identificação de padrões alimentares infantis e a análise de sua tendência secular bem como de seus fatores associados propiciará a compreensão mais ampla e histórica da alimentação infantil no Brasil. 


\section{OBJETIVOS}

\subsection{OBJETIVO PRINCIPAL}

Analisar a tendência secular da alimentação de crianças brasileiras menores de cinco anos entre 1986 e 2006.

\subsection{OBJETIVOS ESPECÍFICOS}

-Descrever a trajetória dos indicadores do aleitamento materno e analisar os fatores associados a sua duração entre 1986 e 2006;

-Caracterizar os padrões alimentares de crianças brasileiras menores de cinco anos entre 1996 e 2006;

-Analisar o efeito de fatores sociodemográficos, materno-infantis e contextuais sobre a evolução dos padrões alimentares entre 1996 e 2006. 


\section{MÉTODOS}

\subsection{FONTE DOS DADOS E AMOSTRAGEM}

Os dados utilizados neste estudo são provenientes das três Pesquisas Nacionais de Demografia e Saúde (PNDS) realizadas nas três últimas décadas. As PNDS selecionadas foram realizadas em 1986, 1996 e $2006^{1}$ e são integrantes do projeto Monitoring and Evaluation to Assess and Use Results Demographic and Health Survey (Measure DHS) (http://www.dhsprogram.com/), da Instituição Macro International, com apoio e colaboração da Agência dos Estados Unidos para o Desenvolvimento (USAID) e outras instituições internacionais e foram financiadas pelo Governo Federal do Brasil. Estes inquéritos correspondem às primeira, terceira e quinta fases, respectivamente, do Projeto Measure DHS. O objetivo central dos inquéritos é fornecer amplo conjunto de dados e indicadores para o monitoramento e avaliação de impacto sobre demografia, saúde e nutrição.

As amostras da PNDS visam a representar probabilisticamente a população feminina em idade fértil (15 a 44 anos em 1986 e 15 a 49 anos em 1996 e 2006) e a população de crianças nascidas nos cinco anos anteriores ao inquérito. Nos dois casos as amostras são desenhadas para ter representatividade nacional. De fato, a amostra de crianças menores de cinco anos é uma subamostra do conjunto de mulheres em idade fértil no território nacional.

Os três inquéritos são de base domiciliar com amostragem probabilística complexa realizada em dois estágios de seleção. No primeiro estágio foram selecionados os setores censitários e no segundo estágio os domicílios (Figura 2). As informações mais detalhadas sobre o desenho e a dinâmica das pesquisas estão organizadas no Anexo 1.

1:Sociedade Civil Bem-Estar Familiar no Brasil. Pesquisa Nacional sobre saúde materno-infantil e planejamento familiarPNSMIPF-Brasil,1986. Disponível em: http://dhsprogram.com/data/dataset/Brazil Standard-DHS 1986.cfm?flag=0 Sociedade Civil Bem-Estar Familiar no Brasil. Pesquisa Nacional sobre Demografia e Saúde - 1996. Disponível em: http://dhsprogram.com/data/dataset/Brazil Standard-DHS 1996.cfm?flag $=0$

BRASIL, Ministério da Saúde; Centro Brasileiro de Análise e Planejamento. Pesquisa Nacional de Demografia e Saúde da Criança e da Mulher -2006 Disponível em: http://bvsms.saude.gov.br/bvs/pnds/banco dados.php 


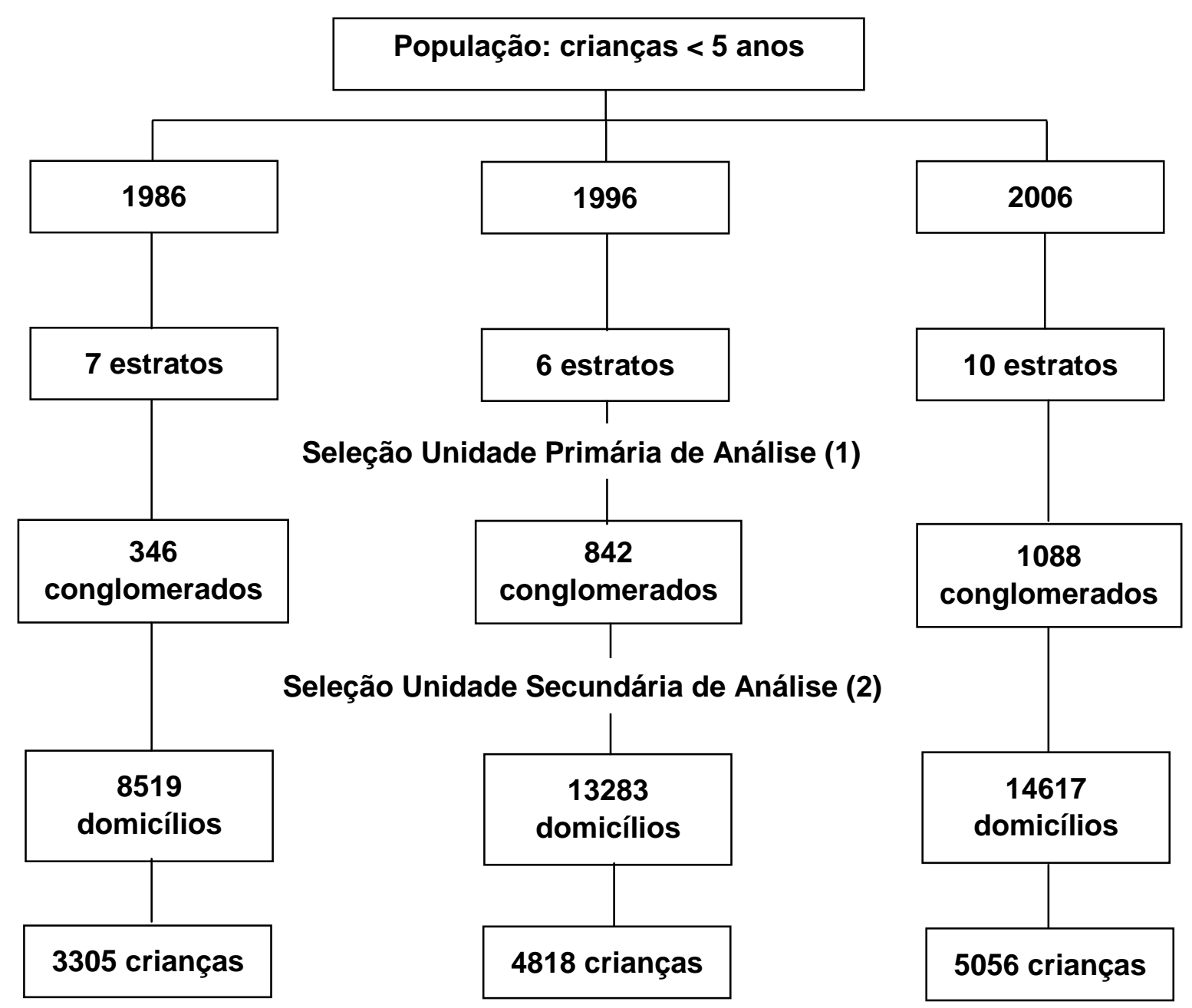

1: 1986, 1996: amostragem proporcional ao número de domicílios em cada setor; 2006: amostragem aleatória simples por conglomerado

2: 1986, 1996: amostragem sistemática, 2006: amostragem inversa

Figura 2. Sumário do desenho amostral das Pesquisas Nacionais de Demografia e Saúde (1986, 1996 e 2006).

\subsection{AMOSTRA E DESENHO DO ESTUDO}

A amostra de crianças nas três Pesquisas Nacionais de Demografia e Saúde foi selecionada a partir do conjunto de crianças nascidas nos cinco anos antecedentes à entrevista, listadas na história de nascimento da mulher elegível e entrevistada nos inquéritos (Figura 1). Para este estudo, foram selecionadas as crianças menores de cinco anos, que estivessem vivas no momento da entrevista e que morassem com o respondente. Desta forma, 12715 crianças atenderam estes critérios, sendo 3218 em 1986, 4680 em 1996 e 4817 em 2006. Estas crianças representam $97,4 \%, 97,1 \%$ e $95,3 \%$, respectivamente, da amostra final dos três inquéritos. 
Os indicadores utilizados nas análises deste estudo são referentes à alimentação das crianças menores de cinco anos. Em cada caso, o grupo etário selecionado se baseou nas faixas etárias recomendadas pela Organização Mundial da Saúde (OMS) para cada indicador(WHO,2008).

No inquérito de 1986, as variáveis referentes aos alimentos consumidos estavam disponíveis somente para as crianças que estivessem recebendo leite materno. Em função desta variabilidade, as análises sobre aleitamento materno incluíram as crianças dos três inquéritos (1986, 1996 e 2006) e sobre alimentos consumidos dos dois inquéritos (1996 e 2006).

As análises deste estudo foram organizadas com base nas características da alimentação, nas recomendações específicas para cada faixa etária e em seus indicadores correspondentes internacionalmente recomendados (Figura 3). 


\section{Aleitamento materno ${ }^{1.2}$}

\section{Indicadores aleitamento materno ${ }^{1.1}$}

\section{AME1}
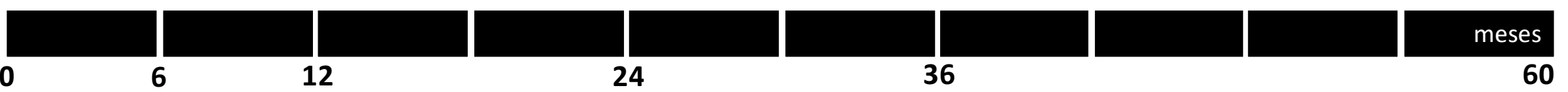

\section{Alimentos \\ oferecidos \\ (não}

recomendado) ${ }^{2}$

\section{Alimentação de transiçãõo 2.1}

\section{Alimentos consumidos (padrões alimentares) 2.2}

1:Duração do aleitamento materno exclusivo (mediana)

1.1:Prevalência dos indicadores do aleitamento materno: exposição ao leite materno após nascimento, exposição ao leite materno, aleitamento materno exclusivo, aleitamento materno predominante, aleitamento materno continuado

1.2:Duração do aleitamento materno (mediana)

2:Frequência dos alimentos oferecidos às crianças $<6$ meses (não recomendados)

2.1:Frequência dos alimentos oferecidos 6 as 24 meses (recomendados)

2.2:Alimentos consumidos (análise multivariada: padrões alimentares)

Figura 3. Desenvolvimento cronológico da alimentação infantil e indicadores correspondentes segundo grupo etário entre crianças menores de cinco anos. 


\subsection{VARIÁVEIS SELECIONADAS}

Neste estudo, o termo alimentação infantil engloba o aleitamento materno e os alimentos consumidos concomitante ou isoladamente do leite materno. Conforme representado na Figura 2, os desfechos considerados neste estudo foram as variáveis referentes à alimentação da criança, a qual contempla o aleitamento materno e os alimentos consumidos, em função da faixa etária analisada. O desfecho aleitamento materno foi expresso em prevalência e duração e o desfecho alimentos consumidos foi expresso em prevalência e em escores de padrões alimentares, identificados por análise de principais componentes. O termo padrão alimentar descreve o conjunto dos alimentos consumidos em cada grupo etário e representa, nessa perspectiva, a ultrapassagem da análise alimentar baseada em alimentos ou seus nutrientes isoladamente.

\subsubsection{Aleitamento materno}

As definições de aleitamento materno exclusivo, predominante e aleitamento materno utilizadas neste estudo foram aquelas propostas pela Organização Mundial da Saúde(WHO,2008). O perfil e a trajetória do aleitamento materno no Brasil nas três últimas décadas foram caracterizados e analisados a partir dos indicadores da alimentação infantil propostos pela Organização Mundial da Saúde(WHO,2008). Estes indicadores são calculados com base nas informações referentes à situação da alimentação no dia anterior para crianças menores de 24 meses (status atual).

Todos os indicadores foram calculados como proporções e foram configurados como variáveis dicotômicas (não/sim) para serem analisados (Quadro 2). 
Quadro 2. Indicadores selecionados da alimentação infantil e seus respectivos grupos etários de referência, tal como propostos pela Organização Mundial da Saúde.

\begin{tabular}{|c|c|c|c|}
\hline Indicador & $\begin{array}{c}\text { Grupo } \\
\text { etário de } \\
\text { referência }\end{array}$ & Numerador & Denominador \\
\hline $\begin{array}{c}\text { Crianças } \\
\text { amamentadas }\end{array}$ & $\begin{array}{l}0 \text { a } 24 \\
\text { meses }\end{array}$ & $\begin{array}{l}\text { Crianças nascidas nos } \\
\text { últimos } 24 \text { meses e que } \\
\text { receberam } \\
\text { materno }\end{array}$ & $\begin{array}{l}\text { Crianças nascidas nos } \\
\text { últimos } 24 \text { meses }\end{array}$ \\
\hline $\begin{array}{c}\text { Amamentação na } \\
1{ }^{\underline{a}} \text { hora }\end{array}$ & $\begin{array}{l}0 \text { a } 24 \\
\text { meses }\end{array}$ & $\begin{array}{l}\text { Crianças nascidas nos } \\
\text { últimos } 24 \text { meses e } \\
\text { foram expostas ao leite } \\
\text { materno até } 1 \text { hora } \\
\text { após o nascimento }\end{array}$ & $\begin{array}{l}\text { Crianças nascidas nos } \\
\text { últimos } 24 \text { meses }\end{array}$ \\
\hline $\begin{array}{c}\text { Aleitamento } \\
\text { materno exclusivo }\end{array}$ & $<6$ meses & $\begin{array}{l}\text { Crianças menores de } 6 \\
\text { meses, que receberam } \\
\text { leite materno no dia } \\
\text { anterior e não } \\
\text { consumiram quaisquer } \\
\text { outros alimentos }\end{array}$ & $\begin{array}{l}\text { Crianças menores de } 6 \\
\text { meses }\end{array}$ \\
\hline $\begin{array}{l}\text { Aleitamento } \\
\text { materno } \\
\text { predominante }\end{array}$ & $<6$ meses & $\begin{array}{l}\text { Crianças menores de } 6 \\
\text { meses, que receberam } \\
\text { leite materno no dia } \\
\text { anterior e líquidos }\end{array}$ & $\begin{array}{l}\text { Crianças menores de } 6 \\
\text { meses }\end{array}$ \\
\hline $\begin{array}{c}\text { Aleitamento } \\
\text { continuado aos } 12 \\
\text { meses }\end{array}$ & $\begin{array}{l}12 \text { a } 15 \\
\text { meses }\end{array}$ & $\begin{array}{l}\text { Crianças com idade } \\
\text { maior ou igual a } 12 \text { e } \\
\text { menor de } 16 \text { meses que } \\
\text { receberam leite } \\
\text { materno no dia anterior }\end{array}$ & $\begin{array}{l}\text { Crianças com idade } \\
\text { maior ou igual a } 12 \text { e } \\
\text { menor de } 16 \text { meses }\end{array}$ \\
\hline $\begin{array}{c}\text { Aleitamento } \\
\text { continuado aos } 24 \\
\text { meses }\end{array}$ & $\begin{array}{l}20 \text { a } 23 \\
\text { meses }\end{array}$ & $\begin{array}{l}\text { Crianças com idade } \\
\text { maior ou igual a } 12 \text { e } \\
\text { menor de } 16 \text { meses que } \\
\text { receberam leite } \\
\text { materno no dia anterior }\end{array}$ & $\begin{array}{l}\text { Crianças com idade } \\
\text { maior ou igual a } 20 \text { e } \\
\text { menor de } 24 \text { meses }\end{array}$ \\
\hline $\begin{array}{l}\text { Introdução de } \\
\text { aleitamentos } \\
\text { pastosos, } \\
\text { semissólidos e } \\
\text { sólidos }\end{array}$ & $\begin{array}{l}6 \text { a } 8 \\
\text { meses }\end{array}$ & $\begin{array}{l}\text { Crianças com idade } \\
\text { maior ou igual a } 6 \\
\text { meses e menor de } 9 \\
\text { meses que receberam } \\
\text { alimentos pastosos, } \\
\text { semissólidos e sólidos } \\
\text { no dia anterior }\end{array}$ & $\begin{array}{l}\text { Crianças com idade } \\
\text { maior ou igual a } 6 \\
\text { meses e menor de } 9 \\
\text { meses }\end{array}$ \\
\hline
\end{tabular}


Nas pesquisas realizadas em 1996 e 2006, todos os indicadores foram calculados. No inquérito realizado em 1986 não foi possível estimar a amamentação na $1^{\underline{a}}$ hora de vida e a introdução de alimentos pastosos, semissólidos e sólidos. Os valores ausentes (missing) ou códigos indicando que as mães não sabiam as respostas foram substituídos pelo código correspondente ao não consumo em cada variável(WHO,2008). O percentual de valores ausentes e correspondente ao não consumo para aleitamento materno foi de $0,7 \%$ em 1986, 1,1\% em 1996 e 0,42\% em 2006.

A duração do aleitamento materno e do aleitamento materno exclusivo foi estimada com base na informação retrospectiva da mãe quanto ao tempo total de exposição das crianças nas duas situações (número de meses inteiros). A estimativa do aleitamento materno exclusivo foi realizada somente em 1996 e 2006, em função da disponibilidade desta variável. A opção pelo uso desta informação se justifica pela decisão de analisar os fatores preditores do início e da manutenção (extensão) do aleitamento materno e do aleitamento materno exclusivo. A informação retrospectiva da duração do aleitamento materno é a única disponível no conjunto dos dados analisados que permite a associação no plano individual entre aleitamento materno e seus fatores associados. O cálculo da duração mediana a partir de dados binários referentes ao consumo do dia anterior, ou current status, proposto pela Organização Mundial da Saúde não permite este tipo de análise. Adicionalmente, a faixa etária selecionada para a análise tornou as duas estimativas virtualmente simultâneas.

\subsubsection{Alimentos consumidos}

As variáveis sobre os alimentos consumidos pelas crianças menores de cinco anos estavam disponíveis em dois formatos: a) variáveis dicotômicas (não/sim), referentes ao consumo de cada alimento nas 24 horas anteriores à entrevista; b) variáveis categóricas referentes ao número de dias em que cada alimento foi consumido nos últimos sete dias ( 0 a 7 dias). $O$ tipo e número de alimentos e a base das respostas diferiram nos três inquéritos (Quadro 3). Em 1996, as crianças cujas mães relataram estar amamentando exclusivamente foram categorizadas como não nas questões sobre os alimentos no dia anterior. Em 2006, o consumo de fórmulas 
foi questionado somente para as mães que ofereceram algum tipo de leite nãomaterno no dia anterior. Como no caso do aleitamento, os valores ausentes (missing) ou códigos indicando que as mães não sabiam as respostas foram substituídos pelo código correspondente ao não consumo em cada variável(WHO, 2008), sendo ambos equivalentes a 3\% em 1996 e 1,5\% em 2006. Com o propósito de compatibilizar a maior parte dos alimentos nos inquéritos, as variáveis referentes ao consumo de sete dias foram convertidas em variáveis dicotômicas (sim/não). $O$ consumo do alimento em uma vez ou mais nos últimos sete dias foi codificado como sim e a ausência de consumo como não.

Nos relatórios dos três inquéritos, não há descrição dos alimentos agrupados na variável outros líquidos. Tradicionalmente, no questionário padrão das Pesquisas de Demografia e Saúde (DHS Measure) este grupo abarca líquidos à base de água e há a opção de incluir nos questionários, os líquidos específicos de cada país. Nos inquéritos de 1996 e 2006, não há alusão à consistência dos alimentos definidos como papa. Entretanto, pelas descrições disponíveis foi possível verificar que o termo se refere a mistura de um alimento sólido e um líquido. Nos questionários constam as seguintes informações para papas: papa com amidos industrializados está descrita como papa ou mingau preparado com produtos industrializados como Cremogena $^{\circledR}$, Ceralac ${ }^{\circledR}$, Neston $^{\circledR}$; papa com farinha enriquecida ou com multimistura está descrita como papa/mingau preparado com farelo/multimistura/farinha enriquecida. 
Quadro 3. Base populacional investigada e variáveis sobre alimentação nas três Pesquisas Nacionais de Demografia e Saúde.

\begin{tabular}{|c|c|c|c|c|c|c|}
\hline \multirow[b]{2}{*}{ Base das respostas } & \multicolumn{2}{|c|}{1986} & \multicolumn{2}{|c|}{1996} & \multicolumn{2}{|c|}{2006} \\
\hline & \multicolumn{2}{|c|}{$\begin{array}{l}\text { Última criança com } \\
\text { idade inferior a } \\
\text { cinco anos na } \\
\text { história } \\
\text { nascimento e que } \\
\text { está recebendo } \\
\text { leite materno }\end{array}$} & \multicolumn{2}{|c|}{$\begin{array}{l}\text { Todas as crianças } \\
\text { menores de cinco } \\
\text { anos da história de } \\
\text { nascimento, vivas } \\
\text { e residentes com o } \\
\text { respondente }\end{array}$} & \multicolumn{2}{|c|}{$\begin{array}{l}\text { Todas as crianças } \\
\text { menores de cinco } \\
\text { anos da história de } \\
\text { nascimento, vivas } \\
\text { e residentes com o } \\
\text { respondente }\end{array}$} \\
\hline Variáveis & $24 \mathrm{~h}$ & 0-7dias & $24 h$ & 0-7dias & $24 h$ & 0-7dias \\
\hline Água & $\mathrm{X}$ & & $\mathrm{X}$ & $\mathrm{X}$ & $\mathrm{X}$ & \\
\hline Água com açúcar & & & $\mathrm{X}$ & & $\bar{X}$ & \\
\hline Chá & & & $\mathrm{X}$ & & $\mathrm{X}$ & \\
\hline Suco de frutas & $\mathrm{X}$ & & $\mathrm{X}$ & & $\bar{X}$ & $\mathrm{X}$ \\
\hline Outros líquidos & $X$ & & $X$ & $\mathrm{X}$ & $X$ & \\
\hline Leite (em pó e fluído) & $\mathrm{X}$ & & $\mathrm{X}$ & $\mathrm{X}$ & $\mathrm{X}$ & \\
\hline Fórmula & & & $\mathrm{X}$ & & $\mathrm{X}$ & \\
\hline $\begin{array}{l}\text { Papa com amidos } \\
\text { industrializados }\end{array}$ & & & $\mathrm{X}$ & & $\bar{X}$ & \\
\hline $\begin{array}{lr}\text { Papa com } & \text { farinha } \\
\text { enriquecida } & \text { ou } \\
\text { multimistura } & \end{array}$ & & & $\mathrm{X}$ & & $\mathrm{X}$ & \\
\hline Papa com arroz/fubá & & & $\mathrm{X}$ & & & \\
\hline Papa de vegetais/frutas & & & $X$ & & & \\
\hline Comida de sal & $\mathrm{X}$ & & & & $\bar{X}$ & \\
\hline logurte & & & $\mathrm{X}$ & & $\bar{X}$ & $\bar{X}$ \\
\hline Ovo/frango/peixe & & & $\mathrm{X}$ & $\mathrm{X}$ & & $\mathrm{X}$ \\
\hline Carne vermelha & & & $X$ & $\mathrm{X}$ & & $X$ \\
\hline Raízes/tubérculos & & & & $\mathrm{X}$ & & $\mathrm{X}$ \\
\hline Legumes & & & & $X$ & & $\mathrm{X}$ \\
\hline Verduras & & & & $\mathrm{X}$ & & $\mathrm{X}$ \\
\hline Frutas & & & & $\mathrm{X}$ & & $X$ \\
\hline Arroz & & & & & & $X$ \\
\hline Feijão & & & & & & $\mathrm{X}$ \\
\hline Pão & & & & & & $\mathrm{X}$ \\
\hline Alimentos fritos & & & & & & $\mathrm{X}$ \\
\hline Alimentos doces & & & & & & $X$ \\
\hline Biscoito & & & & & & $\mathrm{X}$ \\
\hline Salgado assado & & & & & & $\mathrm{X}$ \\
\hline Salgadinho (pacote) & & & & & & $X$ \\
\hline Refrigerante & & & & & & $X$ \\
\hline
\end{tabular}




\subsubsection{Variáveis referentes à criança}

As variáveis utilizadas na descrição e análise dos desfechos de aleitamento materno e alimentação referentes à criança foram sexo, ocorrência de diarreia, tosse ou febre nos últimos 15 dias, número de crianças menores de cinco anos residentes no mesmo domicílio e peso ao nascer. As três variáveis referentes às doenças foram agregadas em uma variável ordinal com quatro categorias: zero (ausência de doenças), uma, duas e três (ocorrência simultânea das três doenças). As categorias da variável número de crianças menores de cinco anos residentes no domicílio foram agregadas em uma, duas e três ou mais crianças para reduzir o percentual de categorias com baixa frequência (especialmente acima de três crianças). A variável peso ao nascer foi categorizada em ausência ou presença de baixo peso. No banco de dados de 1996, havia 10,5\% de valores ausentes (missing). Desta forma, a fim de não excluir estas crianças das análises realizadas, foi realizada imputação da classificação do peso ao nascer. Os valores ausentes foram substituídos por valores preditos em análise de regressão logística tendo como desfecho a variável original baixo peso ao nascer e como preditores o tamanho da criança ao nascer e um escore sintético de três variáveis relativas ao pré-natal. O uso do escore de pré-natal no modelo da imputação justifica-se pelo fato do pré-natal ser considerado um fator importante na identificação de riscos ao nascimento prematuro e a outras intercorrências durante a gestação, com impacto sobre o peso ao nascer, que podem ser evitadas (Anexo 2).

\subsubsection{Variáveis referentes à mãe}

As variáveis relacionadas à mãe da criança selecionada na amostra se referem às condições demográficas e ao cuidado pré e pós-natal. As variáveis demográficas selecionadas foram a idade materna ao nascimento e atual, o estado civil e a paridade. Os cuidados pré e pós-natais selecionados foram as variáveis relacionadas ao pré-natal, local e tipo de parto. As variáveis do pré-natal foram: realização de pré-natal, tempo em que realizou a primeira consulta, número de consultas, consulta pós-natal(BRASIL, 1985). Estas quatro variáveis foram agregadas em uma variável ordinal com cinco categorias para indicar o conjunto de cuidados recebidos, sendo que a última categoria indica a realização de todos os 
cuidados. A variável tipo de parto foi configurada como parto vaginal e cesárea e o local como hospital da rede pública ou privada. Em 1986, todos os locais conveniados ao INAMPS foram categorizados como privados (Anexo 2).

\subsubsection{Variáveis socioeconômicas}

As variáveis socioeconômicas são referentes às mães e ao conjunto de membros do domicílio. As variáveis referentes às mães foram a escolaridade materna, a situação do trabalho materno atual e o tipo de vínculo empregatício. $O$ vínculo empregatício foi incorporado na situação do trabalho para sinalizar a estabilidade do emprego e os benefícios recebidos pela relação de formalidade. Outro aspecto materno selecionado foi a fonte de acesso às notícias cotidianas pela mãe. As três variáveis sobre este aspecto (rádio, televisão e jornais/revistas) foram agregadas em uma variável ordinal com quatro categorias: sem informação, rádio, televisão e jornais/revistas. A ordenação desta última variável foi realizada com base no conjunto de sentidos utilizados para processar a informação recebida, sendo que a leitura sinaliza a forma mais ativa e complexa de interação com a informação. As variáveis referentes às condições socioeconômicas do domicílio em que a criança reside foram a escolaridade do chefe da família, expressa originalmente em anos completos de estudo e configurada como ordinal e o índice de riqueza. Nas Pesquisas Nacionais de Demografia e Saúde em 1986 e 1996 não consta a informação sobre a renda domiciliar disponível, desta forma, o índice de riqueza foi utilizado como proxy de um indicador dos rendimentos de longo prazo do domicílio. As variáveis selecionadas para o cálculo do índice de riqueza foram a escolaridade do chefe do domicílio, serviços de água e esgoto e bens materiais do domicílio. Os tipos de bens diferiram entre as pesquisas e foram categorizados como zero e um. A variação dos itens entre as pesquisas não invalida seu uso nas análises conjuntas, pois a função principal é ser usado como marcador de rendimento (Anexo 3).

As variáveis que sinalizam o local em que as crianças residem foram macrorregião geográfica e situação do domicílio (rural/urbano). A divisão territorial do país adotada nas três Pesquisas de Demografia e Saúde foi diferente quanto ao número e área das regiões geográficas. Conforme disposto no Anexo 1, na pesquisa realizada em 1986 a amostra foi dividida em seis regiões geográficas, em 1996 em sete e em 2006 em cinco. Para compatibilização com as macrorregiões geográficas propostas pelo Instituto Brasileiro de Geografia e Estatística (IBGE), as sete divisões 
geográficas utilizadas em 1996 foram reagrupadas nas cinco macrorregiões geográficas oficiais (Anexo 2).

\subsection{ANÁLISE DOS DADOS}

Nas análises realizadas considerou-se o desenho amostral dos inquéritos. Para os desfechos indicadores do aleitamento materno e sua duração foram consideradas as amostras dos três inquéritos selecionadas. Para os desfechos duração do aleitamento materno exclusivo, alimentos consumidos e padrões alimentares foram considerados somente os anos de 1996 e 2006, em função da disponibilidade completa das variáveis referentes à alimentação das crianças e fatores preditores.

A abordagem da alimentação infantil foi realizada em recortes etários para caracterizar e quantificar as etapas da transição entre o aleitamento e o consumo de alimentos. Entre as crianças menores de seis meses foram descritos os alimentos registrados mensalmente. $O$ foco da análise foi estimar a exposição a alimentos não recomendados. Entre zero e 24 meses, foram descritos os percentuais de crianças que recebem leite materno conjugado a outros alimentos (alimentação de transição). Este período compreende o tempo mínimo recomendado de exposição do leite materno. A descrição da frequência do consumo de leite materno e outros alimentos de forma isolada se baseou na informação das últimas 24 horas ("status quo") pelas mães ou responsáveis.

No espectro etário dos seis aos 59 meses, a descrição da alimentação infantil foi realizada por análise de principais componentes, utilizando como base a informação das últimas 24 horas e últimos sete dias para enfatizar o lado qualitativo da alimentação infantil.

\subsubsection{Descrição dos indicadores e da duração do aleitamento materno}

As frequências e respectivos intervalos de confiança de 95\% dos indicadores do aleitamento materno foram expressos por faixa etária, em cada inquérito, segundo recomendações da OMS(WHO,2008). A variação temporal dos indicadores entre os inquéritos foi estimada por regressão de Poisson considerando o desenho amostral (comando survey do Pacote estatístico Stata 13.0 ${ }^{\circledR}$ ) e expressa em razão 
de prevalência. A estimativa foi ajustada pelos fatores demográficos sexo da criança, idade materna ao parto e situação do domicílio

As variáveis tempo de aleitamento materno e tempo de aleitamento materno exclusivo foram configuradas da seguinte forma: a) substituição dos valores ausentes (missings), não sabe e tempo igual a zero por 0,0164 (0,5 dias/30,4375) para eliminar os valores zero da análise, pois estes são interpretados como dado censurado; b) substituição da idade atual da criança quando a mesma estava em aleitamento materno ou aleitamento materno exclusivo e c) atribuição de um valor simbólico $(0,000001$ mês) para a criança que nunca foi amamentada. $O$ cálculo da duração do aleitamento materno foi realizado com base no conjunto das crianças menores de 36 meses e o do exclusivo, no conjunto das crianças menores de seis meses, conforme recomendação da $\mathrm{WHO}(\mathrm{WHO}, 2008)$. O viés de memória da mãe foi parcialmente controlado por esta definição das faixas, uma vez que a interrupção do aleitamento materno ocorre próximo ao seu relato, especialmente no caso das crianças menores de seis meses. As crianças que estavam em aleitamento materno, exclusivo ou não conforme $\mathrm{o}$ indicador, no momento da entrevista foram identificadas na análise como censura.

A duração do aleitamento materno e do aleitamento materno exclusivo foi modelada segundo ano do inquérito por Modelo de Regressão de Cox, pela função de sobrevida $(S(t))$. Os modelos de sobrevida são tradicionalmente utilizados quando o desfecho apresenta três características principais: representa o tempo de ocorrência do fenômeno durante um período definido, existe observações censuradas que representam ausência da ocorrência do fenômeno no período observado e há o interesse em modelar a ocorrência do fenômeno em função de variáveis preditoras (KLEINBAUM, 1995). Tradicionalmente, o modelo de regressão de Cox é utilizado para modelar a estimativa dos riscos proporcionais da ocorrência de falhas no tempo $t$ com covariáveis $x_{i}\left(\left[\lambda_{i}\left(t / x_{i}\right)=\lambda_{0}(t) \exp \left\{x_{i}^{\prime} \beta\right\}\right]\right)$. Entretanto, como há a distinção do efeito do tempo e das covariáveis na função de riscos proporcionais, é possível estimar a função de sobrevida. Desta forma, é possível expressar a probabilidade da duração do aleitamento materno e aleitamento materno exclusivo em determinado tempo $t$ a partir da fórmula: $S_{i}\left(t / x_{i}\right)=S_{0}(t) \exp \left\{x_{i}^{\prime} \beta\right\}$, aonde $S_{0}$ representa o tempo do aleitamento no nascimento e $x_{i} 0$ ano do inquérito. A duração 
mediana foi estimada quando a probabilidade de estar exposto ao aleitamento materno foi igual a 0,50 .

Neste tipo de análise, a duração mediana do aleitamento materno é estimada considerando-se a informação de todas as crianças, estejam ou não recebendo leite materno no dia da entrevista, e há correção estatística, pelo mecanismo da censura, que incorpora o efeito da perda de seguimento das crianças que estão sendo amamentadas no dia da entrevista. Uma apreciação mais ampla sobre a aplicação desta análise, sua comparação com os métodos convencionais bem como sua aplicação a dados de outros países estão apresentadas em artigo enviado para publicação (Anexo 4).

\subsubsection{Descrição dos alimentos consumidos}

A descrição do aleitamento materno conjugado aos alimentos foi expressa em percentuais relativos para cada mês de idade nas crianças menores de 24 meses, em cada inquérito. Esta análise considera o status atual do aleitamento materno, do aleitamento materno exclusivo e do consumo de alimentos (últimas 24 horas). Estes padrões foram representados em gráficos de barras empilhadas nos quais a soma da frequência relativa dos indicadores é igual a 100 em cada idade. Este tipo de análise é recomendado pela OMS para avaliar as práticas alimentares infantis, suas tendências e identificar áreas prioritárias para o desenvolvimento de ações e programas governamentais(UNICEF, 2010). Os alimentos foram agregados em grupos específicos conforme sugerido pela OMS para este tipo de análise (Quadro 4).

Especificamente entre as crianças menores de seis meses, a descrição do perfil dos alimentos foi baseada nas variáveis dos alimentos consumidos nas últimas 24 horas e também nos últimos sete dias. Optou-se por mesclar os dois tipos de informação, pois o objetivo foi estimar indiretamente a exposição progressiva aos alimentos em cada mês de idade. As variáveis de alimentos consumidos nos últimos sete dias foram categorizadas em variáveis dicotômicas (não/sim). Posteriormente, estas variáveis foram agregadas em quatro variáveis dicotômicas (não/sim): água líquidos, leites e alimentos semissólidos/sólidos (Figura 5). 
A variação temporal do padrão de introdução de alimentos entre 1996 e 2006 foi realizada por regressão de Poisson com variância robusta e expressa em razão de prevalência. Foram estimadas as razões de prevalência brutas e ajustadas para idade, status de aleitamento materno (não/sim) e a interação entre idade da criança e o ano do inquérito. A idade e o aleitamento materno são dois fatores que interferem no consumo destes alimentos e ajustou-se para o ano, pois o perfil do aleitamento materno foi diferente nos inquéritos.

Quadro 4. Conteúdo dos grupos de alimentos segundo grupo etário.

\begin{tabular}{|c|c|c|}
\hline Base amostral da análise & Crianças 0-24 meses & Crianças 0-6 meses \\
\hline Grupos de alimentos & Alimentos* & Alimentos* \\
\hline Água & Leite materno, água & Água \\
\hline Líquidos & $\begin{array}{l}\text { Leite materno, água com } \\
\text { açúcar, chá, sucos naturais, } \\
\text { outros líquidos* }^{*}\end{array}$ & $\begin{array}{l}\text { Água com açúcar, chá, sucos } \\
\text { naturais, outros líquidos* }\end{array}$ \\
\hline Leites e fórmulas & $\begin{array}{l}\text { Leite materno, leite fluído, leite } \\
\text { em pó, fórmula infantil }\end{array}$ & $\begin{array}{l}\text { Leite fluído, leite em pó, } \\
\text { fórmula infantil }\end{array}$ \\
\hline $\begin{array}{l}\text { Alimentos semissólidos e } \\
\text { sólidos }\end{array}$ & $\begin{array}{l}\text { Leite materno, papas com } \\
\text { amido industrializado, papa } \\
\text { com farinha enriquecida, papa } \\
\text { com arroz/fubá, papa de } \\
\text { verduras e frutas, iogurte, } \\
\text { carne vermelha, } \\
\text { ovos/frango/peixe, comida de } \\
\text { sal }\end{array}$ & $\begin{array}{l}\text { Papas com amido } \\
\text { industrializado, papa com } \\
\text { farinha enriquecida, papa com } \\
\text { arroz/fubá, papa de verduras e } \\
\text { frutas, iogurte, todos os tipos } \\
\text { de carne, ovo, legumes, } \\
\text { verduras, frutas, tubérculos }\end{array}$ \\
\hline
\end{tabular}

\subsubsection{Definição dos padrões alimentares e fatores associados}

Entende-se por padrão alimentar o conjunto de alimentos ou grupos de alimentos consumidos em uma dada população, que em estudos epidemiológicos são estimados por meio de métodos estatísticos de redução e/ou agregação de componentes. Pelo fato dos indivíduos não consumirem os alimentos de forma isolada, os padrões alimentares refletem mais adequadamente a complexidade da 
dieta e podem servir de subsídio para elaboração de medidas efetivas de promoção da saúde por meio da alimentação(NEWBY; TUCKER, 2004).

Neste estudo, a estimativa dos padrões alimentares foi realizada por Análise de Principais Componentes (APC), a partir das variáveis de alimentos consumidos nas últimas 24 horas e nos últimos sete dias em cada ano da pesquisa (1996 e 2006). As variáveis referentes ao consumo alimentar de sete dias foram configuradas como dicotômicas (não/sim).

A APC é uma análise multivariada e tem como principal propósito medir, explicar e predizer o grau de relação entre variáveis selecionadas. Nas análises multivariadas, o objeto de análise é produzir uma variável latente (estatística), que é a combinação linear de variáveis com os pesos determinados pela técnica multivariada. $\mathrm{Na}$ APC, as variáveis latentes são definidas de tal forma que representem melhor a estrutura subjacente ou padrões das variáveis conforme representadas por suas intercorrelações. A ideia central da análise de principais componentes é reduzir a dimensionalidade de um conjunto grande de variáveis interrelacionadas de forma a reter a máxima variação das mesmas. A partir destas variáveis são obtidas as variáveis estatísticas ou latentes (componentes principais), as quais são não-correlacionadas e retém o máximo da variação presente nos dados originais (JOLLIFFE, 2002). As variáveis latentes passam a representar e ser interpretada pela sua representação conjunta das variáveis individuais, ou seja, são vistas por aquilo que representam coletivamente e não individualmente na expressão de um conceito. As variáveis estatísticas ou latentes geradas (construtos) na análise são tradicionalmente denominadas como principais componentes (Figura 4).

\begin{tabular}{|l|}
$100 \quad$ variáveis \\
referentes a um grupo \\
populacional
\end{tabular}

Antes da análise:

VARIÁVEIS
$\mathbf{Y}=\mathbf{w}_{1} \mathbf{X}_{1}+\mathbf{w}_{2} \mathbf{X}_{2}+\mathbf{w}_{3} \mathbf{X}_{3} \ldots . . \mathbf{w}_{\mathrm{n}} \mathbf{X}_{\mathrm{n}}$ $Y=v a r i a ́ v e l$ estatística (variate)

$\mathrm{X}_{\mathrm{n}}=$ variável

$\mathrm{w}_{\mathrm{n}}=$ peso determinado pela análise multivariada
4 variáveis estatísticas ou latentes (componentes principais ou padrão alimentar) que concentram a maior parte de toda a variabilidade das variáveis originais.

Após análise:

VARIÁVEIS ESTATÍSTICAS ou LATENTES

Figura 4: Representação simplificada da estrutura das variáveis na análise principais componentes. 
As propriedades dos principais componentes são baseadas nos valores de eigenvalues (auto-valores) e eigenvectors da matriz de correlação ou covariância. Cada principal componente identificado na análise contem um valor de eigenvalue e de eigenvector. Os eigenvalues são resultantes da soma das variâncias das variáveis originais selecionadas para a análise. Cada eigenvalue expressa o valor da variância das variáveis originais contidas em cada principal componente gerado. Os primeiros componentes têm os maiores valores de variância, sendo por isso selecionados para representar a estrutura subjacente das variáveis originais e também utilizados em outras análises. Os eigenvectors representam as cargas fatoriais (loadings) de cada principal componente. Estes valores representam a correlação de cada variável original com o principal componente. Quanto maior o valor da carga fatorial maior é a contribuição ou peso daquela variável para caracterizar o principal componente. Os componentes principais representam a soma ponderada, isto é, combinações lineares das variáveis originais observadas (equação 1).

Dada uma matriz $\mathrm{X}$ de dados $n^{*} p$, onde $n$ representa o número de indivíduos e $p$ representa o número de variáveis. Esta matriz é reduzida a um conjunto de dados consistindo de $n$ medidas em $k$ componentes $(k<p)$, os quais exibem quase a mesma variabilidade identificadas nas variáveis originais $(p)$. De forma simples, os principais componentes podem ser representados da seguinte forma:

$$
\begin{aligned}
& y_{1}=a^{\prime}{ }_{1} x=a_{11} x_{1}+a_{12} x_{2}+\ldots+a_{1 p} x_{p} \\
& \dddot{y} y_{p}=a^{\prime}{ }_{p} x=a_{p 1} x_{1}+a_{p 2} x_{2}+\ldots+a_{p p} x_{p}
\end{aligned}
$$

Aonde, $y_{1} \ldots y_{p}$ representam os principais componentes, $a_{11} \ldots a_{p p} x_{p}$ representam os eigenvectors para cada componente e $\mathrm{x}_{1} \ldots \mathrm{x}_{\mathrm{p}}$, as variáveis originais.

A APC é uma técnica mais indicada para variáveis quantitativas, porém quando usada com o propósito descritivo pode ser realizada a partir de qualquer tipo de variável, inclusive variáveis binárias (JOLLIFFE, 2002).

A partir destas premissas e características, neste trabalho a alimentação é analisada por APC, uma vez que se deseja descrever e interpretar como os alimentos são consumidos conjuntamente e não de forma isolada. Dessa forma, a APC permitirá que se utilizem os principais componentes como descritores sintéticos dos aspectos diversos da alimentação infantil em vários grupos etários e, 
posteriormente, estes serão utilizados como variáveis-desfecho para compreender de modo mais amplo as transformações da alimentação infantil no Brasil e seus principais fatores associados. Neste trabalho, cada um dos principais componentes estimados foi definido como um padrão alimentar independente e com determinada frequência de consumo na população.

A definição dos padrões alimentares foi realizada em duas etapas: descrição e evolução temporal. A descrição foi realizada separadamente por inquérito em função das diferenças de alimentos disponíveis. Esta análise separada também permitiu captar os padrões característicos de cada ano. A evolução temporal foi realizada com os dados dos inquéritos de 1996 e 2006, após compatibilização máxima dos alimentos em cada inquérito (Figura 5).

No inquérito de 1996, 15 alimentos estavam configurados como variáveis binárias (0/1), referentes ao consumo nas 24 horas precedentes à entrevista e nove alimentos como variáveis categóricas ( 0 a 7). Para ampliar o número de alimentos a ser utilizado na análise e utilizar as variáveis categóricas, estas últimas foram convertidas em variáveis binárias. No inquérito de 2006, 11 alimentos estavam configurados como variáveis binárias e 17 alimentos como variáveis categóricas. Entretanto, neste inquérito somente dois alimentos estavam configurados como variável binária e categórica. Optou-se por converter as variáveis categóricas em binárias a fim de padronizar a configuração das variáveis em todas as análises e também para utilizá-las no modelo conjunto de 1996 e 2006.

As variáveis leite em pó e leite fluído foram agrupadas em uma única variável denominada leite, por considerar que estes dois alimentos se distinguem somente quanto ao aspecto físico. As variáveis água, água com açúcar, chá e outros líquidos foram agrupadas em uma única variável denominada líquidos. Com exceção da água, os outros três alimentos representam pequeno percentual das crianças com idade superior a seis meses. Para as duas variáveis geradas, a categoria "1" (consumo) foi definida quando pelo menos um dos alimentos foi consumido.

A variável leite materno foi a única variável ordinal com quatro categorias $(0,1,2,3)$ utilizada na APC. Esta variável é referente ao número de vezes que a mãe relatou oferecer leite materno no dia e na noite anterior. Em função da variabilidade de respostas ( 0 a 30 vezes), estes valores foram expressos em terços de consumo, 
sendo que as crianças que não receberam leite materno no dia ou noite anterior foram categorizadas como 0 e aquelas que consumiram como 1, 2 ou 3. As razões para esta categorização foram: a necessidade de maximar a exposição e representatividade do leite materno na análise e também diferenciá-la da variável status do aleitamento materno (sim/não) no momento da entrevista, inserida como variável preditora nos modelos de efeitos mistos. A síntese desses procedimentos está expressa na Figura 5. 


\begin{tabular}{|c|c|}
\hline \multicolumn{2}{|c|}{ Formato original das variáveis } \\
\hline 24h: 0 e 1 & 7 dias: $0,1,2,3,4,5,6,7$ \\
\hline 1996 & 2006 \\
\hline $\begin{array}{l}\text { Leite materno, líquidos, suco de frutas, leite, } \\
\text { fórmula infantil, papa com amidos } \\
\text { industrializados, papa com farinha enriquecida } \\
\text { ou multimistura, iogurte, ovo/frango/peixe, } \\
\text { carne vermelha, mingau, papa com arroz/fubá, } \\
\text { papa de vegetais/frutas }\end{array}$ & $\begin{array}{l}\text { Leite materno, líquidos, suco de frutas, leite, } \\
\text { fórmula infantil, papa com amidos } \\
\text { industrializados, papa com farinha enriquecida } \\
\text { ou multimistura, iogurte }\end{array}$ \\
\hline Raízes/tubérculos, legumes, verduras, frutas & $\begin{array}{l}\text { Raízes/tubérculos, legumes, verduras, frutas, } \\
\text { ovo/frango/peixe, carne vermelha, comida de } \\
\text { sal, arroz, feijão, pão, alimentos fritos, alimentos } \\
\text { doces, biscoito, salgado assado, salgadinho } \\
\text { (pacote), refrigerante }\end{array}$ \\
\hline
\end{tabular}
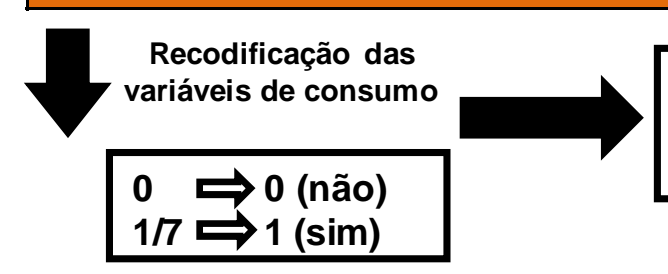

\section{Análise de principais componentes} (alimentos selecionados de cada inquérito)

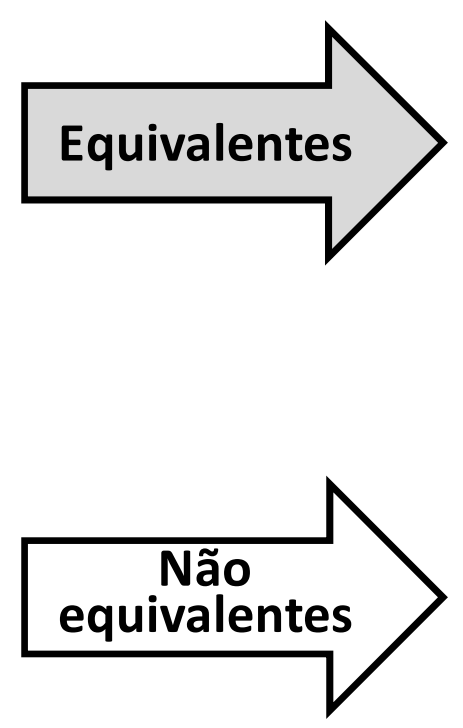

\begin{tabular}{|c|c|c|}
\hline 1996 & 2006 & 1996-2006 \\
\hline Leite materno & Leite materno & Leite materno \\
\hline Líquidos & Líquidos & Líquidos \\
\hline Suco de frutas & Suco de frutas & Suco de frutas \\
\hline Leite & Leite & Leite \\
\hline Fórmula & Fórmula & Fórmula \\
\hline $\begin{array}{l}\text { Papa com amidos } \\
\text { industrializados }\end{array}$ & $\begin{array}{l}\text { Papa com amidos } \\
\text { industrializados }\end{array}$ & $\begin{array}{c}\text { Papa com amidos } \\
\text { industrializados }\end{array}$ \\
\hline $\begin{array}{l}\text { Papa com farinha } \\
\text { enriquecida ou } \\
\text { multimistura }\end{array}$ & $\begin{array}{l}\text { Papa com farinha } \\
\text { enriquecida ou } \\
\text { multimistura }\end{array}$ & $\begin{array}{c}\text { Papa com farinha } \\
\text { enriquecida ou } \\
\text { multimistura }\end{array}$ \\
\hline logurte & logurte & logurte \\
\hline Raízes/tubérculos & Raízes/tubérculos & Raízes/tubérculos \\
\hline Legumes & Legumes & Legumes \\
\hline Verduras & Verduras & Verduras \\
\hline Frutas & Frutas & Frutas \\
\hline Ovo/frango/peixe & Ovo/frango/peixe & Ovo/frango/peixe \\
\hline Carne vermelha & Carne vermelha & Carne vermelha \\
\hline Papa com arroz/fubá & Comida de sal & \\
\hline \multirow[t]{9}{*}{$\begin{array}{c}\text { Papa de } \\
\text { vegetais/frutas }\end{array}$} & Arroz & \\
\hline & Feijão & \\
\hline & Pão & \\
\hline & Alimentos fritos & \\
\hline & Alimentos doces & \\
\hline & Biscoito & \\
\hline & Salgado assado & \\
\hline & Salgadinho (pacote) & \\
\hline & Refrigerante & \\
\hline
\end{tabular}

Figura 5. Síntese das etapas de padronização das variáveis do consumo alimentar em 1996 e 2006 para a realização da estimativa multivariada dos padrões alimentares. 
Os padrões foram extraídos considerando valores de eigenvalues superior a 1,0 e de eigenvectors ou cargas fatoriais (loadings) superiores a 0,2. Este ponto de corte relativamente baixo foi adotado com o objetivo de ampliar a compreensão da composição de cada padrão, principalmente em razão da base de alimentos nos inquéritos ser restrita. Adicionalmente, este ponto de corte permite ampliar a identificação e discriminação de alimentos que são consumidos em menor frequência pelas crianças juntamente com os alimentos com cargas maiores. Após a extração dos padrões, aplicou-se a rotação ortogonal Varimax. A rotação ortogonal garante a independência dos padrões tornando possível entender isoladamente os fatores associados àquele determinado padrão alimentar. Para a adequação das variáveis à análise foi utilizado a estatística KMO (Kaiser-Meyer-Olkin). Uma vez que os padrões são variáveis latentes geradas a partir das variáveis originais, todo indivíduo da amostra tem uma probabilidade conhecida e diferente de pertencer a cada padrão estimado.

Para cada padrão alimentar extraído pela análise de principais componentes foram gerados escores padronizados com média zero, representando a aderência de cada criança ao padrão. Todas as crianças tinham escores de todos os padrões, entretanto, os escores mais elevados representaram a proximidade da criança a determinado padrão.

Tradicionalmente nos estudos que utilizam esta técnica, após a identificação dos padrões alimentares são calculados escores padronizados com média zero que representam a aderência de cada criança ao padrão (DEMETRIOU et al., 2012)(HU et al., 2000). Essa forma de analisar permite que as relações entre os padrões sejam extensivamente exploradas no plano populacional.

Neste estudo, optou-se por um passo além: após gerar os escores padronizados, a cada indivíduo foi atribuído um padrão característico. O padrão alimentar atribuído a cada indivíduo foi aquele no qual a probabilidade adesão era a mais elevada. Assim, foram geradas variáveis dicotômicas (não/sim) que atribuíam a cada indivíduo um único padrão com o objetivo de quantificar a frequência de cada padrão entre as crianças da amostra. Desta forma, foi possível identificar o padrão que melhor caracteriza os grupos etários a partir de sua prática mais provável pelos indivíduos da amostra e não apenas pela relação entre as variáveis da alimentação como no procedimento tradicional. Ressalta-se que nesta forma de analisar os padrões alimentares, nem sempre o primeiro padrão extraído - que na análise 
explica o maior percentual de variabilidade das variáveis alimentares - é o mais prevalente.

Após essa atribuição, a frequência percentual de cada padrão alimentar foi descrita segundo faixa etária (6-12 meses, 12-24 meses e 24-59 meses), macrorregião brasileira, situação do domicílio (urbano, rural), escolaridade materna, índice de riqueza e status do trabalho materno. Posteriormente, cada padrão alimentar foi utilizado como variável desfecho nos modelos de regressão linear de efeitos mistos. As variáveis independentes nestes modelos de regressão foram agrupadas em três blocos: variáveis relacionadas à criança (idade: 6-12 meses, 1224 meses e 24-59 meses; presença de doenças; número de crianças menores de cinco anos); variáveis relacionadas à mãe (idade materno no nascimento, principal meio de acesso à informação materna, situação de trabalho atual, escolaridade) e fatores ambientais (índice de riqueza, regiões geográficas e situação do domicílio). Os escores de cada padrão alimentar e as variáveis dicotômicas de cada padrão foram considerados como desfechos nos modelos de efeitos mistos.

\subsubsection{Cálculo do índice de riqueza}

O cálculo do índice de riqueza foi baseado no conjunto de variáveis que descrevem os bens presentes no domicílio e na escolaridade do chefe da família. $O$ índice foi estimado por APC tal como recomendado internacionalmente para esse tipo de inquérito(FILMER; PRITCHETT, 2001). Este índice é utilizado como proxy dos rendimentos monetários da uma família. O primeiro componente extraído foi utilizado na predição dos escores atribuídos a cada criança do domicílio e, posteriormente, esse escore foi dividido em quintos do índice de riqueza. As variáveis disponíveis para descrever os bens no domicílio foram testadas em diversas combinações e selecionou-se o modelo com maior percentual de explicação no $1^{\circ}$ componente e maior valor de KMO (Anexo 3). O índice de riqueza foi utilizado como escores e como quintis nas análises. 


\subsubsection{Fatores associados à alimentação na infância}

A análise dos fatores associados à alimentação infantil foi desenhada a partir da adaptação de um modelo conceitual proposto por Engle (1992)(ENGLE; MENON; HADDAD, 1997) sobre as práticas de cuidado que determinam o estado nutricional e crescimento infantil. Considerou-se este modelo, pois embora os desfechos sejam distintos daqueles proposto por Engle(1992), a alimentação é um dos principais fatores proximais do estado nutricional, sendo influenciada pelos mesmos fatores intermediários e distais (Figuras 6 e 7).

Neste modelo, julgou-se relevante analisar os efeitos dos fatores preditores sobre três aspectos: a duração do aleitamento materno exclusivo, a duração do aleitamento materno e os padrões alimentares. Para os dois primeiros, foi utilizado o modelo de Cox para incorporação dos dados incompletos, tratados como censura (crianças que estavam recebendo leite materno). Os fatores preditores estão esquematizados na Figura 6. Para os desfechos padrões alimentares foi utilizado modelo de efeito misto.

O modelo de regressão de Cox é um modelo semiparamétrico em que o desfecho é o tempo até a ocorrência de um evento de interesse, com ajuste para as variáveis preditoras, sendo estimado os tempos de falhas entre dois ou mais grupos. O pressuposto deste modelo é a proporcionalidade dos riscos de falha entre os grupos. A estimação do modelo de Cox é realizado pelo método da máxima verossimilhança. O método de Breslow para estimar a máxima verossimilhança foi selecionado para lidar com as falhas ocorridas ao mesmo tempo (failure ties) (STATA, 2013). O teste de adequação do modelo quanto ao pressuposto de riscos proporcionais foi realizado pela análise dos resíduos padronizados de Schoenfeld (STATA, 2013). Nos dois modelos, o fator de ponderação não foi considerado em função da violação do pressuposto dos riscos proporcionais quando este é considerado na análise. As estimativas foram expressas em razão de riscos (hazard ratios) e seus respectivos intervalos de confiança de $95 \%$.

$\mathrm{Na}$ análise com regressão de Cox, exclusivamente, as estimativas foram realizadas sem a ponderação da amostra. A razão para isso é que os efeitos de desenho ( $D E F F$, na sigla em inglês) (Anexo 5) apresentam nesta estimativa um valor elevado, o que torna a maioria dos parâmetros não significante ou mesmo inconsistente. Provavelmente esse efeito também está influenciado pelo baixo valor resultante da divisão entre o número de observações e o número de parâmetros 
incluídos no modelo. Além disso, o estimador de Cox é muito sensível às violações da normalidade nas condições iniciais da modelagem, o que torna complexo usar a ponderação de toda a população de menores de cinco anos para representar apenas o grupo de menores de 6 meses com igual eficiência representativa ao longo de todas as covariáveis utilizadas no modelo. Considerando que o mais importante aqui é descrever as relações entre o aleitamento materno exclusivo e seus determinantes, se tomou a decisão heterodoxa de realizar a estimativa não ponderada dos fatores associados nessa etapa da análise. Em outras análises esse efeito não foi observado na mesma magnitude e assim a ponderação original foi mantida.

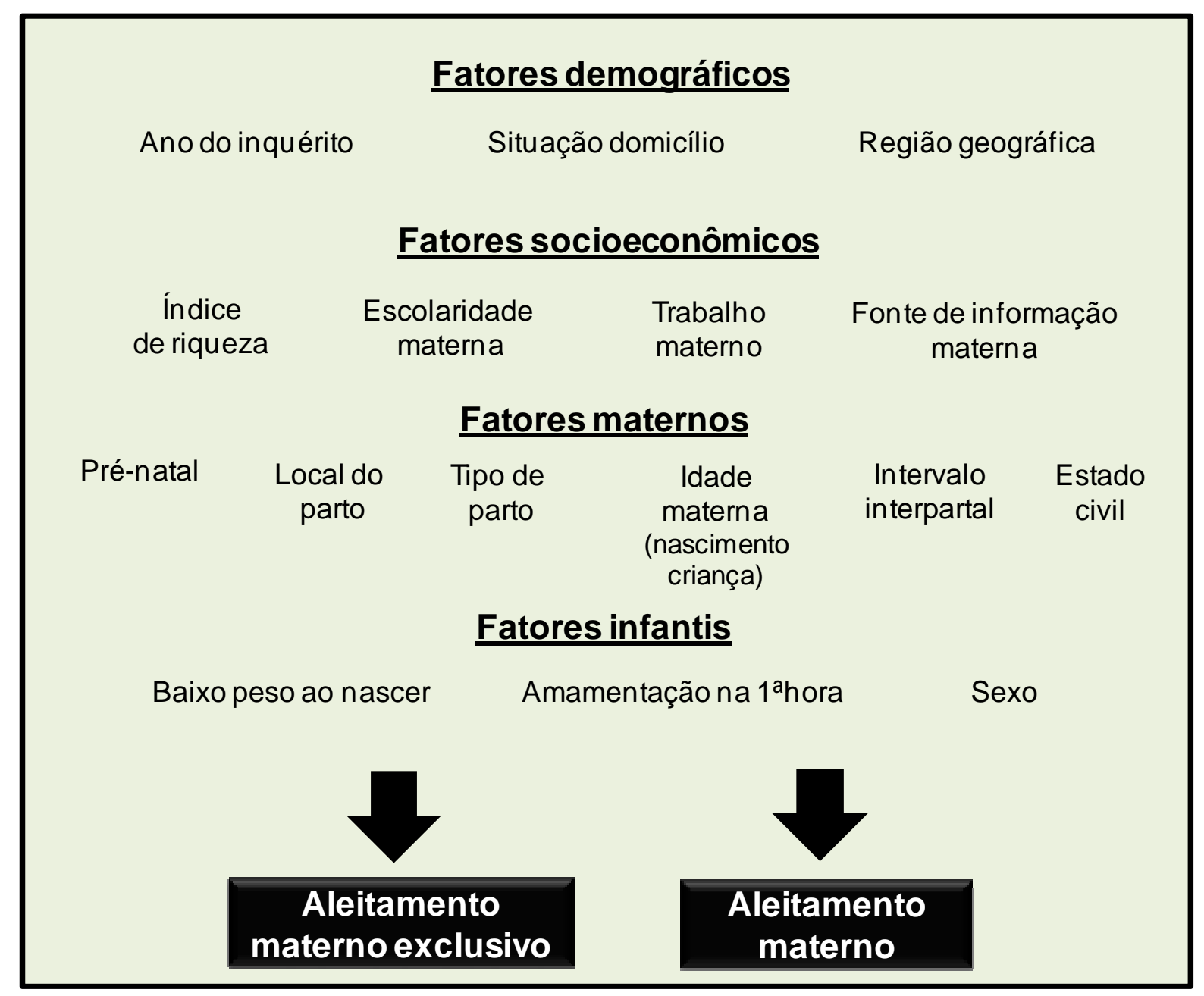

Figura 6. Modelo conceitual da duração do aleitamento materno e do aleitamento materno exclusivo.

Nos estudos com desenhos de amostras complexas, os indivíduos são selecionados a partir de uma estrutura hierarquizada com base em critérios tais 
como macrorregião geográfica, classes de renda, instituições em que estudam ou trabalham, entre outros. Uma consequência desta estrutura hierárquica é que as características compartilhadas pelos indivíduos de um mesmo grupo (intra-grupo) se assemelham em maior grau do que indivíduos de grupos distintos (entre-grupos). A desconsideração desta estrutura na análise viola o princípio da independência das variáveis e dos resíduos obtidos nos modelos estatísticos de associação e altera o efeito real dos preditores sobre o desfecho. Os modelos multinível consideram a estrutura hierárquica na análise de dados e, por isso, nestes modelos as variáveis são alocadas em dois ou mais níveis. Nos estudos com medidas únicas por indivíduo, no primeiro nível dos modelos são alocadas características dos indivíduos que não se alteram ou se alteram pouco ao longo do tempo (exemplo: etnia, sexo, escolaridade). O efeito destas características sobre os desfechos é expresso em valor médio. No segundo ou mais níveis são alocadas as variáveis que identificam o critério de agregação dos indivíduos, como por exemplo, região geográfica, bairro, escola, empresa, também denominado contexto. O efeito destas variáveis nos desfechos é expresso tradicionalmente em variância, desta forma, é possível estimar o quanto o valor médio das características individuais variam entre os contextos. (LECKIE, 2008).

Neste estudo, se assume que a definição de contexto é a localização de uma pessoa ou grupo no tempo e espaço. O termo espaço é usado para se referir à localização geográfica como ser um membro de um grupo (família, amigos, idade, classe, etnia). Pertencer a um contexto afetaria tanto à exposição ao risco como as estratégias de resposta(PORTA, 2008). Desta forma, os efeitos contextuais seriam os efeitos dos fatores no nível do grupo ou área (ex: nível de pobreza em um bairro) nos desfechos no nível do indivíduo após considerar os efeitos confundidores relevantes no nível do indivíduo(ROUX, 2002).

O modelo conceitual adotado neste estudo foi desenhado de forma a incorporar os fatores individuais materno-infantis e sociodemográficos no primeiro nível do modelo (nível individual) e macrorregiões brasileiras no segundo nível (nível contexto) (Figura 7). A variável região geográfica foi selecionada para identificar o contexto. As principais razões para tal escolha foram a manutenção da estrutura amostral das pesquisas nacionais de demografia e saúde utilizadas neste estudo e as diferenças regionais nos indicadores do aleitamento materno já identificadas em pesquisas anteriores. A seleção dos domicílios e das mulheres elegíveis nas 
pesquisas nacionais de demografia e saúde foi realizada considerando as macrorregiões como estratos.

O efeito dos fatores preditores nos padrões alimentares foi analisado por modelo de regressão logística de efeitos mistos com coeficiente probabilístico. No nível individual foram estimados os efeitos médios das variáveis referentes às crianças, às mães e as sociodemográficas sobre o desfecho, sendo que os efeitos dos preditores foram expressos em razão de chances (odds ratio) com seus respectivos intervalos de confiança de $95 \%$ (efeitos fixos). No nível contextual foram estimados os componentes da variância dos efeitos médios dos fatores individuais referentes às macrorregiões (efeitos probabilísticos). A alocação do ano do inquérito no nível contextual caracteriza o modelo de coeficiente randômico, sendo que esta variável permite estimar o percentual da variância entre as regiões que é explicada pela diferença entre os anos dos inquéritos. Posteriormente, foi estimado o coeficiente de partição da variância (CPV) no nível contextual (coeficientes probabilísticos). Este coeficiente expressa a porcentagem da variância do modelo completo atribuída ao nível contextual (parte probabilística do modelo). Na regressão logística o resíduo referente à parte fixa do modelo é constante e equivale à 3,29. Os termos fixos e probabilístico s do modelo geral estão descritos na equação 1 .

$\mathrm{PA}_{i j}=\beta_{0}+\beta_{1}$ ano $_{i j}+\beta_{2}$ aleitamento $_{i j}+\beta_{3}$ idadecriança $_{i j}+\beta_{4}$ sexo $_{i j}+$ $\beta_{5}$ númerodecrianças $_{i j}+\beta_{6}$ doenças $_{i j}+\beta_{7}$ idadematerna $_{i j}+\beta_{8}$ trabalhomaterno $_{i j}+$ $\beta_{9}$ estadocivil ${ }_{i j}+\beta_{10}$ fonteinformação $_{i j}+\beta_{11}$ escolaridadematerna $_{i j}+\beta_{12}$ indiceriqueza $_{i j}+$ $\beta_{13}$ situaçãodomicílio $i j+u_{0 j}+u_{13 j} a \operatorname{no}_{i j}+e_{i j}$

Na qual os termos representam:

PA1....PA4ij= frequência dos padrões alimentares PA1 a PA4 da criança "i" na macrorregião "j"

$B_{0:}$ média geral dos escores dos padrões independente da macrorregião

$\beta_{1 \ldots . .} \beta_{13 i j}$ : coeficiente da regressão (parte fixa)

$u_{0 j}$ : efeito da macrorregião $j$ nos padrões alimentares (variância referente à variável macrorregião geográfica)

$u_{13 j:}$ efeito do ano na macrorregião $j$ nos padrões alimentares (variância referente ao ano do inquérito em cada macrorregião geográfica)

$e_{i j:}$ resíduo referente às variáveis do nível individual 
A variável ano do inquérito foi alocada nos dois níveis dos modelos a fim de estimar efeitos distintos. No nível individual, esta variável expressa o efeito médio da mudança entre os anos sobre os padrões alimentares. Ao alocar esta variável na parte fixa do modelo, se assume a premissa de que o efeito do ano é igual em todas as regiões geográficas. Além disso, o ano representa uma variável sumária de comportamentos não contemplados no modelo pela indisponibilidade nos inquéritos. No nível contextual, esta variável expressa a variabilidade da mudança do ano dentro de cada região geográfica, ou seja, o efeito da mudança entre os anos pode ser diferente entre as regiões e, dessa forma, afetar distintamente a frequência dos padrões alimentares.

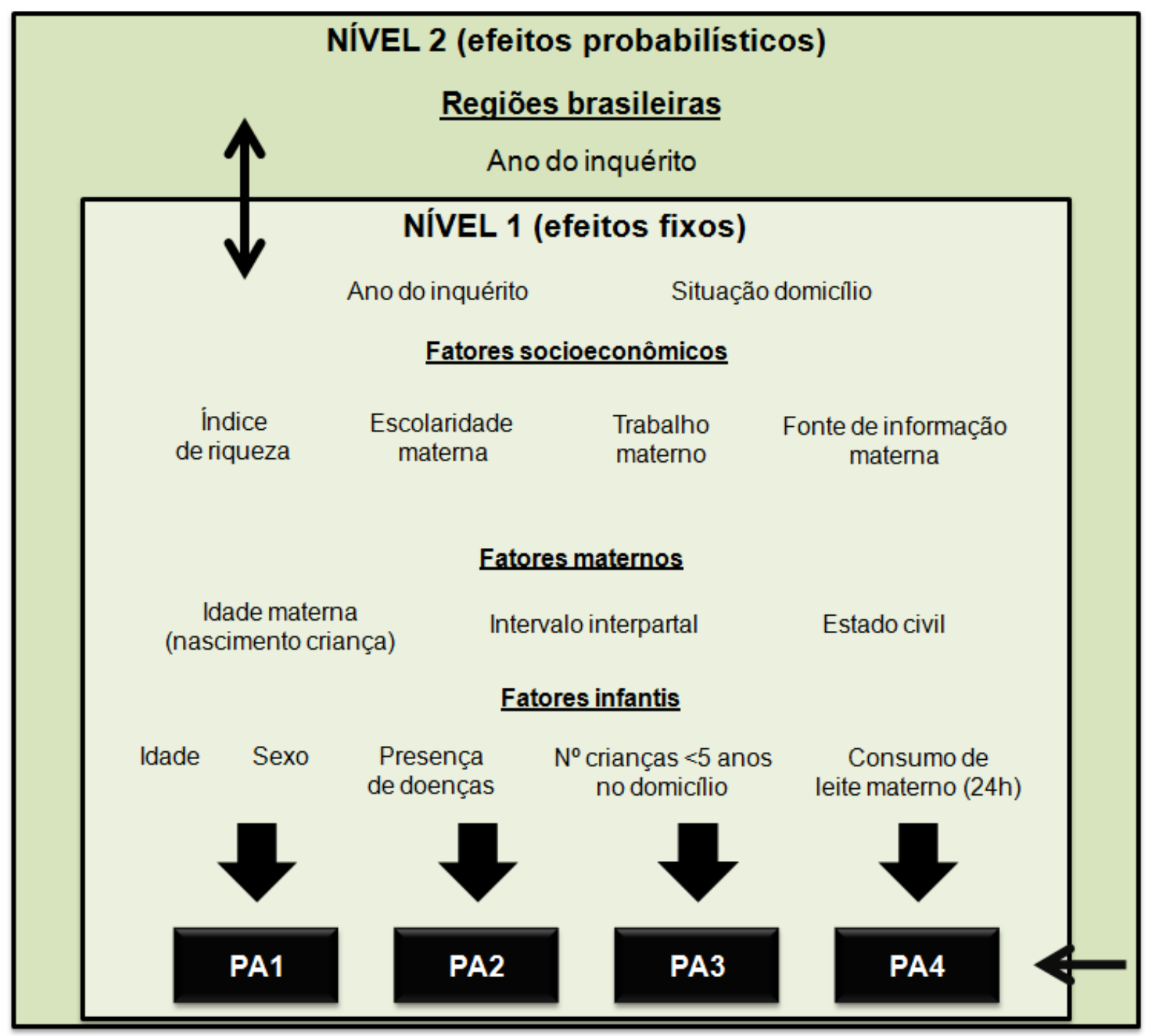

Figura 7. Modelo conceitual dos padrões alimentares na infância.

Todas as análises deste estudo foram realizadas no pacote estatístico Stata MP $13.0^{\circledR}$. O sumário das análises realizados no estudo estão sumarizadas na Figura 8. 


\section{Etapa I: Análise descritiva}

1.Descrição da frequência relativa das variáveis sociodemográficas e da saúde maternas e infantis:

Base de dados: três inquéritos, 0-59 meses;

2.Frequência relativa das indicadores da alimentação na infância:

Base de dados: três inquéritos, 0-24 meses;

3.Duração mediana do aleitamento materno exclusivo (Modelo de Cox):

Base de dados: dois inquéritos (1996, 2006), <6 meses;

4.Duração mediana do aleitamento materno (Modelo de Cox):

Base de dados: três inquéritos, $<36$ meses.

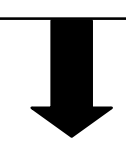

Etapa II: Descrição da alimentação na infância

1.Descrição da frequência dos alimentos consumidos (24 horas e 7 dias) e sua evolução entre 1996 e 2006 (Modelo de regressão de Poisson com variância robusta)

Base de dados: dois inquéritos $(1996,2006),<6$ meses;

2.Descrição da frequência dos alimentos registrados segundo faixa etária mensal (gráfico de barras empilhadas)

Base de dados: três inquéritos, 0-24 meses;

3.Identificação dos padrões alimentares e descrição da suas frequências segundo características sociodemográficas (Análise de Principais Componentes)

Base de dados: dois inquéritos (1996,2006), 6-59 meses.

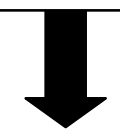

Etapa III: Análises dos fatores preditores da alimentação na infância

Modelo de regressão de Cox

1.Fatores preditores da duração do aleitamento materno exclusivo

Base de dados: dois inquéritos $(1996,2006),<6$ meses;

2.Fatores preditores da duração do aleitamento materno

Base de dados: dois inquéritos (1996,2006), <36 meses;

Modelo de efeitos mistos (coeficiente e intercepto probabilísticos)

3.Fatores preditores dos padrões alimentares

Base de dados: dois inquéritos (1996,2006), 6-59 meses.

Figura 8. Síntese das análises dos dados no estudo. 
Este estudo recebeu apreciação do Comitê de Ética em Pesquisa da Faculdade de Saúde Pública da Universidade de São Paulo sob o protocolo de pesquisa oㅡ 2336 (Of.Coep/004/12). 


\section{RESULTADOS}

\subsection{DESCRIÇÃO E TENDÊNCIA TEMPORAL DOS INDICADORES SOCIODEMOGRÁFICOS E DE SAÚDE MATERNO-INFANTIL}

A análise temporal dos diferentes indicadores sociodemográficos e de saúde materno-infantil disponíveis nas três fases dos inquéritos permite a visualização panorâmica do cenário em que ocorreram as mudanças nas trajetórias da alimentação infantil (Tabela 1).

As mudanças demográficas mais relevantes observadas nas três décadas foram o processo de urbanização da população e a redução do intervalo interpartal inferior a 24 meses de 37\% em 1986 para 15\% em 2006. Essa redução se reflete diretamente na proporção de famílias com apenas uma criança menor de cinco anos que aumentou 1,06 entre 1986 e 1996 e 1,34 entre 1996 e 2006. A frequência de mães primíparas foi crescente entre os inquéritos e aumentou 1,37 entre 1986 e 1996 e 1,5 entre 1996 e 2006.

O perfil da escolaridade materna apresentou mudança expressiva, com destaque para a redução de mães com três ou menos anos de estudo que variou 0,64 e 0,43 entre 1986 e 1996 e entre 1996 e 2006, respectivamente, e para a taxa de aumento da frequência de mães com oito a onze anos de estudo em 1,42 e 1,92 nos mesmos períodos, respectivamente. O percentual de mães responsáveis pelo domicílio foi crescente, embora o aumento seja discreto, correspondendo a 5,3\%, $5,9 \%$ e 6,2\%, em cada inquérito. Desta forma, a análise da escolaridade do chefe do domicílio corresponde à escolaridade do companheiro destas mães ou de outro parente.

O percentual de mães inseridas no mercado de trabalho também aumentou nas três décadas. A análise do perfil de trabalho segundo índice de riqueza, no entanto, mostrou tendência de aumento da desigualdade social, com concentração de mães em trabalho formal no quinto superior e diferenças mais acentuadas entre 1996 e 2006. A razão entre a frequência de mães empregadas no quinto superior do índice de riqueza relativamente ao quinto inferior foi de 1,1, 1,4 e 1,9 em 1986, 1996 e 2006, respectivamente. 
A frequência de diarreia, tosse ou febre nas duas semanas anteriores à pesquisa variou 0,84 entre 1996 e 2006. Ressalte-se que em 2006 mais da metade das crianças investigadas não apresentou nenhum dos três sintomas nas duas semanas anteriores. A taxa de redução do baixo peso ao nascer foi de 0,75 entre 1996 e 2006.

Com relação aos indicadores do cuidado materno que se refletem na saúde do binômio mãe-criança, a cobertura de pré-natal se destaca pelo incremento de 1,14 entre 1986 e 2006 e por ter se tornado virtualmente universal em 2006. A taxa da participação da mulher no pré-natal quanto a quatro procedimentos - realização de pré-natal, realização da primeira consulta até o $3^{\circ}$ mês de gestação, número mínimo de seis consultas e uma consulta pós-natal - aumentou em 1,15 entre 1996 e 2006. O percentual de partos cesáreos aumentou em 1,16 entre 1986 e 1996 e 1,04 entre 1996 e 2006. O tipo de hospital predominante dos nascimentos sofreu inversão do perfil, principalmente entre 1986 e 1996. As taxas de mudança de partos realizados em hospitais públicos foram de 3,35 e 1,04 entre 1986 e 1996 e 1996 e 2006, respectivamente

O efeito do desenho amostral de todas as estimativas deste estudo está descrito no Anexo 5. 
Tabela 1. Características demográficas, socioeconômicas e de saúde infantil e materna. Brasil, 1986-2006.

\begin{tabular}{|c|c|c|c|}
\hline \multirow{4}{*}{$\begin{array}{l} \\
\text { Variáveis demográficas } \\
\text { Faixa etária }\end{array}$} & \multicolumn{3}{|c|}{ Anos [inquéritos] } \\
\hline & 1986 & 1996 & 2006 \\
\hline & \multicolumn{3}{|c|}{ Frequência relativa (Intervalo de confiança 95\%) } \\
\hline & & & \\
\hline $0-6$ meses & $11,0(10,0 ; 13,0)$ & $11,0(10,0 ; 12,0)$ & $11,0(9,0 ; 13,0)$ \\
\hline 6-12 meses & $10,0(9,0 ; 11,0)$ & $10,0(9,0 ; 11,0)$ & $11,0(9,0 ; 12,0)$ \\
\hline $12-24$ meses & $18,0(16,0 ; 19,0)$ & $20,0(19,0 ; 22,0)$ & $19,0(17,0 ; 21,0)$ \\
\hline 24-59 meses & $61,0(59,0 ; 62,0)$ & $59,0(58,0 ; 61,0)$ & $60,0(57,0 ; 62,0)$ \\
\hline \multicolumn{4}{|l|}{ Situação do domicílio } \\
\hline Urbano & $68,0(61,0 ; 73,0)$ & $76,0(72,0 ; 80,0)$ & $81,0(77,0 ; 84,0)$ \\
\hline Rural & $32,0(27,0 ; 38,0)$ & $24,0(20,0 ; 28,0)$ & $19,0(16,0 ; 22,0)$ \\
\hline \multicolumn{4}{|l|}{ Sexo da criança } \\
\hline Feminino & $49,0(47,0 ; 51,0)$ & $49,0(47,0 ; 51,0)$ & $48,0(45,0-50,0)$ \\
\hline Masculino & $51,0(49,0 ; 53,0)$ & $51,0(49,0 ; 52,0)$ & $52,0(50,0-55,0)$ \\
\hline \multicolumn{4}{|c|}{$\begin{array}{l}\text { Número de crianças menores de } \\
\text { cinco anos no domicílio }\end{array}$} \\
\hline 1 & $47,0(44,0 ; 50,0)$ & $50,0(47,0 ; 52,0)$ & $67,0(64,0 ; 69,0)$ \\
\hline 2 & $38,0(36,0 ; 41,0)$ & $36,0(34,0 ; 38,0)$ & $28,0(25,0 ; 31,0)$ \\
\hline$\geq 3$ & $15,0(13,0 ; 18,0)$ & $14,0(13,0 ; 16,0)$ & $5,0(4,0 ; 7,0)$ \\
\hline \multicolumn{4}{|l|}{ Baixo peso ao nascer } \\
\hline Não & $\ldots$ & $91,0(90,0 ; 92,0)$ & $94,0(93,0 ; 95,0)$ \\
\hline Sim & $\ldots$ & $8,0(7,0 ; 10,0)$ & $6,0(5,0 ; 7,0)$ \\
\hline \multicolumn{4}{|l|}{ Paridade } \\
\hline Primípara & $19,0(18,0 ; 21,0)$ & $26,0(25,0 ; 28,0)$ & $39,0(37,0 ; 42,0)$ \\
\hline Multípara & $81,0(79,0 ; 83,0)$ & $74,0(72,0 ; 75,0)$ & $61,0(58,0 ; 63,0)$ \\
\hline \multicolumn{4}{|l|}{ Intervalo interpartal } \\
\hline Filho único & $19,0(18,0 ; 21,0)$ & $26,0(25,0 ; 28,0)$ & $40,0(37,0 ; 42,0)$ \\
\hline$<24$ meses & $37,0(35,0 ; 40,0)$ & $27,0(25,0 ; 29,0)$ & $15,0(13,0 ; 17,0)$ \\
\hline$\geq 24$ meses & $44,0(42,0 ; 46,0)$ & $47,0(45,0 ; 49,0)$ & $45,0(42,0 ; 48,0)$ \\
\hline \multicolumn{4}{|c|}{ Idade materna ao nascimento } \\
\hline$<20$ anos & $12,0(10,0 ; 13,0)$ & $17,0(15,0 ; 18,0)$ & $21,0(18,0 ; 23,0)$ \\
\hline $20-29$ anos & $58,0(56,0 ; 60,0)$ & $56,0(54,0 ; 58,0)$ & $55,0(53,0 ; 58,0)$ \\
\hline 30-45 anos & $31,0(29,0 ; 33,0)$ & $27,0(25,0 ; 29,0)$ & $24,0(21,0 ; 27,0)$ \\
\hline \multicolumn{4}{|l|}{ Estado civil } \\
\hline Sem companheiro & $8,0(7,0 ; 10,0)$ & $15,0(14,0 ; 17,0)$ & $14,0(12,0 ; 16,0)$ \\
\hline Com companheiro & $91,0(89,0 ; 92,0)$ & $85,0(83,0 ; 86,0)$ & $86,0(84,0 ; 88,0)$ \\
\hline \multicolumn{4}{|c|}{ Variáveis socioeconômicas } \\
\hline \multicolumn{4}{|l|}{ Escolaridade materna } \\
\hline$\leq 3$ anos & $43,0(40,0 ; 47,0)$ & $28,0(26,0 ; 30,0)$ & $12,0(10,0 ; 14,0)$ \\
\hline 4-7 anos & $32,0(30,0 ; 35,0)$ & $40,0(38,0 ; 42,0)$ & $30,0(27,0 ; 32,0)$ \\
\hline 8-11 anos & $20,0(17,0 ; 22,0)$ & $28,0(26,0 ; 30,0)$ & $52,0(48,0 ; 55,0)$ \\
\hline$\geq 12$ anos & $5,0(4,0 ; 6,0)$ & $5,0(4,0 ; 6,0)$ & $7,0(6,0 ; 9,0)$ \\
\hline \multicolumn{4}{|c|}{ Escolaridade chefe do domicílio } \\
\hline$\leq 3$ anos & $45,0(41,0 ; 49,0)$ & $40,0(37,0 ; 43,0)$ & $26,0(23,0 ; 29,0)$ \\
\hline
\end{tabular}




\begin{tabular}{|c|c|c|c|}
\hline 4-7 anos & $30,0(28,0 ; 33,0)$ & $\begin{array}{l}33,0(31,0 ; 36,0) \\
\text { Anos [inquéritos] }\end{array}$ & $\begin{array}{r}30,0(27,0 ; 32,0) \\
\text { continuação }\end{array}$ \\
\hline & 1986 & 1996 & 2006 \\
\hline $8-11$ anos & $19,0(16,0 ; 22,0)$ & $22,0(21,0 ; 24,0)$ & $38,0(35,0 ; 41,0)$ \\
\hline$\geq 12$ anos & $6,0(5,0 ; 8,0)$ & $4,0(3,0 ; 5,0)$ & $6,0(5,0 ; 8,0)$ \\
\hline \multicolumn{4}{|c|}{ Situação atual de trabalho materno } \\
\hline Não trabalha & $67,0(64,0 ; 70,0)$ & $50,0(48,0 ; 52,0)$ & $59,0(56,0 ; 62,0)$ \\
\hline Trabalho não-formalizado & $21,0(18,0 ; 23,0)$ & $34,0(32,0 ; 37,0)$ & $26,0(24,0 ; 29,0)$ \\
\hline Trabalho formalizado & $12,0(11,0 ; 14,0)$ & $16,0(14,0 ; 17,0)$ & $15,0(13,0 ; 17,0)$ \\
\hline \multicolumn{4}{|l|}{$\begin{array}{l}\text { Principal meio de acesso à } \\
\text { informação materna }\end{array}$} \\
\hline Nenhuma & $15,0(13,0 ; 18,0)$ & $8,0(6,0 ; 9,0)$ & $2,0(1,0 ; 3,0)$ \\
\hline Radio & $18,0(15,0 ; 20,0)$ & $6,0(5,0 ; 7,0)$ & $3,0(2,0 ; 4,0)$ \\
\hline Televisão & $35,0(32,0 ; 38,0)$ & $41,0(40,0 ; 44,0)$ & $55,0(52,0 ; 58,0)$ \\
\hline Jornais/revistas & $32,0(29,0 ; 35,0)$ & $45,0(42,0 ; 47,0)$ & $41,0(37,0 ; 44,0)$ \\
\hline \multicolumn{4}{|l|}{ Variáveis saúde } \\
\hline \multicolumn{4}{|l|}{ Crianças } \\
\hline \multicolumn{4}{|l|}{ Presença de diarreia } \\
\hline Não & $83,0(81,0 ; 85,0)$ & $87,0(85,0 ; 88,0)$ & $91,0(89,0 ; 92,0)$ \\
\hline Sim & $17,0(15,0 ; 19,0)$ & $13,0(12,0 ; 15,0)$ & $9,0(8,0 ; 11,0)$ \\
\hline \multicolumn{4}{|c|}{$\begin{array}{l}\text { Presença de doenças nas duas } \\
\text { últimas semanas }{ }^{1}\end{array}$} \\
\hline 0 & $\ldots$ & $42,0(40,0 ; 43,0)$ & $54,0(51,0 ; 57,0)$ \\
\hline 1 & $\ldots$ & $33,0(32,0 ; 35,0)$ & $27,0(25,0 ; 29,0)$ \\
\hline 2 & $\ldots$ & $21,0(20,0 ; 22,0)$ & $17,0(15,0,0 ; 20,0)$ \\
\hline 3 & $\ldots$ & $4,0(3,0 ; 5,0)$ & $2,0(1,0 ; 3,0)$ \\
\hline \multicolumn{4}{|l|}{ Baixo peso ao nascer } \\
\hline Não & $\ldots$ & $92,0(90,0 ; 93,0)$ & $94,0(93,0 ; 95,0)$ \\
\hline Sim & $\ldots$ & $8,0(7,0 ; 10,0)$ & $6,0(5,0 ; 7,0)$ \\
\hline \multicolumn{4}{|l|}{ Mães } \\
\hline Consulta pré-natal (sim) & $76,0(72,0 ; 79,0)$ & $88,0(86,0 ; 90,0)$ & $99,0(98,0 ; 100,0)$ \\
\hline \multicolumn{4}{|c|}{ Tempo $1^{a}$ consulta pré-natal } \\
\hline$\leq 3^{\circ}$ mês & $73,0(70,0 ; 76,0)$ & $77,0(76,0 ; 79,0)$ & $83,0(80,0 ; 85,0)$ \\
\hline$>3^{\circ}$ mês & $27,0(24,0 ; 30,0)$ & $23,0(21,0 ; 25,0)$ & $18,0(15,0 ; 20,0)$ \\
\hline \multicolumn{4}{|l|}{ Número de visitas pré-natal } \\
\hline$\leq 6$ & $\ldots$ & $37,0(35,0 ; 39,0)$ & $23,0(21,0 ; 25,0)$ \\
\hline$>6$ & $\ldots$ & $63,0(60,0 ; 65,0)$ & $77,0(75,0 ; 80,0)$ \\
\hline Consulta pós-natal (sim) & $\ldots$ & $34,0(32,0 ; 36,0)$ & $39,0(36,0 ; 42,0)$ \\
\hline \multicolumn{4}{|l|}{ Escore do pré-natal ${ }^{2}$} \\
\hline Não fez & $\ldots$ & $12,0(10,0 ; 13,0)$ & $1,0(0,7 ; 2,0)$ \\
\hline 1 procedimento & $\ldots$ & $13,0(12,0 ; 15,0)$ & $9,0(8,0 ; 11,0)$ \\
\hline 2 procedimentos & $\ldots$ & $13,0(12,0 ; 15,0)$ & $13,0(12,0 ; 15,0)$ \\
\hline 3 procedimentos & $\ldots$ & $35,0(33,0 ; 37,0)$ & $45,0(43,0 ; 48,0)$ \\
\hline 4 procedimentos & $\ldots$ & $27,0(25,0 ; 29,0)$ & $31,0(28,0 ; 34,0)$ \\
\hline \multicolumn{4}{|l|}{ Tipo de parto (vaginal) } \\
\hline Vaginal & $70,0(67,0 ; 73,0)$ & $62,0(60,0 ; 64,0)$ & $56,0(53,0 ; 59,0)$ \\
\hline Cesárea & $30,0(27,0 ; 33,0)$ & $38,0(36,0 ; 40,0)$ & $44,0(41,0 ; 47,0)$ \\
\hline
\end{tabular}




\section{Local do parto}

Hospital público

$32,0(28,0 ; 36,0) \quad 70,0(68,0 ; 72,0) \quad 77,0(74,0 ; 79,0)$

Hospital privado

$68,0(64,0 ; 72,0) \quad 30,0(28,0 ; 32,0) \quad 23,0(21,0 ; 26,0)$

....Ausência do dado no inquérito, ${ }^{1}$ :somatório de três doenças (diarreia, febre e tosse), ${ }^{2}: 4$ variáveis: consulta pré-natal, período gestacional na $1^{\underline{a}}$ consulta, número de visitas de pré-natal e consulta pós-natal

\subsection{DESCRIÇÃO DOS INDICADORES DO ALEITAMENTO MATERNO}

O conjunto de indicadores da alimentação infantil proposto pela Organização Mundial da Saúde descreve a frequência, a precocidade, a exclusividade e a extensão da exposição da criança ao leite materno (Tabela 2).

A exposição da criança ao aleitamento materno se tornou virtualmente universal a partir de 1996. A frequência de todos os indicadores aumentou durante 0 período analisado. O percentual de crianças menores de seis meses que estavam em aleitamento materno exclusivo no momento da entrevista aumentou em todo o período, porém a frequência atual ainda está na faixa de valores considerados ruins pela Organização Mundial da Saúde. Em 2006, o percentual de crianças que completam os 12 meses recebendo leite materno é inferior a $50 \%$ nos três anos e o percentual aos 24 meses foi inferior a 30\%. A intensidade da mudança dos indicadores foi superior entre 1986 e 1996 mesmo após ajuste para fatores demográficos, com exceção do aleitamento materno continuado aos 24 meses, superior entre 1996 e 2006 (Tabela 2). 
Tabela 2. Frequência e razão de prevalência dos indicadores do aleitamento materno de crianças menores de dois anos segundo ano do inquérito. Brasil, 1986-2006.

\begin{tabular}{|c|c|c|c|c|c|}
\hline \multirow{2}{*}{$\begin{array}{l}\text { Indicadores aleitamento } \\
\text { materno }\end{array}$} & \multicolumn{3}{|c|}{ Ano do inquérito } & \multicolumn{2}{|c|}{ Razão de prevalência (IC95\%) $^{1}$} \\
\hline & 1986 & 1996 & 2006 & 1996/1986 & 2006/1996 \\
\hline \multicolumn{6}{|c|}{$\%$ (IC95\%) } \\
\hline Crianças amamentadas & $91,0(89,0 ; 93,0)$ & $96,0(94,0 ; 97,0)$ & $97,0(95,0 ; 98,0)$ & $1,05(1,02 ; 1,08)$ & $\overline{1,02(1,01 ; 1,04)}$ \\
\hline $\begin{array}{l}\text { Amamentação na } \mathbf{1}^{\text {a }} \\
\text { hora }\end{array}$ & NA & $31,0(28,0 ; 33,0)$ & $43,0(38,0 ; 48,0)$ & NA & $1,41(1,22 ; 1,62)$ \\
\hline $\begin{array}{l}\text { Aleitamento materno } \\
\text { exclusivo (0-6 meses) }\end{array}$ & $2,0(1,0 ; 6,0)$ & $28,0(24,0 ; 33,0)$ & $38,0(31,0 ; 47,0)$ & $12,9(4,85 ; 34,33)$ & $1,37(1,07 ; 1,76)$ \\
\hline $\begin{array}{l}\text { Aleitamento materno } \\
\text { predominante }(0-6 \text { meses })\end{array}$ & $24,0(19,0 ; 30,0)$ & $41,0(36,0 ; 47,0)$ & $53,0(44,0 ; 61,0)$ & $1,74(1,34 ; 2,25)$ & $1,28(1,07 ; 1,54)$ \\
\hline $\begin{array}{l}\text { Introdução de alimentos } \\
\text { pastosos, semissólidos } \\
\text { e sólidos (6-8 meses) }\end{array}$ & NA & $76,0(68,0 ; 82,0)$ & $89,0(78,0 ; 95,0)$ & NA & $1,19(1,05 ; 1,34)$ \\
\hline $\begin{array}{l}\text { Aleitamento continuado } \\
\text { aos } 12 \text { meses }(12-15 \\
\text { meses) }\end{array}$ & $24,0(17,0 ; 32,0)$ & $34,0(29,0 ; 39,0)$ & $48,0(38,0 ; 58,0)$ & $1,53(1,07 ; 2,19)$ & $1,44(1,13 ; 1,83)$ \\
\hline $\begin{array}{l}\text { Aleitamento continuado } \\
\text { aos } 24 \text { meses }(20-23 \\
\text { meses) }\end{array}$ & $11,0(7,0 ; 16,0)$ & $16,0(12,0 ; 22,0)$ & $24,0(16,0 ; 33,0)$ & $1,46(0,86 ; 2,50)$ & $1,58(0,99 ; 2,51)$ \\
\hline
\end{tabular}

Outro indicador tradicionalmente utilizado na análise do perfil de aleitamento materno é a sua duração, que reflete a extensão da exposição da criança ao leite materno.

A taxa de aumento da duração mediana do aleitamento materno foi de 1,2 entre 1986 e 1996 e 1,7 entre 1996 e 2006. Em todos os inquéritos, há um grupo de crianças não exposto ao aleitamento materno (o início das curvas fica abaixo de $1,00)$ com redução progressiva deste percentual nos três anos. A velocidade de queda das curvas no período foi reduzida e houve consequente aumento da área abaixo das curvas, refletida no aumento da mediana (Figura 9A), principalmente em 2006. Outro aspecto relevante foi o aumento do número de crianças que estavam em aleitamento materno no momento da entrevista, representadas como censura na análise. Os valores semelhantes quanto ao aleitamento continuado aos 12 e 24 meses observados na curva de sobrevida (Figura 9A) e na Tabela 2 indicam a consistência entre a informação retrospectiva e a informação do dia anterior convencionalmente utilizada nas estimativas de duração do aleitamento materno. 
A taxa de aumento da duração mediana do aleitamento materno exclusivo foi de 2,7 entre 1996 e 2006 (Figura 9B). A velocidade de queda das curvas também é inferior em 2006 e mais pronunciada até o $1^{\circ}$ mês de vida, nos dois inquéritos. As inflexões mais pronunciadas na curva em 2006 são resultantes do maior número de crianças em aleitamento materno exclusivo, computadas como censura na análise. O ponto crítico de diferenciação das velocidades de queda das curvas nos dois inquéritos foi 0,5 mês (15 dias). $O$ formato da curva em ângulos retos entre as idades inteiras é explicado pelo fato de a duração do aleitamento materno exclusivo ter sido registrada em meses completos nos três inquéritos. 

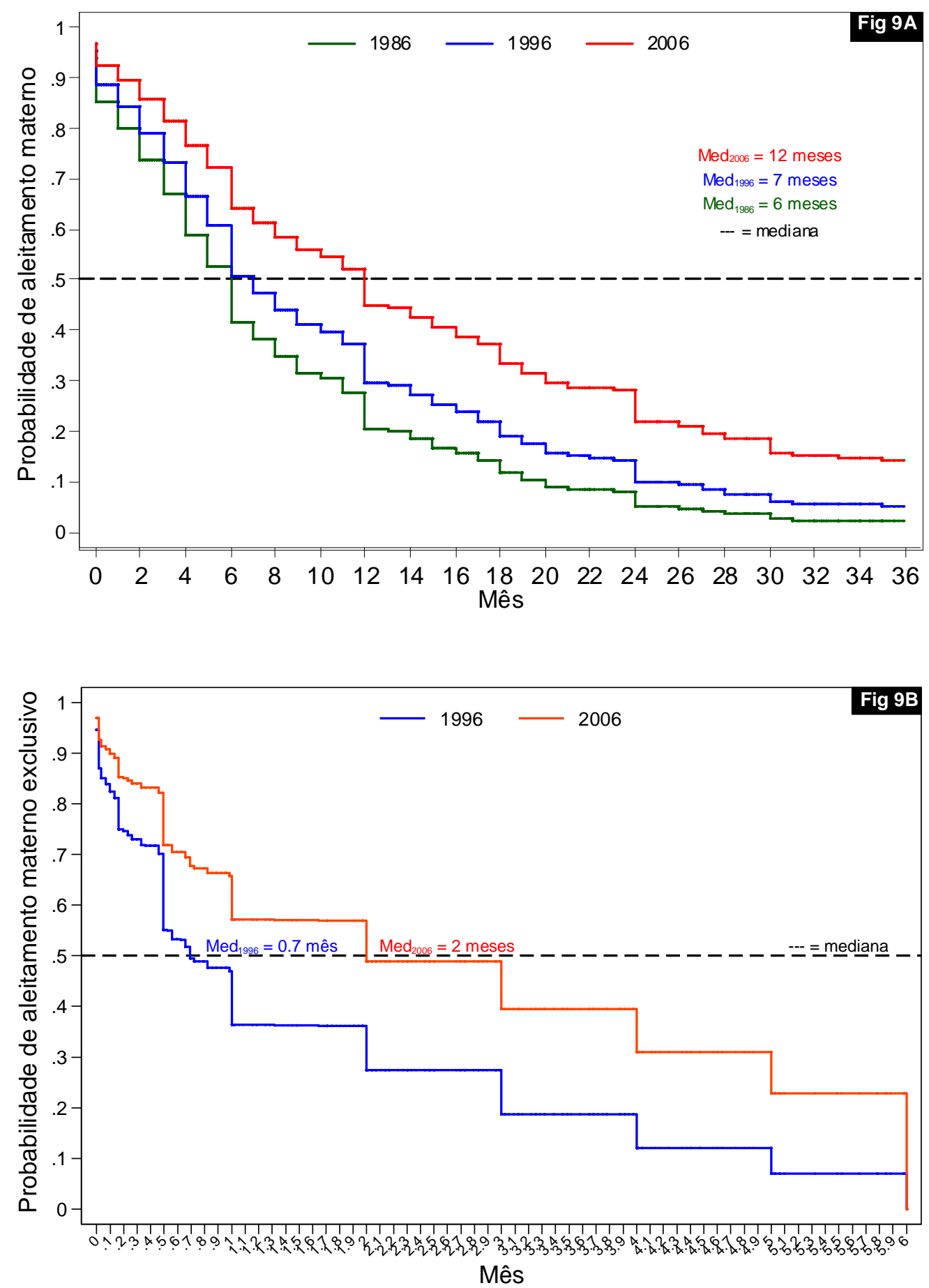

Figura 9. Curvas de sobrevida modeladas por regressão de Cox para a duração do aleitamento materno $(9 \mathrm{~A})$ e do aleitamento materno exclusivo $(9 \mathrm{~B})$ nas três últimas décadas. Brasil, 1986-2006.

A seguir serão apresentadas as análises exploratórias dos fatores associados à duração do aleitamento materno e aleitamento materno exclusivo realizadas com modelo de regressão de Cox nos anos de 1996 e 2006 (Tabela 3). 
A amamentação na $1^{\underline{a}}$ hora de vida, o intervalo interpartal e o ano do inquérito foram os fatores associados a maior duração nos dois tipos de aleitamento materno e o baixo peso ao nascer foi associado a menor duração. Os fatores protetores e de risco para os dois tipos de aleitamento materno foram distintos. A duração do aleitamento materno exclusivo foi superior conforme aumento dos procedimentos realizados nas consultas de pré-natal e que tinham mais de oito anos de estudo. $O$ efeito isolado do índice de riqueza, utilizado como proxy de renda, contribui para a redução duração do aleitamento materno, porém seu efeito é protetor para as mães com maior escolaridade. $O$ fato de a idade da criança aparecer como um fator protetor na duração do aleitamento materno exclusivo e de os intervalos para a velocidade de queda das curvas de sobrevida permanecerem constantes em 0,5 mês entre as décadas é sugestivo de que haja um período crítico para a interrupção da oferta exclusiva do leite materno e que a opção pelo aleitamento materno exclusivo esteja bem consolidada em certos grupos sociais, à espera apenas de situações que favoreçam socialmente a prática do aleitamento materno exclusivo.

No modelo do aleitamento materno, a duração foi superior nas crianças que nasceram por parto vaginal realizados em hospitais públicos, cujas mães tinham idade superior a 30 anos e o intervalo interpartal entre a criança incluída neste estudo e a anterior foi superior a 24 meses. As mães que trabalham em regime formal de trabalho amamentaram por período menor. A duração do aleitamento materno foi superior nas regiões Norte e Centro-Oeste (Tabela 3). 
Tabela 3. Efeitos dos fatores sociodemográficos e materno-infantil sobre a duração do aleitamento materno exclusivo e do aleitamento materno modelados por regressão de Cox. Brasil, 1996-2006.

\begin{tabular}{|c|c|c|}
\hline & AME & AM \\
\hline & \multicolumn{2}{|c|}{ Razão de riscos (IC95\%) } \\
\hline \multicolumn{3}{|l|}{ Ano } \\
\hline 1996 & 1 & 1 \\
\hline 2006 & $0,55(0,45 ; 0,67)$ & $0,72(0,67 ; 0,79)$ \\
\hline \multicolumn{3}{|l|}{ Amamentação na $1^{a}$ hora } \\
\hline Não & 1 & 1 \\
\hline Sim & $0,80(0,68 ; 0,95)$ & $0,79(0,74 ; 0,85)$ \\
\hline Idade (meses) & $0,94(0,89 ; 0,99)$ & $1,01(1,00 ; 1,01)$ \\
\hline \multicolumn{3}{|l|}{ Sexo } \\
\hline Masculino & 1 & 1 \\
\hline Feminino & $1,03(0,88 ; 1,20)$ & $0,95(0,89 ; 1,02)$ \\
\hline \multicolumn{3}{|l|}{ Baixo peso ao nascer } \\
\hline Não & 1 & 1 \\
\hline Sim & $1,47(1,09 ; 1,97)$ & $1,22(1,08 ; 1,37)$ \\
\hline \multicolumn{3}{|l|}{ Intervalo interpartal } \\
\hline Filho único & 1 & 1 \\
\hline$\geq 24$ meses & $0,81(0,66 ; 0,99)$ & $0,85(0,78 ; 0,92)$ \\
\hline$<24$ meses & $0,83(0,63 ; 1,07)$ & $1,26(1,14 ; 1,39)$ \\
\hline \multicolumn{3}{|l|}{ Pré-natal (escore) } \\
\hline Não fez & 1 & 1 \\
\hline 1 procedimento & $0,74(0,52 ; 1,05)$ & $0,97(0,83 ; 1,14)$ \\
\hline 2 procedimentos & $0,74(0,51 ; 1,07)$ & $0,95(0,81 ; 1,11)$ \\
\hline 3 procedimentos & $0,68(0,48 ; 0,97)$ & $1,02(0,88 ; 1,19)$ \\
\hline 4 procedimentos & $0,70(0,46 ; 1,05)$ & $1,01(0,86 ; 1,20)$ \\
\hline \multicolumn{3}{|l|}{ Tipo e local do parto } \\
\hline Parto vaginal em hospital público & 1 & 1 \\
\hline Parto vaginal em hospital privado & $1,10(0,82 ; 1,47)$ & $0,97(0,86 ; 1,10)$ \\
\hline Parto cesáreo em hospital público & $1,03(0,84 ; 1,25)$ & $0,98(0,90 ; 1,07)$ \\
\hline Parto cesáreo em hospital privado & $0,99(0,75 ; 1,31)$ & $1,19(1,07 ; 1,32)$ \\
\hline \multicolumn{3}{|l|}{ Estado civil } \\
\hline Sem companheiro & 1 & 1 \\
\hline Com companheiro & $0,93(0,75 ; 1,31)$ & $0,93(0,84 ; 1,02)$ \\
\hline \multicolumn{3}{|l|}{ Idade materna nascimento } \\
\hline$<20$ & 1 & 1 \\
\hline 20-29 anos & $1,07(0,84 ; 1,31)$ & $0,93(0,85 ; 1,03)$ \\
\hline 30-49 anos & $0,99(0,75 ; 1,30)$ & $0,75(0,67 ; 0,85)$ \\
\hline \multicolumn{3}{|l|}{ Trabalho materno } \\
\hline Não trabalha & 1 & 1 \\
\hline Trabalho informal & $0,90(0,74 ; 1,09)$ & $0,98(0,91 ; 1,06)$ \\
\hline Trabalho formal & $0,96(0,74 ; 1,25)$ & $1,15(1,04 ; 1,28)$ \\
\hline
\end{tabular}

Fonte de informação materna 


\begin{tabular}{|c|c|c|}
\hline & AME & AM \\
\hline & \multicolumn{2}{|c|}{ Razão de riscos (IC95\%) } \\
\hline Nenhuma & 1 & 1 \\
\hline Rádio & $0,75(0,49 ; 1,14)$ & $1,10(0,89 ; 1,35)$ \\
\hline Televisão & $0,74(0,53 ; 1,05)$ & $1,06(0,90 ; 1,26)$ \\
\hline Jornais/revistas & $0,71(0,49 ; 1,02)$ & $0,97(0,82 ; 1,16)$ \\
\hline \multicolumn{3}{|l|}{ Escolaridade materna } \\
\hline $0-3$ anos & 1 & 1 \\
\hline 4-7 anos & $0,82(0,64 ; 1,06)$ & $0,95(0,85 ; 1,06)$ \\
\hline$\geq 8$ anos & $0,62(0,46 ; 0,83)$ & $1,00(0,89 ; 1,14)$ \\
\hline Índice de riqueza (escore) & $1,23(1,05 ; 1,44)$ & $1,04(0,98 ; 1,11)$ \\
\hline $\begin{array}{l}\text { Escolaridade materna*índice de } \\
\text { riqueza }^{1}\end{array}$ & $0,92(0,86 ; 0,98)$ & $1,00(0,98 ; 1,03)$ \\
\hline \multicolumn{3}{|l|}{ Situação do domicílio } \\
\hline Urbano & 1 & 1 \\
\hline Rural & $1,15(0,94 ; 1,39)$ & $1,01(0,93 ; 1,10)$ \\
\hline \multicolumn{3}{|l|}{ Regiões geográficas } \\
\hline Norte & 1 & 1 \\
\hline Nordeste & $1,02(0,80 ; 1,29)$ & $1,25(1,12 ; 1,40)$ \\
\hline Sudeste & $0,82(0,62 ; 1,07)$ & $1,16(1,02 ; 1,31)$ \\
\hline Sul & $0,99(0,74 ; 1,33)$ & $1,26(1,11 ; 1,44)$ \\
\hline Centro-oeste & $0,84(0,63 ; 1,12)$ & $1,05(0,92 ; 1,19)$ \\
\hline
\end{tabular}

\subsection{ALIMENTOS CONSUMIDOS ENTRE CRIANÇAS MENORES DE DOIS} ANOS

No espectro etário dos seis primeiros meses, especificamente, houve redução da oferta de leite/fórmulas infantis e alimentos sólidos entre o período de 1996 e 2006 (Tabela 4). O perfil do consumo de água e líquidos foi semelhante nos dois inquéritos, tanto no que se refere à frequência em que os mesmos são consumidos quanto à idade (razões de prevalência). Entretanto, entre as crianças que estão recebendo leite materno, a prevalência do consumo destes alimentos é na média dos inquéritos, inferior em todos os anos. O efeito do aleitamento materno é maior na redução do consumo de leite ou fórmulas infantis, indicando o efeito substituto destes alimentos para o leite materno (Tabela 4). 
Tabela 4. Razão de prevalência e intervalo de confiança (95\%) para o registro mais precoce de água, líquidos, leite e fórmulas infantis e alimentos semissólidos e sólidos para crianças menores de seis meses segundo idade da criança e ano do inquérito. Brasil, 1996-2006.

\begin{tabular}{|c|c|c|c|c|c|c|c|c|c|c|c|c|c|}
\hline \multirow{2}{*}{$\begin{array}{c}\text { Alimentos } \\
\text { introduzidos }\end{array}$} & \multicolumn{12}{|c|}{ Idade (mês)/Ano } & \multirow{2}{*}{$\begin{array}{c}\operatorname{RP}(\text { IC95\%) } \\
2006 / 1996 \\
\end{array}$} \\
\hline & \multicolumn{2}{|c|}{0} & \multicolumn{2}{|c|}{1} & \multicolumn{2}{|c|}{2} & \multicolumn{2}{|c|}{3} & \multicolumn{2}{|c|}{4} & \multicolumn{2}{|c|}{5} & \\
\hline$\%$ & 1996 & 2006 & 1996 & 2006 & 1996 & 2006 & 1996 & 2006 & 1996 & 2006 & 1996 & 2006 & \\
\hline Água & 20,0 & 9,0 & 44,0 & 47,0 & 55,0 & 44,0 & 73,0 & 33,0 & 75,0 & 58,0 & 75,0 & 78,0 & $0,48(0,17 ; 1,39)$ \\
\hline Líquidos & 27,0 & 29,0 & 41,0 & 40,0 & 48,0 & 36,0 & 46,0 & 17,0 & 60,0 & 40,0 & 54,0 & 51,0 & $1,11(0,57 ; 2,18)$ \\
\hline $\begin{array}{l}\text { Leite e } \\
\text { fórmulas }\end{array}$ & 24,0 & 6,00 & 37,0 & 43,0 & 56,0 & 33,0 & 63,0 & 35,0 & 69,0 & 41,0 & 56,0 & 60,0 & $0,25(0,07 ; 0,09)$ \\
\hline $\begin{array}{l}\text { Alimentos } \\
\text { sólidos }\end{array}$ & 15,0 & 1,0 & 16,0 & 24,0 & 36,0 & 24,0 & 56,0 & 28,0 & 64,0 & 53,0 & 56,0 & 67,0 & $0,10(0,01 ; 0,75)$ \\
\hline
\end{tabular}

${ }^{1}$ Ajustado para idade da criança, aleitamento materno (sim/não) e interação entre ano do inquérito e idade.

A Figura 10 mostra a distribuição percentual relativa das várias combinações do consumo de leite materno e outros alimentos segundo faixa etária $(0$ a 24 meses). $O$ aumento da frequência de crianças expostas ao aleitamento materno nessa faixa etária é expressivo e em 2006 a manutenção do leite materno alcança uma em cada cinco crianças ao final do período recomendado. A razão de prevalência para o aleitamento materno 1996 e 2006, ajustada por idade, alcançou 1,23 (IC95\%:1,18;1,32).

Outro aspecto importante é a redução de líquidos, leites e fórmulas consumidos entre os períodos analisados, especialmente antes dos seis meses de idade. A análise gráfica sugere que o movimento de modificação da alimentação infantil é contínuo entre os três inquéritos analisados. Sugere, também que as modificações mais expressivas tanto do ponto de vista quantitativo quanto do perfil da alimentação estão concentradas no período 1996-2006. 
AME

AM+agua

AM+liquidos

AM+leite/formula

AM+ leite+liquidos+sólidos

Não-aleitamento
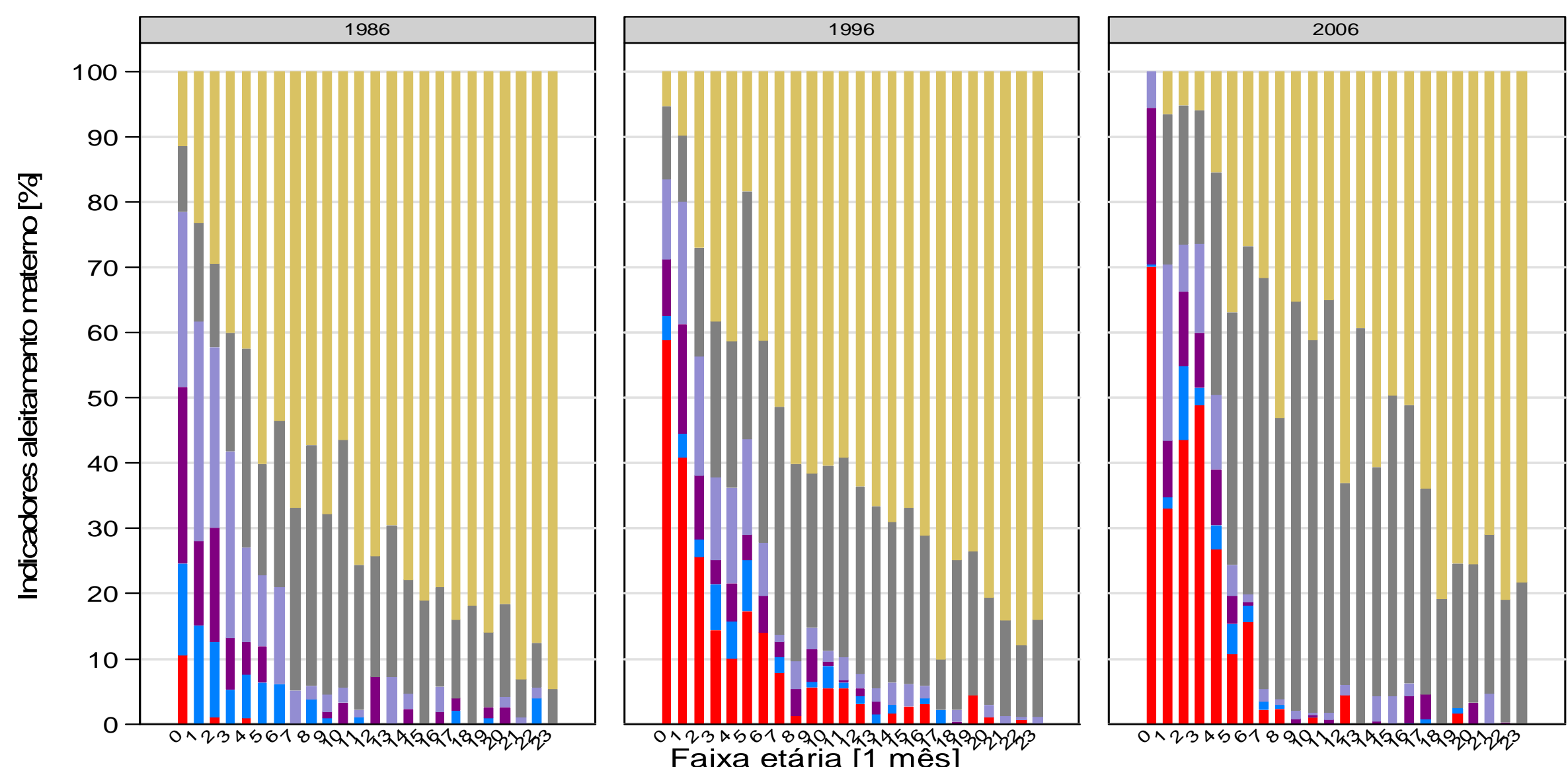

Fonte dos dados: Pesquisas Nacionais de Demografia e Saúde $(1986,1996,2006)$

Figura 10. Frequência relativa (\%) do consumo de leite materno e outros alimentos entre crianças brasileiras ao longo do período recomendado para amamentação. Brasil, 1986-2006. 


\subsection{PADRÕES ALIMENTARES NA INFÂNCIA EM TODO O ESPECTRO ETÁRIO (6-59 MESES)}

A descrição dos padrões e a caracterização quanto aos fatores sociodemográficos foram realizadas em 1996 e 2006 separadamente. Nos dois inquéritos os valores do critério de Kaiser foram superiores a 0,70.

Em 1996, os cinco primeiros componentes selecionados explicaram conjuntamente $52 \%$ da variabilidade total da alimentação. O componente rotulado como PA1 é composto basicamente por alimentos sólidos variados, o PA2 por líquidos, carnes e frutas, o PA3 por fórmulas infantis, o PA4 por alimentos pastosos à base de amido e PA5 por alimentos pastosos à base de hortaliças e frutas (Tabela 5). O leite materno foi associado somente ao padrão PA2, com carga negativa, indicando pequena participação na caracterização dos padrões, possivelmente pela frequência reduzida de crianças que recebem leite materno na idade analisada. 
Tabela 5. Descrição dos padrões alimentares de crianças entre 6 e 59 meses. Brasil, 1996.

\begin{tabular}{lccccc}
\hline Alimentos & PA1 & PA2 & PA3 & PA4 & PA5 \\
\hline Leite materno & & $-0,5320$ & & & \\
Líquidos & & 0,5230 & & 0,4217 & \\
Suco & & & & & \\
Leite (fluído, pó) & & & $-0,6927$ & & \\
$\begin{array}{l}\text { Fórmula } \\
\text { Papa com amido }\end{array}$ & & 0,6781 & & \\
industrializado & & & 0,5183 & \\
Papa com farinha enriquecida & & & 0,4536 & \\
Papa com arroz/fubá & & & & 0,8240 \\
Papa de verduras e frutas & & & & 0,5328 \\
logurte & & & & & \\
Ovo/frango/peixe & 0,2049 & 0,4024 & & & \\
Tubérculos & 0,4237 & & & & \\
Carne vermelha & 0,2536 & 0,3430 & & & \\
Legumes & 0,5298 & & & & \\
Verduras & 0,5069 & & & & \\
Frutas & 0,3052 & 0,2414 & & & \\
\hline \%variância & 15,3 & 10,8 & 9,5 & & \\
\hline \%variância acumulada & 15,3 & 26,2 & 35,7 & 44,3 & 51,7 \\
\hline kmo=0,7883 & & & & & \\
\hline
\end{tabular}

Na Figura 11 está representada a distribuição dos cinco padrões alimentares segundo faixa etária. Os padrões com alimentos de consistências líquida e pastosa (PA3, PA4, PA5) apresentam frequência decrescente com a idade e os dois padrões com predominância de alimentos sólidos apresentam frequência crescente com a idade. A mudança dos padrões alimentares observada no grupo de 6 a 24 meses indica a um só tempo, a transição de uma alimentação com consistência mais pastosa para uma sólida e o perfil dos alimentos substituídos ou conservados nessa transição. 


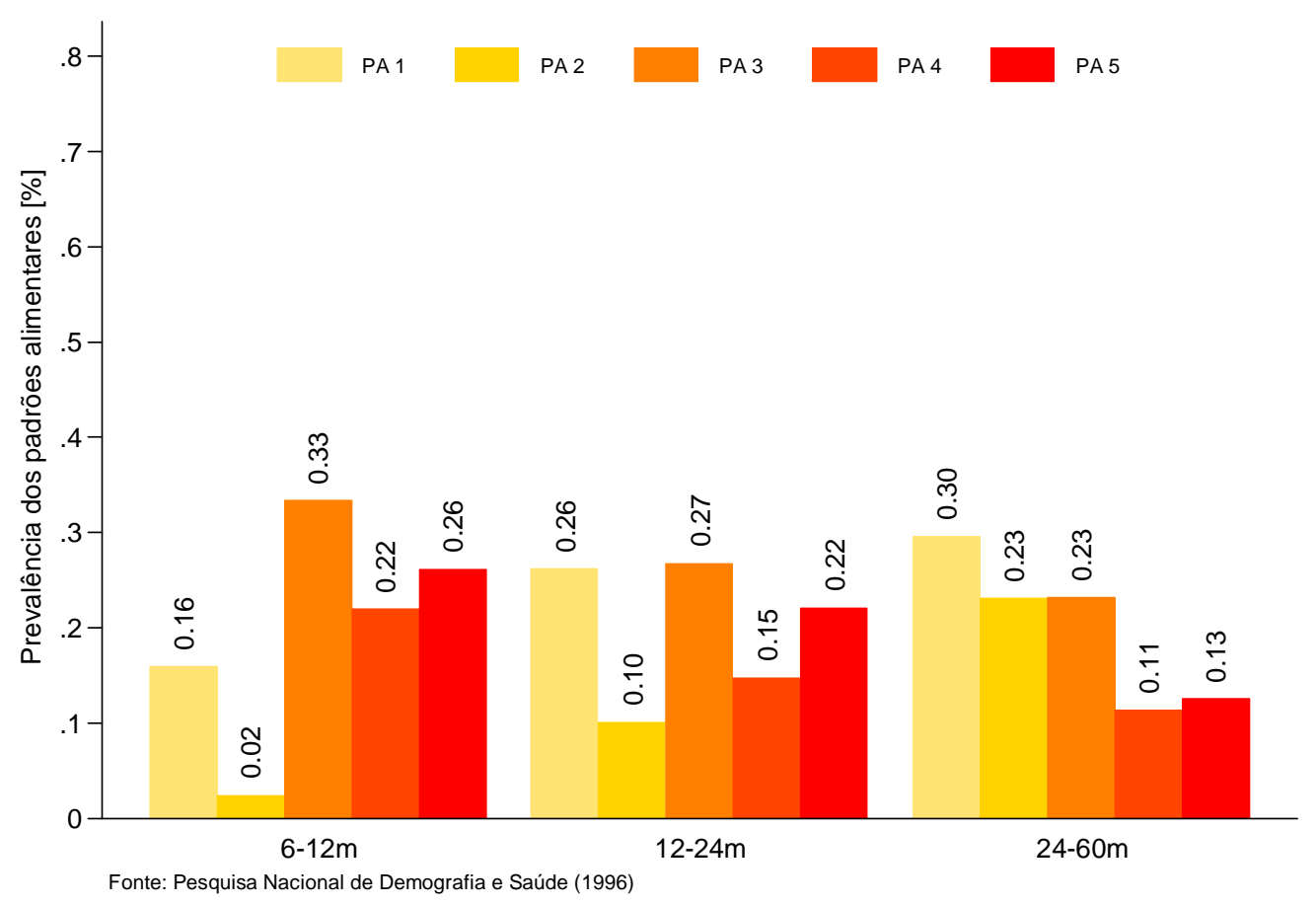

Figura 11. Frequência dos cinco padrões alimentares de crianças entre 6 e 59 meses segundo faixa etária. Brasil, 1996.

Os PA1 e PA3 apresentaram variações regionais opostas, o PA1 é mais frequente na região centro-sul do país e o PA3 mais frequente na região nortenordeste. Os PA1 e PA4 apresentaram distribuição crescente com a escolaridade materna e com o índice de riqueza, e para os padrões PA2, PA3 e PA5 esta distribuição foi decrescente. Destaca-se que os quatro tipos de papas foram distribuídas em dois padrões distintos (PA4 e PA5) e a distribuição das frequências são opostas quanto a escolaridade materna e o índice de riqueza (Tabela 6). A separação das papas em padrões distintos indica perfis distintos de crianças. Os cinco padrões alimentares apresentaram distribuição semelhante quanto à situação do domicílio e status do trabalho materno (Tabela 6). 
Tabela 6. Distribuição percentual dos padrões alimentares segundo fatores sociodemográficos. Brasil, 1996.

\begin{tabular}{|c|c|c|c|c|c|}
\hline & PA1 & PA2 & PA3 & PA4 & PA5 \\
\hline \multicolumn{6}{|c|}{ Região geográfica } \\
\hline Norte & 14,0 & 17,0 & 45,0 & 8,0 & 16,0 \\
\hline Nordeste & 14,0 & 17,0 & 43,0 & 12,0 & 14,0 \\
\hline Centro-oeste & 34,0 & 19,0 & 12,0 & 9,0 & 26,0 \\
\hline Sudeste & 33,0 & 19,0 & 21,0 & 13,0 & 14,0 \\
\hline Sul & 34,0 & 18,0 & 11,0 & 15,0 & 23,0 \\
\hline \multicolumn{6}{|l|}{ Área } \\
\hline Urbano & 26,0 & 17,0 & 27,0 & 14,0 & 15,0 \\
\hline \multicolumn{6}{|l|}{$\begin{array}{l}\text { Escolaridade } \\
\text { materna }\end{array}$} \\
\hline $0-3$ anos & 19,0 & 18,0 & 37,0 & 8,0 & 18,0 \\
\hline 4-7 anos & 27,0 & 18,0 & 26,0 & 12,0 & 17,0 \\
\hline 8-11 anos & 29,0 & 18,0 & 21,0 & 17,0 & 14,0 \\
\hline$>=12$ anos & 40,0 & 13,0 & 18,0 & 18,0 & 11,0 \\
\hline \multicolumn{6}{|c|}{ Índice de riqueza } \\
\hline $1^{0}$ & 15,0 & 19,0 & 39,0 & 8,0 & 20,0 \\
\hline $2^{\circ}$ & 22,0 & 16,0 & 38,0 & 8,0 & 15,0 \\
\hline $3^{\circ}$ & 24,0 & 19,0 & 28,0 & 11,0 & 18,0 \\
\hline $4^{\circ}$ & 33,0 & 18,0 & 19,0 & 16,0 & 13,0 \\
\hline $5^{\circ}$ & 33,0 & 18,0 & 16,0 & 19,0 & 15,0 \\
\hline \multicolumn{6}{|c|}{ Trabalho materno } \\
\hline Sim & 27,0 & 18,0 & 27,0 & 13,0 & 15,0 \\
\hline Não & 25,0 & 18,0 & 28,0 & 12,0 & 18,0 \\
\hline
\end{tabular}


Em 2006, metade da variabilidade total da alimentação infantil foi explicada pelos sete primeiros componentes selecionados. O componente rotulado como PA1 é composto basicamente por alimentos sólidos variados, O PA2 por alimentos sólidos com excesso de açúcar e gorduras, o PA3 por alimentos sólidos de origem vegetal, o PA4 por alimentos pastosos e líquidos e os padrões PA5, PA6 e PA7 por alimentos de consistência líquida. O PA6 é caracterizado pela presença do leite materno (maior carga fatorial, indicando maior correlação com o componente) e papas à base de farinhas enriquecidas (Tabela 7). 
Tabela 7. Descrição dos padrões alimentares de crianças entre 6 e 59 meses. Brasil, 2006.

\begin{tabular}{|c|c|c|c|c|c|c|c|}
\hline Alimentos & PA1 & PA2 & PA3 & PA4 & PA5 & PA6 & PA7 \\
\hline Leite materno & & & & & & 0,6496 & \\
\hline Líquidos & & & & 0,5601 & & & \\
\hline Suco & & & & & 0,4457 & & $-0,2021$ \\
\hline Leite & & & & & & $-0,5440$ & 0,2124 \\
\hline Formula & & & & & & & 0,8377 \\
\hline $\begin{array}{l}\text { Papa com amido } \\
\text { industrializado }\end{array}$ & & & & & 0,5798 & & \\
\hline $\begin{array}{l}\text { Papa com farinha } \\
\text { enriquecida }\end{array}$ & $-0,2060$ & & & 0,3573 & & 0,3994 & \\
\hline Comida de sal & & & & 0,5579 & & & \\
\hline logurte & & & 0,2263 & 0,2172 & 0,3279 & & \\
\hline Ovo/frango/peixe & 0,3731 & & & & & & \\
\hline Tubérculos & & & 0,4644 & & & & \\
\hline Carne vermelha & 0,2725 & & & & & & \\
\hline Legumes & & & 0,5172 & & & & \\
\hline Verduras & & & 0,5315 & & & & \\
\hline Frutas & 0,2960 & & & $-0,2054$ & 0,2256 & & \\
\hline Arroz & 0,4292 & & & 0,2238 & & & \\
\hline Feijão & 0,3374 & & & & & & \\
\hline Pão & 0,2874 & & & & & & \\
\hline Alimentos fritos & & 0,4269 & & & & & \\
\hline Alimentos doces & & 0,3792 & & & & & \\
\hline Biscoitos & 0,3942 & & & & 0,2557 & & \\
\hline Salgado assado & & 0,4302 & & & & & \\
\hline Salgadinho (pacote) & & 0,4940 & & & & & \\
\hline Refrigerante & & 0,3976 & & & & & \\
\hline \%variância & 10,7 & 8,9 & 8,4 & 6,0 & 5,9 & 5,4 & 4,6 \\
\hline $\begin{array}{l}\text { \%variância } \\
\text { acumulada }\end{array}$ & 10,7 & 19,7 & 28,0 & 34,0 & 39,9 & 45,3 & 49,9 \\
\hline
\end{tabular}

Entre as crianças de seis a doze meses os três padrões mais prevalentes foram os padrões PA5, PA6 e PA7. Entre as crianças de 12 a 24 meses os padrões PA1, PA5 e PA6 foram os mais prevalentes marcando a transição de uma alimentação de consistência mais pastosa para a sólida e com a presença de leite materno. Os PA1, PA2 e PA3 apresentaram aumento da frequência com o aumento da idade e os PA5 e PA6 redução. Os PA4 e PA7 foram os padrões menos frequentes entre as crianças (Figura 12). 


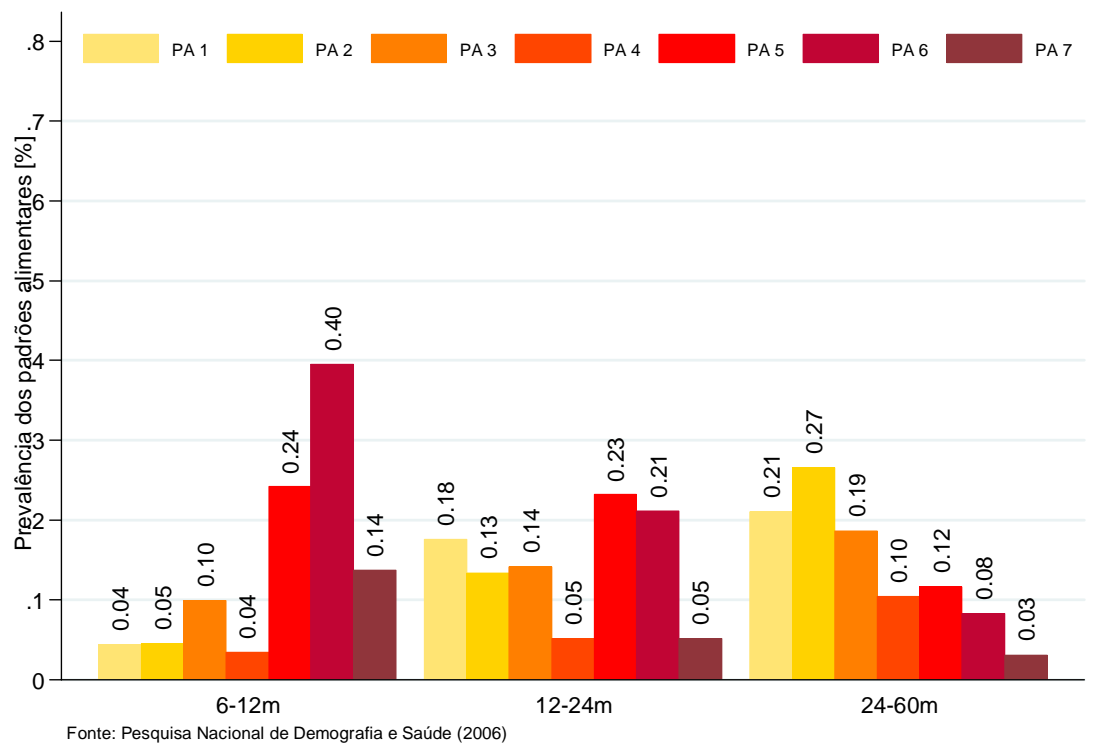

Figura 12. Prevalência dos cinco padrões alimentares de crianças entre 6 e 59 meses segundo faixa etária. Brasil, 2006.

Os PA2 e PA3 são mais frequentes na região centro-sul, os padrões PA1, PA4 e PA6 nas regiões norte e nordeste e o PA5 é um padrão típico da região Nordeste. Destaca-se que dois padrões - PA2, PA3 - apresentaram distribuições opostas quanto ao índice de riqueza e escolaridade materna em comparação com o padrão PA6. O PA7 apresentou frequência reduzida e relativamente homogênea em todas as faixas etárias e fatores sociodemográficos (Tabela 8). 
Tabela 8. Distribuição percentual dos padrões alimentares segundo fatores sociodemográficos. Brasil, 2006.

\begin{tabular}{|c|c|c|c|c|c|c|c|}
\hline & PA1 & PA2 & PA3 & PA4 & PA5 & PA6 & PA7 \\
\hline \multicolumn{8}{|c|}{ Região geográfica } \\
\hline Norte & 19,0 & 16,0 & 10,0 & 17,0 & 12,0 & 19,0 & 8,0 \\
\hline Nordeste & 24,0 & 15,0 & 6,0 & 6,0 & 27,0 & 17,0 & 5,0 \\
\hline Centro-oeste & 17,0 & 21,0 & 26,0 & 6,0 & 9,0 & 16,0 & 5,0 \\
\hline Sudeste & 15,0 & 25,0 & 21,0 & 9,0 & 13,0 & 13,0 & 4,0 \\
\hline Sul & 18,0 & 27,0 & 22,0 & 8,0 & 10,0 & 11,0 & 4,0 \\
\hline \multicolumn{8}{|l|}{ Área } \\
\hline Urbano & 18,0 & 22,0 & 18,0 & 8,0 & 15,0 & 14,0 & 4,0 \\
\hline \multicolumn{8}{|l|}{$\begin{array}{l}\text { Escolaridade } \\
\text { materna }\end{array}$} \\
\hline $0-3$ anos & 21,0 & 18,0 & 5,0 & 16,0 & 11,0 & 22,0 & 7,0 \\
\hline 4-7 anos & 19,0 & 19,0 & 13,0 & 10,0 & 16,0 & 18,0 & 5,0 \\
\hline 8-11 anos & 16,0 & 23,0 & 20,0 & 7,0 & 17,0 & 13,0 & 4,0 \\
\hline$>=12$ anos & 23,0 & 21,0 & 30,0 & 3,0 & 12,0 & 5,0 & 6,0 \\
\hline \multicolumn{8}{|c|}{ Índice de riqueza } \\
\hline $1 \stackrel{\circ}{1}$ & 24,0 & 15,0 & 7,0 & 11,0 & 10,0 & 24,0 & 9,0 \\
\hline $2^{\circ}$ & 17,0 & 19,0 & 10,0 & 10,0 & 23,0 & 18,0 & 4,0 \\
\hline $3^{\circ}$ & 18,0 & 19,0 & 16,0 & 10,0 & 20,0 & 15,0 & 3,0 \\
\hline $4^{\circ}$ & 17,0 & 24,0 & 25,0 & 9,0 & 13,0 & 9,0 & 4,0 \\
\hline $5^{\circ}$ & 17,0 & 29,0 & 25,0 & 3,0 & 12,0 & 9,0 & 4,0 \\
\hline \multicolumn{8}{|c|}{ Trabalho materno } \\
\hline Sim & 18,0 & 24,0 & 20,0 & 7,0 & 15,0 & 12,0 & 4,0 \\
\hline Não & 18,0 & 19,0 & 14,0 & 9,0 & 16,0 & 17,0 & 5,0 \\
\hline
\end{tabular}

Para a análise da mudança temporal dos padrões alimentares infantis os padrões alimentares foram estimados para o conjunto dos dois inquéritos a fim de padronizar a ordem de explicação da variabilidade e para gerar a compatibilidade necessária para analisar o comportamento dos padrões alimentares entre as décadas.

Nessa etapa, os quatro primeiros componentes selecionados explicaram conjuntamente $45 \%$ da variabilidade total da alimentação. O componente rotulado como PA1 foi caracterizado pela diversidade de alimentos de consistência sólida, com cargas fatoriais maiores para tubérculos e legumes; O PA2 foi caracterizado principalmente por leite e com correlação negativa para o leite materno; o PA3 por alimentos de consistência líquida e pastosa e o PA4 por alimentos de consistência líquida, como fórmulas e leite (Tabela 9). 
Tabela 9. Descrição dos padrões alimentares de crianças entre 6 e 59 meses nas duas últimas décadas. Brasil, 1996-2006.

\begin{tabular}{lcccc}
\hline Alimentos & PA1 & PA2 & PA3 & PA4 \\
\hline $\begin{array}{l}\text { Leite materno } \\
\text { Líquidos }\end{array}$ & & $-0,584$ & & \\
Suco & 0,2948 & 0,3209 & \\
Leite (fluído, pó) & & 0,4146 & \\
$\begin{array}{l}\text { Fórmula } \\
\text { Papa com amido }\end{array}$ & & 0,5459 & & 0,2569 \\
industrializado & & & 0,7855 \\
$\begin{array}{l}\text { Papa com farinha } \\
\text { enriquecida }\end{array}$ & & & 0,5090 & \\
$\begin{array}{l}\text { logurte } \\
\text { Ovo/frango/peixe }\end{array}$ & 0,2115 & $-0,2898$ & 0,4238 & $-0,2198$ \\
$\begin{array}{l}\text { Tubérculos } \\
\text { Carne vermelha }\end{array}$ & 0,2412 & 0,2661 & 0,4199 & \\
Legumes & 0,4628 & & & $-0,3292$ \\
Verduras & 0,3207 & 0,2503 & $-0,2239$ & \\
Frutas & 0,5191 & & & \\
\hline \%variância & 0,3940 & & & \\
\hline \%variância acumulada & 16,5 & & & \\
\hline KMO=0,7476 & 0,3480 & 10,2 & 10,2 & \\
\hline
\end{tabular}

A distribuição dos quatro padrões alimentares foi distinta segundo idade da criança e ano do inquérito. A frequência dos padrões PA1 e PA2 aumentou segundo o aumento da idade nos dois inquéritos. Os padrões PA3 e PA4 embora mais frequentes entre as crianças de seis a doze anos, apresentaram distribuições opostas segundo ano do inquérito (Figura 13). 


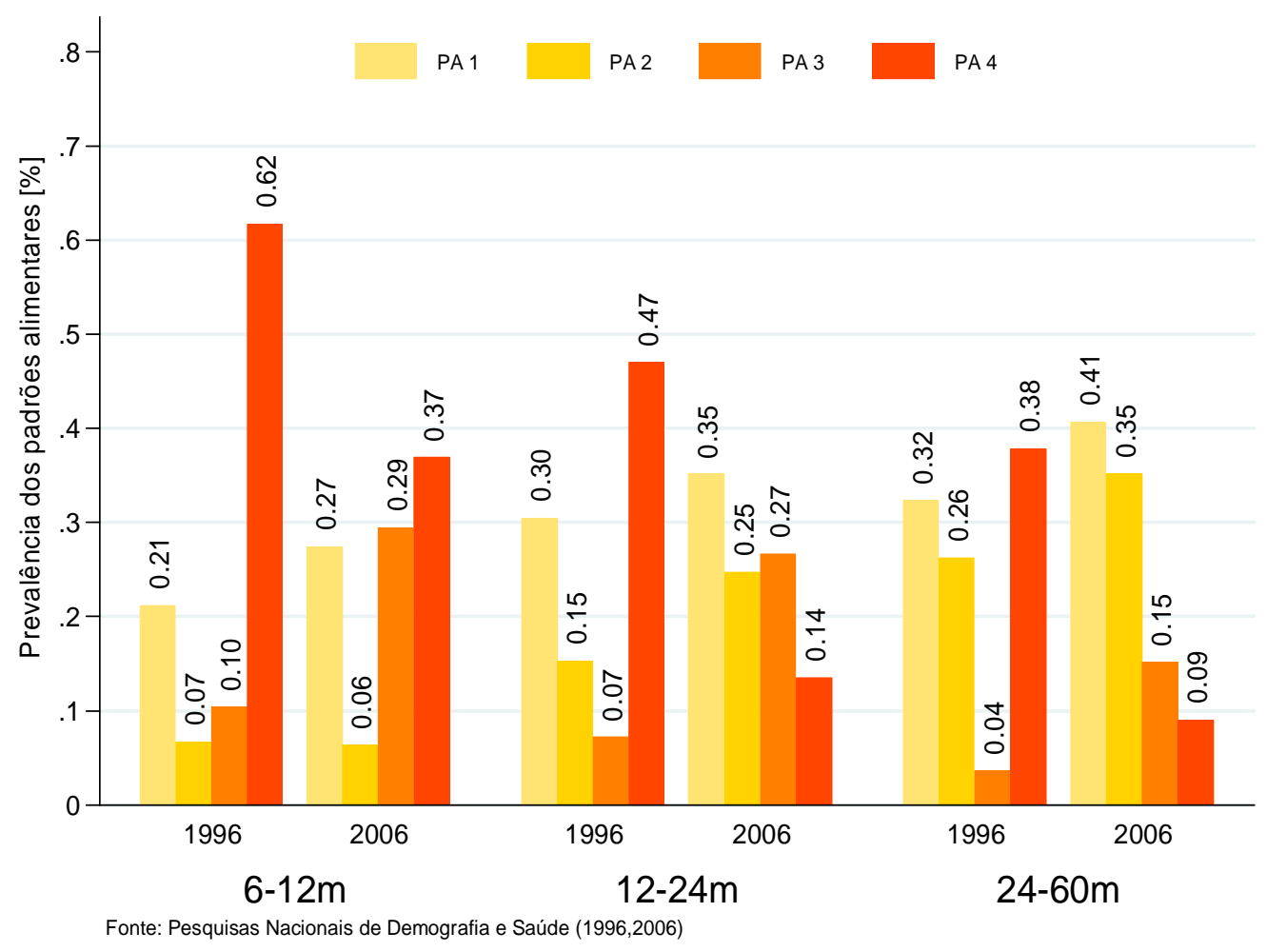

Figura 13. Prevalência dos cinco padrões alimentares de crianças entre 6 e 59 meses segundo ano do inquérito. Brasil, 1996-2006.

Os padrões PA3 e PA4 foram característicos em 2006 e 1996, respectivamente. A frequência do padrão PA3 segundo todos os fatores apresentados na Tabela 10 é superior em 1996, enquanto o padrão PA4 foi mais frequente em 1996. A distribuição dos padrões alimentares apresentou tendência distinta segundo as regiões geográficas, escolaridade materna e índice de riqueza e similar quanto ao trabalho materno e a situação do domicílio. O padrão alimentar PA1 é o único padrão que apresentou tendência de distribuição no mesmo sentido nos dois anos do inquérito segundo região geográfica, escolaridade materna e índice de riqueza (Tabela 10). As diferenças de distribuição segundo região e ano do inquérito sinalizou características atreladas às regiões, balizando a escolha da análise de efeitos mistos para compreensão mais clara do peso dos fatores individuais e dos fatores contextuais na determinação dos padrões alimentares. 
Tabela 10. Descrição dos padrões alimentares de crianças entre 6 e 59 meses nas duas últimas décadas. Brasil, 1996-2006

\begin{tabular}{lcccccccc}
\hline Variáveis & \multicolumn{2}{c}{ PA1 } & \multicolumn{2}{c}{ PA2 } & \multicolumn{2}{c}{ PA3 } & \multicolumn{2}{c}{ PA4 } \\
\hline $\begin{array}{l}\text { Ano da pesquisa } \\
\text { Idade }\end{array}$ & $\mathbf{1 9 9 6}$ & $\mathbf{2 0 0 6}$ & $\mathbf{1 9 9 6}$ & $\mathbf{2 0 0 6}$ & $\mathbf{1 9 9 6}$ & $\mathbf{2 0 0 6}$ & $\mathbf{1 9 9 6}$ & $\mathbf{2 0 0 6}$ \\
6-12 meses & & & & & & & & \\
12-24 meses & 21,0 & 27,0 & 7,0 & 6,0 & 10,0 & 29,0 & 62,0 & 37,0 \\
24-59 meses & 30,0 & 35,0 & 15,0 & 25,0 & 7,0 & 27,0 & 48,0 & 14,0 \\
Região geográfica & 32,0 & 41,0 & 26,0 & 35,0 & 3,0 & 15,0 & 39,0 & 9,0 \\
Norte & & & & & & & & \\
Nordeste & 18,0 & 25,0 & 15,0 & 39,0 & 3,0 & 17,0 & 65,0 & 19,0 \\
Centro-oeste & 18,0 & 22,0 & 20,0 & 38,0 & 4,0 & 24,0 & 57,0 & 15,0 \\
Sudeste & 40,0 & 51,0 & 27,0 & 22,0 & 4,0 & 13,0 & 30,0 & 13,0 \\
Sul & 36,0 & 46,0 & 22,0 & 23,0 & 5,0 & 20,0 & 37,0 & 11,0 \\
Área & 40,0 & 46,0 & 21,0 & 29,0 & 9,0 & 12,0 & 30,0 & 13,0 \\
Urbano & & & & & & & & \\
Rural & 31,0 & 41,0 & 20,0 & 27,0 & 5,0 & 20,0 & 44,0 & 12,0 \\
Escolaridade & 26,0 & 27,0 & 26,0 & 39,0 & 5,0 & 17,0 & 43,0 & 17,0 \\
materna & & & & & & & & \\
0-3 anos & & & & & & & & \\
4-7 anos & 21,0 & 24,0 & 24,0 & 40,0 & 3,0 & 16,0 & 52,0 & 20,0 \\
8-11 anos & 30,0 & 31,0 & 22,0 & 31,0 & 6,0 & 22,0 & 43,0 & 16,0 \\
>=12 anos & 38,0 & 43,0 & 18,0 & 26,0 & 5,0 & 20,0 & 38,0 & 11,0 \\
Índice de riqueza & 40,0 & 54,0 & 16,0 & 27,0 & 8,0 & 10,0 & 36,0 & 8,0 \\
1은 & & & & & & & & \\
20 & 18,0 & 22,0 & 25,0 & 39,0 & 3,0 & 16,0 & 54,0 & 22,0 \\
3o & 23,0 & 29,0 & 19,0 & 31,0 & 3,0 & 25,0 & 54,0 & 15,0 \\
4o & 28,0 & 36,0 & 22,0 & 29,0 & 5,0 & 23,0 & 45,0 & 12,0 \\
50 & 37,0 & 44,0 & 21,0 & 26,0 & 6,0 & 18,0 & 37,0 & 12,0 \\
Trabalho materno & 41,0 & 57,0 & 19,0 & 23,0 & 8,0 & 14,0 & 32,0 & 6,0 \\
Não & & & & & & & & \\
Sim & 30,0 & 35,0 & 21,0 & 29,0 & 5,0 & 20,0 & 45,0 & 16,0 \\
& 30,0 & 41,0 & 22,0 & 30,0 & 5,0 & 18,0 & 43,0 & 10,0 \\
\hline
\end{tabular}

A Tabela 11 apresenta os resultados dos modelos de efeitos mistos. O padrão PA1 foi o único padrão distribuído uniformemente nas regiões geográficas (pequena variância explicada pelo nível contextual). Este padrão apresentou maior variância explicada pelas variáveis alocadas no nível individual, sendo mais frequente em 2006, entre as crianças com idade superior a 12 meses e que estavam recebendo leite materno, filhas de mães com idade superior a 30 anos, com mais de oito anos de estudo e maior índice de riqueza. O padrão PA2 foi mais frequente entre as crianças que não receberam leite materno, aquelas com idade superior a 12 meses, que moram na zona rural e cujas mães leem com menor frequência jornais e revistas. A distribuição deste padrão foi heterogênea entre as regiões, pois 35\% da 
variância foi explicada pelo nível contextual, sendo mais frequente nas regiões Norte e Nordeste. Os padrões PA3 e PA4 apresentaram distribuição inversa entre 1996 e 2006. Ambos mostraram associação inversa com 0 idade e elevada heterogeneidade entre as regiões geográficas. O PA4 mostrou associação inversa com o índice de riqueza e escolaridade materna e a prática deste padrão foi maior na zona urbana. Os valores de odds ratio da análise multinível (Tabela 11) e a frequência dos padrões segundo idade e ano do inquérito (Tabela 11) sugerem que o padrão PA3 - mais frequente em 2006 e com maior crescimento no período - irá substituir o padrão PA4, o mais frequente em 1996. Destaca-se como ponto positivo desta mudança, o acréscimo de alimentos com consistência pastosa em detrimento da consistência predominantemente líquida do PA4, em uma faixa etária que não deveria receber alimentos desta consistência (Tabela 11). 
Tabela 11. Fatores sociodemográficos e materno-infantis e os escores dos padrões alimentares em modelo de efeitos mistos. Brasil, 1996-2006.

\begin{tabular}{|c|c|c|c|c|}
\hline & PA1 & PA2 & PA3 & PA4 \\
\hline Efeito fixo & \multicolumn{4}{|c|}{ OR (IC95\%) } \\
\hline \multicolumn{5}{|l|}{ Ano } \\
\hline 1996 & 1,00(Referência) & 1,00(Referência) & 1,00(Referência) & 1,00(Referência) \\
\hline 2006 & $1,52(1,35 ; 1,71)$ & $1,58(0,96 ; 2,61)$ & $4,29(2,91 ; 6,33)$ & $0,20(0,14 ; 0,31)$ \\
\hline \multicolumn{5}{|l|}{$\begin{array}{l}\text { Aleitamento } \\
\text { materno }\end{array}$} \\
\hline Não & 1,00(Referência) & 1,00(Referência) & 1,00(Referência) & 1,00(Referência) \\
\hline Sim & $1,90(1,64 ; 2,19)$ & $0,11(0,08 ; 0,14)$ & $1,46(1,21 ; 1,77)$ & $1,47(1,27 ; 1,71)$ \\
\hline \multicolumn{5}{|l|}{ Idade } \\
\hline 6-12 meses & 1,00(Referência) & 1,00(Referência) & 1,00(Referência) & 1,00(Referência) \\
\hline $12-24$ meses & $2,21(1,81 ; 2,69)$ & $2,15(1,61 ; 2,86)$ & $0,82(0,65 ; 1,03)$ & $0,41(0,34 ; 0,49)$ \\
\hline 24-60 meses & $2,88(2,37 ; 3,49)$ & $2,93(2,22 ; 3,85)$ & $0,45(0,36 ; 0,57)$ & $0,29(0,25 ; 0,35)$ \\
\hline \multicolumn{5}{|l|}{ Sexo } \\
\hline Masculino & 1,00(Referência) & 1,00(Referência) & 1,00(Referência) & 1,00(Referência) \\
\hline Feminino & $1,14(1,03 ; 1,25)$ & $1,03(0,93 ; 1,15)$ & $0,85(0,74 ; 0,99)$ & $0,90(0,81 ; 0,99)$ \\
\hline \multicolumn{5}{|l|}{$\begin{array}{l}\text { Número de } \\
\text { crianças }<5 \text { anos }\end{array}$} \\
\hline 1 & 1,00(Referência) & 1,00(Referência) & 1,00(Referência) & 1,00(Referência) \\
\hline 2 & $0,94(0,85 ; 1,05)$ & $1,06(0,94 ; 1,19)$ & $0,86(0,73 ; 1,01)$ & $1,10(0,98 ; 1,24)$ \\
\hline $3+$ & $0,91(0,76 ; 1,07)$ & $0,85(0,71 ; 1,01)$ & $0,94(0,73 ; 1,22)$ & $1,30(1,10 ; 1,53)$ \\
\hline \multicolumn{5}{|l|}{ Doenças nas } \\
\hline $\begin{array}{l}\text { duas semanas } \\
\text { anteriores }\end{array}$ & $0,92(0,87 ; 0,98)$ & $1,04(0,98 ; 1,10)$ & $1,07(0,98 ; 1,16)$ & $1,04(0,98 ; 1,10)$ \\
\hline $\begin{array}{l}\text { Idade materna ao } \\
\text { nascimento }\end{array}$ & $1,09(1,00 ; 1,17)$ & $0,95(0,87 ; 1,03)$ & $0,91(0,81 ; 1,03)$ & $1,01(0,93 ; 1,10)$ \\
\hline \multicolumn{5}{|l|}{ Trabalho materno } \\
\hline Não & 1,00(Referência) & 1,00(Referência) & 1,00(Referência) & 1,00(Referência) \\
\hline Trabalho informal & $0,94(0,84 ; 1,05)$ & $1,07(0,95 ; 1,20)$ & $1,09(0,93 ; 1,30)$ & $0,96(0,85 ; 1,08)$ \\
\hline \multicolumn{5}{|l|}{ Estado civil } \\
\hline Sem companheiro & 1,00(Referência) & 1,00(Referência) & 1,00(Referência) & 1,00(Referência) \\
\hline Com companheiro & $0,96(0,83 ; 1,10)$ & $1,13(0,97 ; 1,32)$ & $1,21(0,91 ; 1,38)$ & $0,87(0,75 ; 1,01)$ \\
\hline \multicolumn{5}{|l|}{$\begin{array}{l}\text { Principal fonte de } \\
\text { informação } \\
\text { materna }\end{array}$} \\
\hline Nenhuma & 1,00(Referência) & 1,00(Referência) & 1,00(Referência) & 1,00(Referência) \\
\hline Rádio & $1,14(0,81 ; 1,60)$ & $0,82(0,59 ; 1,12)$ & $1,04(0,57 ; 1,91)$ & $1,11(0,82 ; 1,48)$ \\
\hline Televisão & $0,87(0,67 ; 1,14)$ & $1,09(0,85 ; 1,39)$ & $1,22(0,77 ; 1,95)$ & $1,08(0,86 ; 1,37)$ \\
\hline Jornais/revistas & $1,21(0,92 ; 1,58)$ & $0,73(0,56 ; 0,95)$ & $1,57(0,97 ; 2,53)$ & $0,93(0,73 ; 1,19)$ \\
\hline \multicolumn{5}{|l|}{$\begin{array}{l}\text { Escolaridade } \\
\text { materna }\end{array}$} \\
\hline $0-3$ anos & 1,00(Referência) & 1,00(Referência) & 1,00(Referência) & 1,00(Referência) \\
\hline 4-7 anos & $1,16(0,99 ; 1,36)$ & $0,98(0,83 ; 1,15)$ & $0,95(0,73 ; 1,22)$ & $0,91(0,78 ; 1,08)$ \\
\hline$\geq 8$ anos & $1,37(1,16 ; 1,63)$ & $0,92(0,77 ; 1,11)$ & $0,82(0,62 ; 1,08)$ & $0,82(0,69 ; 0,99)$ \\
\hline
\end{tabular}




\begin{tabular}{|c|c|c|c|c|}
\hline & PA1 & PA2 & PA3 & PA4 \\
\hline Efeito fixo & \multicolumn{4}{|c|}{ OR (IC95\%) } \\
\hline $\begin{array}{l}\text { Índice de riqueza } \\
\text { (escore) }\end{array}$ & $1,18(1,07 ; 1,30)$ & $0,91(0,83 ; 1,01)$ & $1,13(0,98 ; 1,31)$ & $0,90(0,82 ; 0,99)$ \\
\hline \multicolumn{5}{|l|}{$\begin{array}{l}\text { Situação do } \\
\text { domicílio }\end{array}$} \\
\hline Urbano & Referência & Referência & Referência & Referência \\
\hline Rural & $1,10(0,97 ; 1,25)$ & $1,27(1,12 ; 1,45)$ & $0,92(0,76 ; 1,10)$ & $0,74(0,64 ; 0,84)$ \\
\hline Escolaridade & & & & \\
\hline $\begin{array}{l}\text { materna*índice de } \\
\text { riqueza }^{1}\end{array}$ & $0,99(0,95 ; 1,02)$ & $1,00(0,96 ; 1,04)$ & $0,98(0,92 ; 1,03)$ & $0,99(0,96 ; 1,04)$ \\
\hline Intercepto & $0,09(0,05 ; 0,16)$ & $0,09(0,04 ; 0,21)$ & $0,09(0,03 ; 0,32)$ & $3,66(1,86 ; 7,21)$ \\
\hline \multicolumn{5}{|l|}{$\begin{array}{l}\text { Efeito } \\
\text { probabilístico }\end{array}$} \\
\hline \multicolumn{5}{|l|}{ Variância } \\
\hline Ano & 0,001 & 0,307 & 0,144 & 0,193 \\
\hline Região & 0,128 & 2,02 & 0,849 & 1,969 \\
\hline \multicolumn{5}{|l|}{ CPV (\%) } \\
\hline Ano & 0,03 & 5,47 & 3,36 & 3,53 \\
\hline Região & 3,74 & 35,96 & 19,84 & 36,11 \\
\hline
\end{tabular}




\section{DISCUSSÃO}

\subsection{SÍNTESE DOS RESULTADOS}

A análise da alimentação infantil no Brasil nas últimas décadas ressaltou os seguintes aspectos: a) a duração mediana do AM e AME, estimada a partir de dados retrospectivos, duplicou entre 1986 e 2006 e entre 1996 e 2006, respectivamente; b)a amamentação da $1^{\underline{a}}$ hora de vida é um vetor comum no aumento da extensão do AM e do AME. A duração do AM apresenta comportamento distinto entre as regiões brasileiras, com maiores valores nas regiões Norte e Centro-oeste; c) a alimentação pós desmame pode ser sintetizada em quatro padrões alimentares nas duas décadas: PA1 composto por alimentos sólidos (legumes, tubérculos, verduras, frutas, carnes e ovos), PA2 composto por alimentos líquidos e em menor extensão por sólidos (leite e líquidos e carnes), PA3 composto por alimentos semissólidos e líquidos (papas a base de amido, líquidos à base de água, suco e iogurte) e PA4 composto por líquidos (leite e fórmulas); d) o padrão PA1 está distribuído de forma homogênea nas regiões brasileiras e associado principalmente a fatores socioeconômicos. Os padrões PA2, PA3 e PA4 estão concentrados em dois blocos regionais: norte-nordeste e centro-sul; e) embora o leite materno não tenha sido relevante na composição dos quatro padrões alimentares, a sua prática aumentou a probabilidade de prática dos padrões PA1 e PA3; f) o PA3 virtualmente substitui o PA4, principalmente entre as crianças de seis a doze meses: o aspecto positivo desta mudança é a inclusão de alimentos de consistência e composição mais apropriada à idade da criança, o aspecto negativo é a ausência do leite materno no padrão.

\subsection{ALEITAMENTO MATERNO}

A Organização Mundial da Saúde, desde 1991, recomenda o uso de dados atuais (current status) para estimar a prevalência do aleitamento materno e do aleitamento materno exclusivo no nível populacional. O ponto relevante deste indicador quando comparado ao dado retrospectivo é redução do viés de memória da mãe e o ponto limitante é a impossibilidade analítica de usar a informação da duração mediana com fatores preditores no plano individual. Adicionalmente, este tipo de estimativa pontual não seria a mais adequada para captar a informação da 
recomendação do aleitamento materno exclusivo até o sexto mês e do aleitamento materno até os 24 meses. Estas duas recomendações demandam a mensuração do tempo transcorrido a partir do nascimento(GREINER, 2014). A combinação dos dois tipos de informação - current status e dado retrospectivo permitiria a análise mais ampla do fenômeno, uma vez que resumem informações distintas(GREINER, 2014). A escolha do indicador depende do objetivo do estudo e possivelmente um único indicador não é suficiente para abordar todas as informações desejadas.

Dada a disponibilidade de estimativas do aleitamento materno no Brasil segundo os indicadores tradicionais, se optou neste estudo por abordar a tendência temporal do aleitamento materno sob duas óticas: 1) descrição da prevalência dos indicadores propostos pela OMS em cada inquérito e a 2) modelagem da duração segundo fatores preditivos. A análise da duração do aleitamento materno e seus fatores associados é relevante, pois os benefícios à saúde a curto e longo prazo são maiores quando a exposição é realizada por período maior(MARTINS; GIUGLIANI, 2012)

A evolução temporal do aleitamento materno foi marcada por dois pontos positivos: o sentido crescente das frequências dos indicadores do aleitamento materno e a manutenção do crescimento nos três anos dos inquéritos.

$\mathrm{Na}$ análise da tendência temporal dos indicadores do aleitamento materno entre 1986 e 2006, optou-se pela seleção da recomendação mais recente da OMS (WHO,2008). Neste período considerado no estudo, a recomendação do aleitamento materno exclusivo foi expandida de quatro para seis meses e a idade adequada de introdução de alimentos semissólidos e sólidos reduzida de seis a nove meses para seis a oito meses. Desta forma, o denominador dos indicadores foi modificado para contemplar esta alteração da recomendação. Ao comparar o efeito da alteração da recomendação na frequência do indicador aleitamento materno exclusivo, foi possível verificar a manutenção das prevalências em 1986 (2,6\% e 2\% para recomendação de 1991 e 2006, respectivamente). O efeito para 1996 foi a redução de 7,8 pontos percentuais ao adotar a nova definição $(35,8 \%$ e $28 \%$ para recomendação de 1991 e 2006, respectivamente). Para o indicador introdução dos alimentos não houve alteração da estimativa. Desta forma, o uso dos indicadores com a nova recomendação a título de analisar a tendência temporal foi legítimo.

O comportamento de três indicadores do aleitamento materno no período de 1990 e 2010 foi analisado em 137 países em desenvolvimento, distribuídos em quatro regiões mundiais (América Latina e Caribe, África, Ásia e Europa 
Oriental)(ROBERTS; CARNAHAN; GAKIDOU, 2013). O indicador aleitamento materno exclusivo aumentou em $81 \%$ dos países e o indicador aleitamento materno continuado entre 12 e 24 meses em 26\%. As taxas globais de aumento dos indicadores aleitamento materno exclusivo e o aleitamento continuado entre os $12 \mathrm{e}$ 24 meses foram de 1,23 (27,9\% e 34,2\% em 1990 e 2010, respectivamente) e de 1,30 (31,9\% e 59,2\% em 1990 e 2010, respectivamente). Entretanto, houve redução de 0,77 na taxa do indicador amamentação na $1^{\underline{a}}$ hora. No Brasil, as taxas para os mesmos indicadores foram, respectivamente, 14,3 (2,7\% e 38,7\% em 1986 e 2006 , respectivamente), 2,02 (17\% e 34,4\% em 1996 e 2006, respectivamente) e 1,38 (31\% e 43\% em 1996 e 2006). A taxa de mudança destes indicadores no presente estudo, concretiza o avanço brasileiro no sucesso das ações pró-aleitamento já implementadas. Na China, a taxa de aleitamento materno exclusivo aos seis meses foi $28,7 \%$ e para a amamentação na $1^{\underline{a}}$ hora de vida foi $59 \%$ (GUO et al., 2013).

Os indicadores amamentação na $1^{\underline{a}}$ hora de vida e o aleitamento materno exclusivo são utilizados como indicadores de cobertura no relatório de acompanhamento das Metas de Desenvolvimento do Milênio. Estas duas práticas são consideradas fatores protetores da mortalidade infantil, uma vez que devem ocorrer nos primeiros seis meses de vida, período em que o risco de morte ainda é alto. O relatório dos resultados mais recente aponta cobertura de $50 \%$ na amamentação na $1^{\underline{a}}$ hora de vida e apenas $41 \%$ para o aleitamento materno exclusivo. Um ponto positivo dos resultados é a evolução semelhante da distribuição dos percentuais da amamentação na $1^{\underline{a}}$ hora de vida segundo os quintis de renda (WHO,2015). Um dos principais fatores associados de forma inversa a esta prática é o parto cesariano(ESTEVES et al., 2014).

As contribuições adicionais do presente estudo na trajetória do aleitamento materno e do aleitamento materno exclusivo no Brasil são as estimativas da duração mediana a partir de dados retrospectivos em três décadas e a definição dos fatores associados. Destacam-se dois pontos que tornaram a comparação das estimativas entre os inquéritos mais robustas: uniformidade do dado retrospectivo (mesma questão) e da distribuição similar de crianças nas faixas etárias selecionadas para a análise - menores de seis meses para AME e 36 meses para AM.

A análise da duração do aleitamento materno é relevante, pois os benefícios à saúde a curto e longo prazo são maiores quando a exposição é realizada por período maior(MARTINS; GIUGLIANI, 2012) 
No Brasil, existem oito inquéritos e pesquisas nacionais que abordam a temática aleitamento materno, os quais são: o Estudo Nacional de Despesa Familiar (ENDEF) (1974-75); a Pesquisa Nacional de Saúde e Nutrição (PNSN) (1989); as três Pesquisas Nacionais de Demografia e Saúde $(1986,1996,2006)$, utilizadas neste estudo, as duas Pesquisas de Prevalência de Aleitamento nas Capitais Brasileiras e Distrito Federal $(1999,2008)$ e a Pesquisa de Orçamentos Familiares (POF) (20022003). Nos primeiro e último inquéritos, havia a informação se as mães estavam amamentando seus filhos (sim/não). No segundo inquérito, foram incluídas questões sobre tempo, exclusividade do aleitamento e alimentos consumidos. Nas outras pesquisas, a abordagem do aleitamento foi mais ampla em função dos objetivos centrais incluírem o aleitamento materno.

A duração mediana do aleitamento materno entre 1974 e 2008 aumentou de 2,5 para 11,3 meses e a prevalência do aleitamento materno exclusivo aumentou de 3,1 para 41,3\% estimadas a partir destes inquéritos(VENANCIO et al., 2013). Estas estimativas foram calculadas utilizando dados da situação atual (current status) e diferentes técnicas de modelagem - médias móveis $(\mathrm{WHO}, 2008)$ ou análise de logito.

A mudança positiva do patamar da prática do aleitamento materno em uma sociedade traz, também, novos desafios analíticos $O$ uso da estimativa pontual era legítimo quando um percentual pequeno de crianças era amamentada exclusivamente por seis meses. Desta forma, este tipo de dado ofereceria uma estimativa basal mais elevada (por usar a informação do dia anterior), indicando que - AME parecia ser mais comum do que realmente era. Entretanto, mesmo após diversas ações de promoção do aleitamento, a avaliação do impacto destas ações no AME usando a estimativa pontual indica avanços muito pequenos, que poderiam ser mais efetivos se fossem avaliados por outro indicador(GREINER, 2014).

Paradoxalmente o sucesso das medidas pró-aleitamento podem contribuir para a subestimação de sua mensuração pelo indicador tradicional, uma vez que este não considera a possibilidade de as crianças em amamentação no dia do inquérito serem amamentadas posteriormente por tempo médio superior ao daquelas que deixaram de amamentar antes do dia do inquérito.

A favor da estimativa pontual pesa os pontos positivos da redução do viés de memória e da facilidade da obtenção mais acurada do dado. Entretanto, este indicador não capta a extensão do aleitamento materno exclusivo no intervalo do nascimento até o sexto mês. O viés de memória da mãe ao relatar a duração do 
aleitamento materno é um dos pontos mais discutidos nos estudos sobre esta temática(AARTS et al., 2000) (BARBOSA et al., 2012)(LAUNER et al., 1992)(PIWOZ et al., 1995). A informação retrospectiva se mostra acurada e precisa quando o intervalo entre a interrupção do aleitamento e o relato for inferior a três anos ( $\mathrm{Li}$ et al, 2005). Adicionalmente, a informação sobre a oferta do leite materno é superior à qualidade da informação retrospectiva da introdução dos alimentos consumidos(LI; SCANLON; SERDULA, 2005)(BARBOSA et al., 2012). O relato acurado e preciso é mais afetado por fatores culturais e pela forma de abordagem do entrevistador do que por renda, escolaridade, etnia, local de residência (urbano/rural)(LI; SCANLON; SERDULA, 2005), embora uma revisão mais ampla desta questão não foi abordada neste estudo de revisão. O dado recordado sobre aleitamento materno exclusivo apresenta a limitação da recordação da data exata de introdução de algum alimento e a definição de alimento envolve questões culturais, pois a ideia da água ser um alimento não é tão simples e direta. Neste tipo de aleitamento, poderia haver superestimação da informação. O término do aleitamento materno é mais marcante para a mãe em relação à interrupção do $A M E$, pois neste caso a mãe não interrompe a oferta do leite, somente acrescenta outros alimentos.

A técnica mais recomendada para tratar os dados retrospectivos do aleitamento materno é a análise de sobrevida uma vez que as crianças que estão recebendo leite materno, de forma exclusiva ou não, são computadas de forma distinta na análise. A consequência do uso seria a subestimação da mediana no aleitamento materno quando o percentual de crianças censuradas é elevado, uma vez que a duração é superior à idade em que a criança foi censurada(GREINER, 2014).

Embora o desenho mais adequado para avaliar a duração seja a coorte, estes são mais caros e com perdas relativamente maiores. Além disso, a informação sobre aleitamento materno em estudos de base populacionais e domiciliares estão disponíveis em diversos países adotando o mesmo questionário, o que facilita a realização de análises de tendência temporal e na avaliação indireta do efeito das ações de promoção.

Neste estudo, o desempenho do cálculo da duração mediana do aleitamento materno exclusivo usando dados retrospectivos e atuais (current status) foi semelhante, diferindo apenas 0,3 mês em 1996 e 0,5 mês em 2006 (Anexo 6). As diferenças entre as medianas do aleitamento materno se ampliaram quando esta prática se torna mais frequente (Anexo 6). As diferenças das estimadas a partir dos 
dois tipos de dados aumentam quando o aleitamento materno é uma prática frequente no país (Anexo 4).

A partir das análises do presente estudo, a mediana do aleitamento materno aumentou seis meses em vinte anos, sendo que o aumento de cinco meses ocorreu em dez anos. Na América Latina e Caribe, entre 1980 e 2000, a duração do aleitamento materno variou entre 1,2 a 6,2 meses de forma heterogênea segundo condições sociodemográficas e de saúde(LUTTER; CHAPARRO; GRUMMERSTRAWN, 2011). Em todos os países, com exceção da Nicarágua, o aumento foi superior na zona urbana. Na Colômbia, Nicarágua e República Dominicana houve tendência de queda na duração do aleitamento materno conforme aumento dos anos de estudos maternos, enquanto na Bolívia, Haiti e Peru a tendência foi inversa. $\mathrm{Na}$ Guatemala a tendência de aumento foi observada até 12 anos de estudos com redução da duração entre as mulheres com tempo superior. A duração do aleitamento materno foi maior entre as crianças nascidas por partos realizados por profissionais da saúde na Bolívia, Colômbia, Guatemala e Peru e menor no Haiti, República Dominicana e Nicarágua. Os dados dos inquéritos brasileiros realizados em 1986 e 1996 foram incluídos nesta análise e o aumento da duração média do aleitamento foi de 2,2 meses. O padrão de aumento foi igual na zona urbana e rural e superior nas crianças cujos partos foram realizados por profissionais da saúde. A escolaridade materna apresentou comportamento diferente dos outros países, pois a duração foi menor nos extremos dos níveis de escolaridade. De maneira geral, os resultados da análise deste pool de países indicaram maior aumento da duração do aleitamento materno entre as crianças com menor risco de morbi-mortalidade. A situação do domićlío determinou tanto o acesso aos serviços de saúde como de emprego e escolaridade, que estão atrelados ao aleitamento materno. A Nicarágua foi o único país que investiu em ações de promoção e apoio ao aleitamento materno direcionadas para a população em maior vulnerabilidade social - residentes na zona rural.

A comparação direta da magnitude entre o aumento do aleitamento materno no Brasil estimado no estudo de revisão na América Latina e os valores brasileiros aqui recalculados é limitada por três questões metodológicas: a) fonte da informação da duração do aleitamento - no presente estudo foi utilizada a informação retrospectiva materna e na revisão dos dados da América Latina, a informação do aleitamento correspondente ao dia anterior (current status); b) a medida de tendência central utilizada - neste estudo a duração foi expressa em mediana e na 
revisão da América Latina em média e c) o tipo de análise para estimar a duração neste estudo a mediana foi modelada por modelo de regressão de Cox e na revisão da América Latina a média foi modelada pela situação atual do aleitamento com splines cúbicos naturais(GRUMMER-STRAWN, 1993). Por estas razões, aqui as comparações foram feitas levando-se em conta apenas a tendência dos resultados e os fatores associados.

Neste estudo, os únicos fatores comuns associados direta e inversamente com os dois tipos de aleitamento - AME e AM - foi a amamentação na primeira hora de vida e o baixo peso ao nascer, respectivamente. A amamentação na $1^{\underline{a}}$ hora de vida é dos 10 passos para o Sucesso do Aleitamento (UNICEF) e um dos indicadores da alimentação infantil propostos pela Organização Mundial da Saúde. A ênfase a sua prática se justifica pela oferta precoce do colostro, principal fonte de imunidade passiva; pelo desenvolvimento do vínculo mãe-filho e pelo estímulo à manutenção do aleitamento materno. No Brasil, nascer em um Hospital Amigo da Criança aumentou a chance em $9 \%$ da criança ser exposta ao aleitamento na primeira hora de vida(VENANCIO et al., 2012). Entretanto, nos Estados Unidos o efeito positivo na exposição precoce ao aleitamento materno em função de nascer em um Hospital Amigo da Criança foi verificado somente para as crianças com menor nível socioeconômico, pois estas são menos propensas a nascerem neste tipo de hospital(HAWKINS et al., 2014). Em estudo realizado na Bahia, esta prática foi associada ao recebimento de informações sobre os benefícios do aleitamento materno durante as consultas de pré-natal, parto vaginal e nascimento à termo(VIEIRA et al., 2010).

Neste estudo, a participação do pré-natal com maior frequência e o início no tempo recomendado esteve associado com maior duração do aleitamento materno exclusivo, assim como dois estudos realizados no nordeste brasileiro(DEMÉTRIO; PINTO; ASSIS, 2012)(OLIVEIRA et al., 2013)(VENANCIO; MONTEIRO, 2006). As questões sobre pré-natal disponíveis nos inquéritos de 1996 e 2006 não fazem alusão ao aconselhamento sobre aleitamento materno nas consultas. Entretanto, a maior pontuação do escore mostrou associação positiva na duração do aleitamento exclusivo, apontando que o maior tempo com profissionais da saúde durante 0 período gestacional estimularia à adesão ao aleitamento materno. A consulta materna pós-natal constitui em oportunidade para a mãe estar novamente com um profissional de saúde que possa lhe auxiliar no manejo do aleitamento materno. Outra explicação seria que as mães que realizam todos os procedimentos do pré- 
natal (maior pontuação do escore) marcaria um perfil de mãe que se preocupa com sua saúde e do seu filho e desta forma, já seria mais propensa a amamentar(SANTO; DE OLIVEIRA; GIUGLIANI, 2007). O contato com os profissionais durante consultas de pré-natal contribuiu para aumentar a segurança da mãe em amamentar em quatro países do sul da Ásia(DIBLEY et al., 2010).

O parto cesáreo em hospital privado foi associado a menor duração do aleitamento materno. No Brasil, as taxas de aumento dos partos cesáreos nos hospitais públicos foram de 1,13 entre 1996 e 2006 e 1,40 nos hospitais privados. Desta forma, no ano de 2006 nascer um em hospital privado foi considerado proxy de parto cesáreo (80\%). O percentual global de cesárea foi de $15 \%$ em 2002 , representando $89 \%$ das crianças nascidas vivas. A frequência foi superior em países da América Latina e Caribe (29\%) e na América do Norte (24\%), com variações segundo região mundial, tais como, 3,5\% na África, 16\% na Ásia, 19\% na Europa e 15\% na Oceania(BETRÁN et al., 2007).

No Brasil, a cesárea também está associada à esterilização feminina, o que pode dificultar ainda mais a amamentação na $1^{\text {a }}$ hora de vida, pois o procedimento cirúrgico para a esterilização é realizado imediatamente após o parto. Em 1996, 80\% dos casos de esterilização foram realizados após o parto cesáreo, principalmente nas regiões centro-sul e em mulheres com maior escolaridade, que é o público principal dos hospitais privados(BEMFAN, 1997). Em 2006, houve redução do percentual da esterilização feminina, principalmente entre as mulheres com maior escolaridade, mas este método juntamente com o uso de pílulas anticoncepcionais ainda respondem por dois terços de todos os métodos contraceptivos utilizados(BRASIL, 2009).

Em estudo de meta-análise, o parto cesáreo mostrou associação negativa com a amamentação na $1^{\underline{a}}$ hora de vida e com o aleitamento materno exclusivo. Entretanto, quando esta prática foi garantida, o tipo de parto não interferiu na duração do aleitamento materno(PRIOR et al., 2012). O mecanismo pelo qual o parto cesáreo poderia prejudicar a exposição precoce ao leite materno seria pelo atraso no início da lactação pelo retardo na ejeção do colostro, uso de anestésicos, dificuldade de manter o filho em contato com a mãe pelos procedimentos cirúrgicos. Além disso, o parto cesáreo, em especial quando este é eletivo, esteve associado à exposição precoce às formulas infantis no ambiente hospitalar(ZANARDO et al., 2013). 
Um outro fator que pode estar associado na relação entre parto e aleitamento, porém ainda pouco explorado, é o perfil de mães que escolhem o parto cesáreo. As mães que optam por este tipo de parto seriam aquelas que não tem intenção de amamentar seu filho(PRIOR et al., 2012).

O perfil da mãe que amamenta exclusivamente por mais tempo apresenta características distintas da mãe que continua amamentando após os seis meses, principalmente para fatores socioeconômicos.

No presente estudo, a escolaridade materna favoreceu a maior duração do aleitamento materno exclusivo e seu efeito modificou o efeito inverso do índice de riqueza. Desta forma, mães com maior escolaridade e que pertencem aos quintis superiores do índice de riqueza amamentam exclusivamente por mais tempo. A escolaridade materna esteve associada ao índice de riqueza do domicílio. Nos três inquéritos o percentual de mulheres com maior escolaridade esteve concentrado nos dois quintis superiores do índice de riqueza. O mesmo perfil foi observado em outros países em desenvolvimento(WHO, 2010). No Nepal(ADHIKARI et al., 2014) e na Índia(PATEL; BANERJEE; KALETWAD, 2013) a exposição ao leite materno na primeira hora de vida mostrou associação positiva com a escolaridade materna. $A$ escolaridade materna está relacionada à saúde infantil de maneira ampla por duas razões principais que são a situação socioeconômica mais favorável e a adoção de comportamentos que reduzem à exposição da criança aos fatores de riscos para o desenvolvimento de doenças aliados à procura precoce por medidas de intervenção para reduzir o agravo da doença já instalada(DESAl; ALVA, 1998)(WHO, 2010). Além disso, a escolaridade materna está associada a maior compreensão das recomendações sobre aleitamento materno e à exposição ao parto realizada por profissionais da saúde que estimulem práticas mais adequadas de aleitamento materno(ADHIKARI et al., 2014).

Em estudo prospectivo, a amamentação na $1^{\underline{a}}$ hora aumentou o percentual de crianças em aleitamento exclusivo durante a permanência no hospital. Entretanto, esta exposição precoce não foi suficiente para sustentar a exclusividade do aleitamento materno para a maioria das crianças. A duração do aleitamento materno exclusivo foi superior quando esta exposição foi associada às visitas periódicas de pessoas capacitadas para promover o aleitamento materno e auxiliar a mãe a continuar a oferta exclusiva do aleitamento materno, de forma igualitária em todos os grupos sociais(COUTINHO et al., 2005). 
No presente estudo, a duração do aleitamento materno exclusivo foi homogênea nas regiões brasileiras, porém a duração do aleitamento materno apresentou disparidades regiões, sendo superiores nas regiões Norte e CentroOeste. A duração do aleitamento materno exclusivo foi semelhante segundo as macrorregiões brasileiras, sugerindo redução das disparidades sociais e distribuição relativamente homogênea das ações de promoção ao aleitamento materno.

A implementação do Programa de Saúde da Família a partir de 1994 contribuiu para a redução das desigualdades de acesso aos serviços básicos de saúde segundo índice de riqueza e macrorregiões(VICTORA et al., 2011). No presente estudo, as mudanças não diretamente mensuradas pelas variáveis individuais estão em grande parte refletidas na variável ano do inquérito, e são um indicativo indireto do efeito positivo de todas as ações que promovem, protegem e apoiam o aleitamento materno implementadas no período analisado. Não foi possível estimar as ações específicas de aleitamento materno implementas em cada macrorregião brasileira, porém as diferenças regionais sugerem heterogeneidade na realização e implementação destas ações.

A implementação de quatro ou mais ações agregadas de promoção, apoio e de proteção ao aleitamento materno no município em que a criança reside contribuiu para o aumento das taxas do aleitamento materno exclusivo. A presença de quatro ou mais destas ações no município em que a criança vive reduziu o impacto negativo da baixa escolaridade materna, do acompanhamento em serviço público e do baixo peso ao nascer (VENANCIO; MONTEIRO, 2006). Resultado semelhante quanto ao efeito positivo da presença de legislação que promove o aleitamento materno foi verificado em estudo realizado nos Estados Unidos. O nível contextual considerado foi a presença de legislação por estado e o desfecho a exposição ao aleitamento materno e ser amamentado por seis meses. Nos estados com mais de uma legislação a taxa de aleitamento materno foi $19 \%$ superior e a taxa do aleitamento materno até o sexto mês foi $32 \%$ superior(KOGAN et al., 2008).

A avaliação da efetividade de cada ação separadamente em nível nacional é desconhecida até o momento, entretanto, o avanço dos indicadores do aleitamento materno nestes vinte anos pode ser creditado à implementação conjunta das ações de promoção, apoio e proteção ao aleitamento materno.

A primeira ação pró-aleitamento desenvolvida no Brasil foi praticamente concomitante às recomendações da OMS e UNICEF(REA, 1990). O Programa Nacional de Incentivo ao Aleitamento Materno (PNIAM) foi implementado em março 
de 1981 sob a coordenação do Ministério da Saúde e a primeira ação foi a veiculação de uma mensagem nas emissoras de rádio e televisão incentivando o aleitamento materno por no mínimo seis meses. Esta mesma mensagem foi impressa em contas de luz, telefone, água, casas lotéricas e bancos. As outras ações relevantes estabelecidas neste programa foram 0 treinamento dos profissionais da saúde, a elaboração de um código para regulamentar os produtos substitutos do leite materno, implantação de ações no ambiente de trabalho materno, inclusão do tema aleitamento nos currículos dos profissionais de saúde. Ainda na década de 80 , três importantes ações de apoio e de proteção foram desenvolvidas: obrigatoriedade do alojamento conjunto nos hospitais públicos e conveniados (1983) e universitários (1986), instalação e funcionamento de bancos de leite humanos (1988) e a primeira versão do código internacional para regulamentação de substitutos do leite materno (1988). Na década de 1990, as principais ações de incentivo ao aleitamento materno foram a Declaração de Innocenti e a Semana Mundial do Aleitamento Materno; a de proteção foi a modificação nas Normas de Comercialização dos produtos substitutos do leite materno (NBCAL) e de apoio a implementação e acreditação progressivas dos Hospitais amigo da criança. No período de 2000 a 2006, se destacam as modificações na NBCAL, bancos de leite humano e a instituição do Dia Nacional da Doação de Leite Humano(BRASIL, 2011).

De forma indireta, é possível estabelecer relação entre a evolução dos indicadores com as ações de incentivo, apoio e proteção ao aleitamento materno. As ações de incentivo ao aleitamento materno como mensagens da mídia, treinamento dos profissionais da saúde, semana mundial do aleitamento materno contribuiu para a virtual universalização do aleitamento materno (oferta do leite materno em algum momento da vida da criança) e a extensão do aleitamento materno até os 12 e 24 meses. Estas ações de incentivo são relevantes para fomentar, fortalecer e manter a cultura pró-aleitamento na sociedade. Os Hospitais Amigo da Criança favorecem a amamentação na $1 \underline{\underline{a}}$ hora de vida, fortalecendo o vínculo mãe-filho, a segurança da mãe para amamentar e o atraso da exposição aos outros líquidos e fórmulas, o que pode refletir em maior tempo de exposição exclusiva ao leite materno. Os bancos de leite humano contribuem para aumentar exposição ao leite materno para crianças que não receberiam na sua ausência e a garantia de oferta exclusiva do leite materno durante a permanência no hospital. $\mathrm{O}$ alojamento conjunto contribui para a prática do aleitamento materno em livre demanda, garantindo também o 
recebimento do colostro, além de estimular a mãe a oferecer o leite materno exclusivamente. A licença maternidade contribui para a prática do aleitamento materno exclusivo e para a segurança da mãe em amamentar. $O$ sucesso de todas as ações cujos efeitos se concentram no período perinatal auxilia no desenvolvimento da segurança da mãe em continuar amamentando.

Estratégias mais recentes como, a Rede Amamenta implementada em nível nacional, e a Iniciativa unidade básica amiga da amamentação, implementada no Rio de Janeiro, contribuíram para aumentar a prevalência do AME. O objetivo de ambas é capacitar as equipes de profissionais que trabalham na atenção básica para promoção do aleitamento materno neste local. Mais recentemente, foi lançada a Estratégia Amamenta e Alimenta Brasil, que uniu a Rede Amamenta e a Estratégia Nacional para Promoção da Alimentação Complementar Saudável (ENPACS). Esta ação de promoção evidencia a importância de tratar o aleitamento materno e a alimentação como um vetor único de proteção e promoção à saúde infantil e adulta.

\subsection{ALEITAMENTO E ALIMENTAÇÃO INFANTIL}

A partir das recomendações das práticas alimentares infantis estabelecidas pela OMS(WHO,1991)(WHO,2008) as análises deste aspecto foram realizadas em recortes etários.

No espectro etário de zero a 24 meses, as principais mudanças identificadas nos três anos foram: a) o aumento do percentual de crianças menores de seis meses em aleitamento materno exclusivo (área vermelha); b) a redução do percentual de crianças que recebiam leite materno juntamente com leite, fórmulas (área roxa) e alimentos sólidos (área cinza) antes dos seis meses e o aumento do percentual de crianças que recebiam leite materno e outros alimentos até 24 meses (área cinza) e c) a redução do percentual de crianças que não recebiam leite materno em todas as faixas de idade (área bege). A redução da oferta de leite e alimentos sólidos entre as crianças menores de seis meses foi uma consequência do aumento da prevalência de crianças em aleitamento materno predominante. Apesar do consumo de água e líquidos não se ter alterado no período analisado, este resultado deve ser ressaltado como ponto positivo, pois estes alimentos não tem efeito substituto do leite materno e sim são oferecidos de forma adicional. A redução de leite, fórmulas e alimentos sólidos antes dos seis meses deve ser destacada como uma prática positiva, uma vez que estes alimentos têm efeito 
substituto do leite materno superior aos líquidos em função do valor calórico e da quantidade oferecida.

No município do Rio de Janeiro, a tendência de consumo destes alimentos e dos líquidos entre as crianças menores de seis meses também foi decrescente entre 1998 e 2008 (DE OLIVEIRA; DE CASTRO; JAIME, 2014).

Segundo as recomendações da OMS, estes gráficos deveriam ter no máximo três cores que são barras vermelhas para as crianças os menores de seis meses representando o aleitamento materno exclusivo, cinza para as crianças entre seis e de 24 meses representando o aleitamento materno associado a outros alimentos e uma pequena faixa bege entre os 20 e 24 meses representando um percentual de $10 \%$ de crianças não amamentadas. Com base na representação ideal do gráfico, pode-se monitorar o comportamento destas práticas ao longo do tempo, identificar e embasar as ações de intervenção prioritárias dos profissionais de saúde e avaliar a efetividade destas ações implementadas(UNICEF,2010). Desta forma, ao analisar a situação atual do aleitamento materno e dos alimentos consumidos representados no último inquérito (2006) uma das ações prioritárias seria o foco no incentivo ao aleitamento materno exclusivo.

A descrição conjunta do aleitamento materno e de outros alimentos consumidos assim como sua tendência temporal são escassos no Brasil até o presente momento. Duas possíveis razões seriam a restrição de inquéritos disponíveis que abordem a temática em nível nacional e a restrita base teórica sobre os indicadores e estimativas mais adequados para esta análise. Dentre os 15 indicadores recomendados pela OMS, três se referem ao consumo alimentar especificamente, com ênfase na diversidade dietética (número de grupos alimentares a serem consumidos), frequência mínima de refeições diárias e consumo de alimentos ricos em ferro. O desafio duplo na aplicação e na interpretação destes indicadores é a escolha do desfecho a ser utilizado para a definição do ponto de corte e o próprio ponto de corte para indicar uma alimentação suficiente. A avaliação da alimentação é complexa uma vez que a gama de alimentos consumidos e suas combinações podem resultar em diferentes desfechos de saúde e sintetizar esta complexidade em poucos indicadores implica em grande esforço. Entretanto, o aleitamento é sumarizado em um indicador único, favorecendo a compreensão dos seus benefícios.

No Brasil, as fontes de informações nacionais sobre alimentação infantil são restritas e provenientes das Pesquisas de Demografia e Saúde para crianças 
menores de cinco anos (BEMFAN, 1997)(BRASIL, 2009) e de Prevalência do Aleitamento Materno nas capitais e municípios em 1999 e 2008 para crianças menores de um ano(BRASIL, 2010b)(BRASIL, 2010c).

A restrita base de informações sobre os alimentos consumidos nos três inquéritos impossibilitou o uso dos indicadores específicos da alimentação infantil propostos pela WHO. Desta forma, no presente estudo a descrição e a análise dos fatores associados à alimentação infantil no espectro etário de seis a 59 meses foram realizadas pela análise de principais componentes. Em epidemiologia nutricional esta técnica é utilizada para descrever os padrões de consumo alimentar e também associá-los às doenças crônicas não-transmissíveis(HU, 2002). Entre crianças, o uso desta técnica ainda é recente(GATICA et al., 2012)(SMITHERS et al., 2012), possivelmente em função da escassez dos estudos que relacionam os efeitos a curto e a longo prazo da alimentação. Nos questionários das Pesquisas de Demografia e Saúde, que incluem dados sobre aleitamento materno e consumo de alimentos das crianças menores de cinco anos, o número de variáveis referentes ao consumo de alimentos expandiu de seis para 28 entre a Fase I e a Fase VI, respectivamente. Este número aumenta segundo país, pois tradicionalmente são acrescidas variáveis de alimentos que fazem parte da cultura local. A exemplo do questionário do inquérito de 1986 (Fase I do ciclo de pesquisas), somente seis grupos de alimentos estavam disponíveis, sendo que os alimentos de consistência sólida são agrupados e representados em uma única variável alimentos semissólidos, sólidos. A expansão das variáveis explicita a importância crescente da temática alimentação infantil nos inquéritos juntamente com os dados de aleitamento materno.

$\mathrm{Na}$ análise de principais componentes não foram incluídos os dados de 1986, em função do reduzido grupo de alimentos disponíveis (seis). Como esta técnica reduz as informações em variáveis latentes que sintetizam a maior variabilidade das variáveis originais, julgou-se desnecessário extrair padrões a partir de seis variáveis. A outra razão da exclusão foi a impossibilidade de comparação entre os três anos, uma vez que em 1986 a base da resposta das variáveis de alimentos é constituída somente pelas crianças amamentadas.

A descrição dos padrões alimentares referente a cada inquérito foi realizada separadamente a fim de captar as principais características referentes à época do inquérito e verificar sua distribuição nos diferentes estratos sociais e demográficos. 
Em 1996, os cinco padrões apresentaram distribuições distintas segundo faixa etária, sendo que os padrões com predominância de alimentos sólidos foram mais frequentes após 12 meses e com predominância de alimentos líquidos, semissólidos e pastosos nas crianças entre seis e 12 meses. As papas preparadas com amidos fortificados e industrializados (PA4) e aquelas à base de frutas, legumes e arroz (PA5) foram caracterizadas em padrões separados, sendo que as primeiras foram mais prevalentes entre as crianças menores de 12 meses. Os padrões PA4 e PA5 caracterizaram diferentes perfis de criança, pois o PA4 foi mais frequente entre as crianças da zona urbana, entre as mães com maior escolaridade e nos quintis superiores de renda e o PA5 entre as crianças residentes na zona rural. $O$ padrão PA2 é mais frequente entre as crianças acima de dois anos, possivelmente por ser um padrão com cargas fatoriais mais elevadas para carnes. O leite materno apresentou correlação negativa com o padrão PA2 e não foi correlacionado com nenhum outro padrão. A explicação mais plausível para a correlação negativa seria o baixo percentual de crianças que estavam em aleitamento materno após sexto mês (15\%). Ao incluir a variável na análise neste pool de crianças, a sua presença não se associou a nenhum padrão. A frequência elevada ou baixa de um alimento tende a não se correlacionar com os padrões, pois a distribuição da sua variabilidade é baixa (SMITHERS et al., 2012).

Em 2006, foram identificados sete padrões alimentares com distribuições distintas segundo as faixas etárias. Neste inquérito, o número de alimentos disponíveis foi superior aos anteriores. Estes novos alimentos refletiram a fase do inquérito (padrão DHS) e sinalizaram a necessidade de identificar a introdução de mudanças ocorridas na estrutura de consumo das famílias brasileiras na alimentação infantil. O padrão PA2 foi caracterizado por alimentos com elevado teor de açúcar e gordura e representou o padrão mais prevalente entre as crianças maiores de 24 meses. Este padrão foi mais prevalente nas regiões sudeste e sul, entre mães com maior escolaridade e maior quintil de renda. Padrões compostos por alimentos com composição nutricional semelhante foi mais frequente em crianças com idade de 48 meses quando comparado àquelas de 12 e de 24 meses em Pelotas-RS. Entretanto, este padrão foi mais frequente entre mães com menor escolaridade e menor quintil de renda(GATICA et al., 2012). O leite materno apresentou forte correlação com o padrão PA6 e foi o mais prevalente entre as crianças de seis e 12 meses. Este resultado é compatível com as taxas de aleitamento materno nesta faixa etária e reflete o aumento da prevalência de 
crianças amamentadas em 2006. Neste padrão PA6, o leite não-materno apresentou carga negativa, assim como em outros estudos (GATICA et al., 2012)(SMITHERS et al., 2012), apontando que o consumo de ambos foram excludentes. $\mathrm{Na}$ análise descritiva por fatores sociodemográficos, pode-se verificar maior frequência deste padrão nas regiões Norte e Nordeste, mães com menor escolaridade e menores quintis de renda. Em outros estudos, este tipo de padrão se associou às mães com maior escolaridade(GATICA et al., 2012)(SMITHERS et al., 2012). Entretanto, neste estudo, a distribuição dos padrões alimentares segundo fatores sociodemográficos identificados em cada ano do inquérito foi realizado de modo descritivo, sem os ajustes necessários para tornar a associação independente de outros fatores correlacionados.

A análise da evolução dos padrões alimentares foi realizada em estudos prospectivos envolvendo coortes de nascimento. A padronização dos protocolos de avaliação, da base de dados e o seguimento dos mesmos indivíduos propiciam este tipo de análise. Nestes estudos, foram comparados os padrões alimentares em duas ou mais idades ao longo da infância. Entretanto, os padrões alimentares foram identificados e associados com os fatores sociodemográficos de forma transversal em cada idade isolada no período do seguimento. As justificativas para a realização das análises em cada período foram a necessidade de representar os padrões alimentares pontualmente na idade em que ocorrem e a necessidade de captar a mudança natural das práticas alimentares em função do crescimento(NORTHSTONE; EMMETT, 2008). Uma das alternativas sugeridas para avaliar a mudança seria a aplicação dos escores dos padrões alimentares extraídos na última faixa etária analisada e aplicá-los na idade anterior(NORTHSTONE; EMMETT, 2008). Entretanto, os autores concluem que esta análise não seria adequada em função da perda das características atreladas à idade.

A alteração dos tipos de alimentos nos protocolos de avaliação do consumo alimentar também foi observada em estudo realizado na Inglaterra com crianças aos seis e 15 meses. A diferença do questionário foi em função da mudança de idade da criança. Na primeira faixa etária, existiam 43 alimentos e na segunda 70. A justificativa da mudança foi a necessidade de incluir alimentos que refletissem 0 aumento da variabilidade de alimentos consumidos, natural do processo de crescimento(SMITHERS et al., 2012). No estudo de Pelotas-RS, também houve acréscimo de alimentos no questionário utilizado para crianças de 48 meses em comparação às crianças de 12 meses(GATICA et al., 2012). 
Neste estudo, optou-se por adicionar três abordagens distintas daquelas tradicionalmente utilizadas nos estudos disponíveis na literatura sobre padrões alimentares infantis, as quais foram: a) adoção do ponto de corte da carga fatorial de 0,2 , considerado inferior àqueles citados em estudos prévios. A razão deste valor foi a máxima exploração do comportamento dos alimentos nos padrões alimentares, uma vez que o número de grupos alimentares inseridos na análise foi reduzido. Além disso, os alimentos com cargas fatoriais menores tem uma representação menor para o padrão, mas mesmo assim esta informação é importante para compreender a complexidade da alimentação e representar o consumo conjunto dos alimentos. Outro aspecto a ser destacado, é que embora um mesmo alimento tenha sido identificado em mais de um padrão, a carga fatorial daquele alimento é sempre superior em um dos padrões. Isso ilustra e reflete o consumo conjunto dos alimentos (um dos objetivos da análise de principais componentes) e sua importância relativa para cada padrão. É de se destacar também que o sentido da associação (carga positiva ou negativa) deve ser observado. Embora sejam os mesmos alimentos, a interpretação do alimento com o padrão é realizada de forma distinta; b) geração de padrões alimentares configurados como variáveis binárias com o objetivo de atribuir para cada criança o padrão alimentar mais característico. Esta abordagem se baseia no fato de que a rotação ortogonal torna os padrões alimentares independentes entre si. A vantagem desta abordagem foi permitir descrever e compreender a frequência dos padrões alimentares segundo estratos etários e demográficos, assim como compreender os fatores preditores individuais e contextuais de cada padrão alimentar; c) identificação dos padrões alimentares considerando o pool de crianças entre 6 e 59 meses dos dois inquéritos para analisar a evolução dos padrões alimentares. Esta decisão partiu da premissa de que na análise de principais componentes a matriz de correlação e de covariância é constituída entre variáveis e não entre indivíduos e que após a geração dos padrões, estes seriam atribuídos a cada criança. Além disso as variáveis alimentares foram padronizadas entre os dois anos. Por estas razões, se considerou que a solução mais apropriada para verificar a estabilidade ou alteração dos padrões alimentares entre os inquéritos era partir da mesma base e analisar o comportamento da distribuição dos padrões em cada ano.

A evolução dos padrões foi analisada incorporando dois componentes temporais, alocados em níveis distintos do modelo multinível. O primeiro componente foi a idade da criança, considerada atributo fixo e alocado no efeito fixo do modelo. $\mathrm{O}$ segundo componente foi o ano do inquérito, alocado no efeito fixo e 
probabilístico do modelo sendo que no segundo efeito foi incorporada a macrorregião geográfica. O efeito da idade marcou a evolução natural esperada da alimentação em função do crescimento e da aproximação do padrão alimentar característico da família. Já o efeito do ano marcou mudanças atreladas à dinâmica das condições sociais e demográficas ocorrida dentro das macrorregiões no período de 10 anos que separam os inquéritos.

O padrão PA1 apresentou comportamento distinto dos demais padrões em função da sua variabilidade estar concentrada nos fatores preditores individuais e apresentar distribuição homogênea nas regiões geográficas. Este padrão apresenta maior diversidade na composição dos grupos alimentares e é mais frequente após 12 meses. Os padrões PA2, PA3 e PA4 apresentam alta variabilidade entre as regiões brasileiras, observada no componente contextual. O aumento da variância referente ao nível contextual foi concomitante à redução da variância referente ao nível individual. Neste estudo, não foi possível reunir outros possíveis fatores atrelados às regiões que explicassem estas diferenças. Entretanto, estes resultados sinalizam a necessidade de incorporar indicadores sociais que representem a situação contextual para indicar características regionais que possam explicar estas diferenças.

Nos estudos prospectivos(GATICA et al., 2012)(NORTHSTONE; EMMETT, 2008)(WEN et al., 2014)(SMITHERS et al., 2012)(BELL et al., 2013), a evolução dos padrões alimentares foi caracterizada em dois, três e quatro idades distintas ao longo do crescimento. Os principais resultados descritos foram: a) entre as crianças menores de doze meses, o leite materno apresentou carga positiva ou negativa com o padrão alimentar, o número de alimentos correlacionados com cada padrão foi menor, caracterizando uma alimentação mais monótona e este padrão se associou positivamente com a escolaridade materna e quintis de renda; b) o número e o tipo de padrões alimentares extraídos em todas os pontos etários foram os mesmos, com exceção do estudo realizado em Pelotas-RS, em que um novo padrão alimentar foi extraído na terceira ponto etário avaliado; c) os padrões denominados saudáveis ou adequados para a idade segundo recomendações nacionais e internacionais foram associados com o consumo de leite materno, escolaridade materna e quintis superiores de renda.

O número de componentes (padrões alimentares) extraídos variaram de três a cinco, independentemente do número de alimentos incluídos nos questionários de frequência ou recordatórios de 24 horas. Uma possível explicação para este número 
semelhante de padrões seriam a composição reduzida de alimentos que efetivamente fazem parte do consumo habitual de crianças menores de 12 ou 24 ou 48 meses. Somado a isso seriam os mesmos critérios para extração dos padrões alimentares que foram o ponto da queda abrupta da variância no screeplot e cargas fatoriais superiores a 0, 3 ou inferiores a -0,3.

A compreensão da distribuição dos padrões segundo fatores sociodemográficos bem como a sua evolução temporal é relevante para direcionar as ações de intervenção e analisar a externalidade das políticas públicas já implementadas. Dentro da perspectiva da saúde pública, a identificação de grupos populacionais com características sociodemográficas e de saúde que apresentem padrões alimentares semelhantes é relevante por embasar o desenvolvimento, 0 direcionamento e a focalização das ações de intervenção, seu monitoramento e efetividade(PRYER; ROGERS, 2009).

\subsection{LIMITAÇÕES}

O primeiro tipo de limitação deste estudo se refere as restrições dos dados nos três anos dos inquéritos. Os questionários das Pesquisas de Demografia e Saúde são constituídos por um núcleo padrão (core questionnaires) de variáveis com o objetivo de permitir análises de tendência intra e entre-países. As variáveis referentes aos alimentos foram modificadas nos três inquéritos brasileiros, principalmente em função da mudança de fase do inquérito. Desta forma, somente a análise temporal de cinco indicadores do aleitamento materno foi realizado nos três inquéritos. Outras variáveis que tradicionalmente estão associadas à frequência ou à duração do aleitamento materno tais como fumo (mãe), índice de massa corporal (IMC) materno, comprimento ao nascer não estavam disponíveis em todos os inquéritos impossibilitando sua inclusão nos modelos. A variável IMC materno estava disponível somente em 2006 e a variável peso ao nascer apresentou 27\% de valores ausentes (missing). As variáveis escore de pré-natal e doenças ocorridas nos últimos 15 dias não foram elaboradas para 1986 em função da ausência do tempo de realização da primeira consulta e consulta após o parto e ausência das doenças febre e tosse. Outras duas variáveis associadas ao aleitamento materno que não foram incluídas nas análises foram o uso de chupeta, por estar presente somente no inquérito de 2006 e a mamadeira, pois a base da resposta foi distinta nos inquéritos. Em 1986 e 2006, esta questão foi aplicada somente às crianças que estavam em 
aleitamento materno e em 1996 para todas as crianças. A informação sobre a participação das famílias em programas sociais estava disponível somente em 2006. O recebimento destes benefícios possivelmente pode alterar o tipo de alimentos disponíveis nos domicílios. Os três indicadores específicos para o consumo de alimentos propostos pela OMS também não foram estimados, pois os tipos de alimentos disponíveis nos bancos não são compatíveis àqueles exigidos para 0 cálculo.

Outro tipo de limitação se refere às análises. A restrição de dados de alimentos no inquérito de 1996 implicou na limitação da análise temporal dos padrões alimentares. Os padrões alimentares identificados a partir da base conjunta dos dados de 1996 e 2006 indicaram semelhança maior com os padrões identificados em 1996, em função da impossibilidade de inclusão dos alimentos disponíveis exclusivamente no inquérito de 2006. Apesar dos padrões alimentares diferirem em sua composição, pode-se verificar que quando a base de dados é mais ampla, como em 2006, os padrões alimentares são definidos com mais clareza. Outra limitação encontrada foi a impossibilidade de determinar de forma mais precisa quando os alimentos com elevado teor de açúcar e gordura passaram a ser incorporados na alimentação das crianças. O padrão PA2 foi o mais frequente entre as crianças maiores de 24 meses.

A alteração da base das respostas dos três inquéritos ("pulos" na sequência das questões) possivelmente foram a fonte de algumas flutuações nas estimativas. Em 1986, as crianças elegíveis para responder as questões sobre alimentos no dia anterior foram aquelas que representaram a última criança na história de nascimento e que estavam em aleitamento materno no momento da pesquisa. Com relação à última criança na história de nascimento, o impacto nas estimativas do consumo de leite materno e outros alimentos não seria significativo, uma vez que as crianças menores de 24 meses naturalmente representam a última criança. Porém, a outra limitação poderia acarretar superestimação das estimativas de consumo do leite materno combinado a outros alimentos. Se esse efeito for real isso ressalta o avanço do aleitamento materno no período 1986-1996. Em 1996, as crianças cujas mães relataram estar amamentando exclusivamente foram categorizadas como "não" nas questões sobre os alimentos no dia anterior. Desta forma, não foi possível verificar a consistência da resposta materna. A consequência deste "pulo" no questionário, seria a superestimação das taxas do aleitamento materno exclusivo e subestimação 
dos outros tipos de aleitamento materno (aleitamento e água, outros líquidos, alimentos sólidos). O percentual de crianças nesta categoria foi de 2,9\%, sendo que $22,7 \%$ tinham idade inferior a seis meses. Em 2006, o consumo de fórmulas foi questionado somente para as mães que ofereceram algum tipo de leite não-materno no dia anterior, não sendo possível garantir a consistência da resposta materna.

Os valores dos efeitos do desenho amostral (DEFF) (Anexo 5) foram elevados para as estimativas calculadas, principalmente para as variáveis referentes às mães. Os DEFF para as variáveis indicadores do aleitamento materno foram superiores principalmente para aquelas que cujo denominador é restrito. Este efeito nos indicadores foi apontado e discutido no material da Organização Mundial da Saúde. Este efeito é minimizado quando o tamanho da amostra é aumentado, porém permanece elevado. Uma explicação plausível seria o tipo de amostra em que estes indicadores são estimados. Tradicionalmente, estes indicadores são calculados a partir de inquéritos cujo público alvo principal são as mulheres (Demographic Health Survey) e as estimativas que servem de base para o cálculo amostral são referentes às mulheres.

Os DEFF das estimativas foram superiores no inquérito de 2006. A amostragem inversa foi adotada no segundo estágio da amostra - seleção dos domicílios. Em cada setor censitário deveriam ser selecionados 12 domicílios, em função da obrigatoriedade de se obter um número mínimo de 15000 mulheres na pesquisa. Desta forma, a reposição do domicílio não elegível possivelmente implicou no aumento do erro amostral. 


\section{CONSIDERAÇÕES FINAIS}

A abordagem da alimentação infantil neste estudo se desdobrou em três vertentes: a análise conjunta do aleitamento materno e dos alimentos consumidos; a análise do fenômeno no espectro etário de zero a cinco anos e a sua evolução ao longo de três décadas.

A exposição ao aleitamento materno no Brasil é considerada uma prática virtualmente universal e sua duração mediana é marcada pela duplicação nas duas últimas décadas. Entre as crianças menores de seis meses, a exclusividade da oferta de leite materno até o sexto mês em 2006 é interrompida principalmente pela oferta de água e líquidos. A amamentação na $1^{\underline{a}}$ hora de vida contribui para a extensão do aleitamento materno e do aleitamento materno exclusivo. A duração do AME é homogênea entre as regiões brasileiras e apresenta associação com fatores predominantemente maternos, enquanto a duração do AM é heterogênea entre as regiões e está associada a fatores que marcam características do ambiente compartilhado pela criança e família distintas daquelas que influenciam o AME.

Os padrões alimentares analisados em 1996 e 2006, separadamente, são caracterizados pela transição de alimentos líquidos e pastosos, como sucos, leite e formulas, papas variadas para alimentos sólidos como tubérculos, frutas, hortaliças e carnes que expressam à adesão às práticas alimentares familiares. A presença de leite materno dentre os padrões alimentares de 2006 marca o aumento da exposição e extensão ao leite materno na faixa etária de seis a doze meses em comparação à 1996. A frequência crescente segundo faixa etária de um padrão alimentar composto por alimentos com elevado teor de açúcar e gordura em 2006 é um indicador da provavelmente elevada disponibilidade de tais produtos no âmbito familiar, da introdução precoce dos mesmos na alimentação das crianças e, ainda, um marcador da vulnerabilidade infantil ao consumo de produtos ultraprocessados. Três padrões alimentares acompanham a distribuição heterogênea do $A M$ entre as regiões geográficas. O padrão alimentar PA1, caracterizado por maior variedade de alimentos, é explicado principalmente por fatores individuais de cunho socioeconômico. Destaca-se como principal evolução no comportamento dos padrões a substituição do PA4 pelo PA3, composto por alimentos mais adequados às necessidades da faixa etária em que é mais prevalente. O leite materno embora 
não sendo representando nos padrões aumenta a prática dos padrões considerados mais adequados à faixa etária.

O quadro que emerge das análises deste estudo indica a necessidade de políticas públicas de alimentação mais abrangentes, consistentes e efetivas direcionadas à infância brasileira. As evidências aqui apresentadas mostram o quanto a alimentação infantil se aproxima das características negativas observadas na alimentação de adultos e adolescentes brasileiros e sugerem que o tempo disponível para reagir se encurtou acentuadamente na última década no Brasil. 


\section{REFERÊNCIAS BIBLIOGRÁFICAS}

1,000 Days. Disponível em: <http://thousanddays.org/>. Acesso em: 2 jan. 2015.

A Dictionary of Epidemiology. 5. ed. [s.I.] Oxford University Press, 2008.

AARTS, C. et al. How exclusive is exclusive breastfeeding? A comparison of data since birth with current status data. International Journal of Epidemiology, v. 29, n. 6, p. 1041-1046, dez. 2000.

ADHIKARI, M. et al. Factors associated with early initiation of breastfeeding among Nepalese mothers: further analysis of Nepal Demographic and Health Survey, 2011. International Breastfeeding Journal, v. 9, n. 1, p. 21, 2014.

AQUINO, R. DE C. DE; PHILIPPI, S. T. Consumo infantil de alimentos industrializados e renda familiar na cidade de São Paulo. Revista de Saúde Pública, v. 36, n. 6, p. 655-660, 2002.

BARBOSA, R. W. et al. Memória das mães sobre amamentação e hábitos de sucção nos primeiros meses da vida de seus filho. Rev. Paul. Pediatr, v. 30, n. 2, p. 180-186, jun. 2012.

BARTOK, C. J.; VENTURA, A. K. Mechanisms underlying the association between breastfeeding and obesity. International journal of pediatric obesity: IJPO: an official journal of the International Association for the Study of Obesity, v. 4, n. 4, p. 196-204, 2009.

BELL, L. K. et al. Dietary patterns of Australian children aged 14 and 24 months, and associations with socio-demographic factors and adiposity. European Journal of Clinical Nutrition, v. 67, n. 6, p. 638645, jun. 2013.

BETRÁN, A. P. et al. Rates of caesarean section: analysis of global, regional and national estimates. Paediatric and Perinatal Epidemiology, v. 21, n. 2, p. 98-113, mar. 2007.

BRASIL. MINISTÉRIO DA SAÚDE. Assistência Integral à Saúde da Mulher: Bases de Ação Programática, 1985. Disponível em:

<http://bvsms.saude.gov.br/bvs/publicacoes/assistencia_integral_saude_mulher.pdf>

BRASIL, Ministério da Saúde; Centro Brasileiro de Análise e Planejamento. Pesquisa Nacional de Demografia e Saúde da Criança e da Mulher -2006 Disponível em: http://bvsms.saude.gov.br/bvs/pnds/banco dados.php

BRASIL. MINISTÉRIO DA SAÚDE. Rede Amamenta Brasil, 2008. Disponível em:

<http://bvsms.saude.gov.br/bvs/publicacoes/rede_amamenta_brasil_primeiros_passos.pdf>

BRASIL. MINISTÉRIO DA SAÚDE. Estratégia Nacional para Promoção da Alimentação Complementar Saudável, 2010a. Disponível em:

<http://189.28.128.100/nutricao/docs/geral/caderno_do_tutor.pdf>

BRASIL. MINISTÉRIO DA SAÚDE. II Pesquisa de Prevalência de Aleitamento Materno nas Caitais Brasileiras e Distrito Federal, 2010b. Disponível em:

<http://bvsms.saude.gov.br/bvs/publicacoes/pesquisa_prevalencia_aleitamento_materno.pdf>

BRASIL. MINISTÉRIO DA SAÚDE. Pesquisa de Prevalância de Aleitamento Materno em municípios

Brasileiros, 2010c. Disponível em: <http://www.redeblh.fiocruz.br/media/pamuni.pdf> 
BRASIL. MINISTÉRIO DA SAÚDE. Estratégia Nacional para Promoção do Aleitamento Materno e AlimentaçãoComplementar Saudável - Estratégia Amamenta e Alimenta Brasil., 2013. Disponível em: <http://bvsms.saude.gov.br/bvs/saudelegis/gm/2013/prt1920_05_09_2013.html>

BRASIL. MINISTÉRIO DA SAÚDE. Guia alimentar para crianças menores de 2 anos, [s.d.]. Disponível em: <http://189.28.128.100/nutricao/docs/geral/guiao.pdf>

BRASIL. MINISTÉRIO DA SAÚDE. Gestões e gestores de políticas públicas de atenção à saúde da criança - $\mathbf{7 0}$ anos de história, 2011. Disponível em:

<http://bvsms.saude.gov.br/bvs/publicacoes/70_anos_historia_saude_crianca.pdf>

BRION, M.-J. A. et al. What are the causal effects of breastfeeding on IQ, obesity and blood pressure? Evidence from comparing high-income with middle-income cohorts. International Journal of Epidemiology, v. 40, n. 3, p. 670-680, jun. 2011.

BUENO, M. et al. Duração da amamentação após a introdução de outro leite: seguimento de coorte de crianças nascidas em um hospital universitário em São Paulo. 2002.

CAI, X.; WARDLAW, T.; BROWN, D. W. Global trends in exclusive breastfeeding. International Breastfeeding Journal, v. 7, n. 1, p. 12, 28 set. 2012.

CASTRO, T. G. et al. Dietary practices and nutritional status of 0-24-month-old children from Brazilian Amazonia. Public Health Nutrition, v. 12, n. 12, p. 2335-2342, dez. 2009.

CORRÊA, E. N. et al. Alimentação complementar e características maternas de crianças menores de dois anos de idade em Florianópolis (SC). Rev Paul Pediatr, v. 27, n. 3, p. 258-64, 2009.

COUTINHO, S. B. et al. Comparison of the effect of two systems for the promotion of exclusive breastfeeding. Lancet, v. 366, n. 9491, p. 1094-1100, 24 set. 2005.

DE OLIVEIRA, D. A.; DE CASTRO, I. R. R.; JAIME, P. C. Complementary feeding patterns in the first year of life in the city of Rio de Janeiro, Brazil: time trends from 1998 to 2008. Cadernos De Saúde Pública, v. 30, n. 8, p. 1755-1764, ago. 2014.

DEMÉTRIO, F.; PINTO, E. DE J.; ASSIS, A. M. O. Factors associated with early breastfeeding cessation: a birth cohort study in two municipalities in the Recôncavo region, Bahia State, Brazil. Cadernos de Saúde Pública, v. 28, n. 4, p. 641-650, abr. 2012.

DEMETRIOU, C. A. et al. The mediterranean dietary pattern and breast cancer risk in Greek-Cypriot women: a case-control study. BMC Cancer, v. 12, n. 1, p. 113, 23 mar. 2012.

DESAI, S.; ALVA, S. Maternal education and child health: is there a strong causal relationship? Demography, v. 35, n. 1, p. 71-81, fev. 1998.

DIBLEY, M. J. et al. Across-country comparisons of selected infant and young child feeding indicators and associated factors in four South Asian countries. Food and Nutrition Bulletin, v. 31, n. 2, p. 366375, jun. 2010.

ENGLE, P. L.; MENON, P.; HADDAD, L. J. Care and Nutrition: Concepts and Measurement. [s.I.] Intl Food Policy Res Inst, 1997.

ESTEVES, T. M. B. et al. Factors associated to breastfeeding in the first hour of life: systematic review. Revista de Saúde Pública, v. 48, n. 4, p. 697-708, ago. 2014. 
FEACHEM, R. G.; KOBLINSKY, M. A. Interventions for the control of diarrhoeal diseases among young children: promotion of breast-feeding. Bulletin of the World Health Organization, v. 62, n. 2, p. 271291, 1984.

FILMER, D.; PRITCHETT, L. H. Estimating Wealth Effects without Expenditure Data-or Tears: An Application to Educational Enrollments in States of India. Demography, v. 38, n. 1, p. 115-132, Fevereiro 2001.

FREIRE, W. Nutrition and an Active Life: From Knowledge to Action. [s.I.] Pan American Health Org, 2005.

FUNG, T. T. et al. Dietary patterns and the risk of coronary heart disease in women. Archives of Internal Medicine, v. 161, n. 15, p. 1857-1862, 13 ago. 2001.

GARCIA DE LIMA PARADA, C. M.; DE BARROS LEITE CARVALHAES, M. A.; JAMAS, M. T. Complementary feeding practices to children during their first year of life. Revista Latino-Americana De Enfermagem, v. 15, n. 2, p. 282-289, abr. 2007.

GATICA, G. et al. Food intake profiles of children aged 12, 24 and 48 months from the 2004 Pelotas (Brazil) birth cohort: an exploratory analysis using principal components. The International Journal of Behavioral Nutrition and Physical Activity, v. 9, p. 43, 2012.

GENEVA, W. H. O. Indicators for assessing breastfeeding practices. WHO Geneva, Switzerland: WHO Document WHO/CDD/SER, v. 91, p. 14, 1991.

GREINER, T. Exclusive breastfeeding: measurement and indicators. International Breastfeeding Journal, v. 9, n. 1, p. 18, 20 out. 2014.

GRUMMER-STRAWN, L. M. Regression analysis of current-status data: an application to breastfeeding. Journal of the American Statistical Association, v. 88, n. 423, p. 758-765, set. 1993.

GUO, S. et al. Breastfeeding rates in central and western China in 2010: implications for child and population health. Bulletin of the World Health Organization, v. 91, n. 5, p. 322-331, 1 maio 2013.

HAIR, J.F. et al. Multivariate data analysis. 7. ed. [S.I.], 2009.

HAWKINS, S. S. et al. Evaluating the impact of the Baby-Friendly Hospital Initiative on breast-feeding rates: a multi-state analysis. Public Health Nutrition, p. 1-9, 14 mar. 2014.

HU, F. B. et al. Prospective study of major dietary patterns and risk of coronary heart disease in men. The American Journal of Clinical Nutrition, v. 72, n. 4, p. 912-921, out. 2000.

HU, F. B. Dietary pattern analysis: a new direction in nutritional epidemiology. Current Opinion in Lipidology, v. 13, n. 1, p. 3-9, fev. 2002.

INSTITUTO BRASILEIRO DE GEOGRAFIA E ESTATÍSTICA-IBGE. Síntese de Indicadores Sociais: Uma Análise das Condições de Vida da População Brasileira. Rio de Janeiro, RJ: IBGE, Ministério do Planejamento, Orçamento e Gestão. Rio de Janeiro: IBGE, 2010. , 2010. Disponível em: <http://www.ibge.gov.br/home/estatistica/populacao/condicaodevida/indicadoresminimos/sintesei ndicsociais2010/SIS_2010.pdf>

JOLLIFFE, I.T. Principal component analysis. 2. ed. [S.I.]: Springer, 2002

JONES, G. et al. How many child deaths can we prevent this year? Lancet, v. 362 , n. 9377, p. 65-71, 5 jul. 2003. 
JÚNIOR, F.; DE, G.; OSÓRIO, M. M. Alimentary profile of under-five year old children. Revista de Nutrição, v. 18, n. 6, p. 793-802, dez. 2005.

KLEINBAUM, D.G. Survival Analysis. A self-learning text. [S.I.]:Springer, 1992

KRIEGER, G.; NOVAES, L. A.; FARIA, T. Todos os sócios do presidente. 3. ed. [S.I.]: Scritta, 1992.

KOGAN, M. D. et al. Multivariate analysis of state variation in breastfeeding rates in the United States. Am J Public Health, v. 98, n. 10, p. 1872-1880, out. 2008.

KRAMER, M. S.; KAKUMA, R. The optimal duration of exclusive breastfeeding: a systematic review. Advances in Experimental Medicine and Biology, v. 554, p. 63-77, 2004.

KRISTIANSEN, A. L. et al. Dietary patterns among Norwegian 2-year-olds in 1999 and in 2007 and associations with child and parent characteristics. The British Journal of Nutrition, v. 110, n. 1, p. 135-144, 14 jul. 2013.

LANDE, B. et al. Infant feeding practices and associated factors in the first six months of life: the Norwegian infant nutrition survey. Acta Paediatrica (Oslo, Norway: 1992), v. 92, n. 2, p. 152-161, 2003.

LAUNER, L. J. et al. Maternal recall of infant feeding events is accurate. Journal of Epidemiology and Community Health, v. 46, n. 3, p. 203-206, jun. 1992.

LI, R.; SCANLON, K. S.; SERDULA, M. K. The validity and reliability of maternal recall of breastfeeding practice. Nutrition Reviews, v. 63, n. 4, p. 103-110, abr. 2005.

LUTTER, C. K.; CHAPARRO, C. M.; GRUMMER-STRAWN, L. M. Increases in breastfeeding in Latin America and the Caribbean: an analysis of equity. Health Policy and Planning, v. 26, n. 3, p. 257-265, maio 2011.

MARTINS, E. J.; GIUGLIANI, E. R. J. Which women breastfeed for 2 years or more? Jornal de Pediatria, v. 88 , n. 1, p. 67-73, fev. 2012.

MATA, L. J.; WYATT, R. G. The uniqueness of human milk. Host resistance to infection. The American Journal of Clinical Nutrition, v. 24, n. 8, p. 976-986, ago. 1971.

MENNELLA, J. A.; JAGNOW, C. P.; BEAUCHAMP, G. K. Prenatal and Postnatal Flavor Learning by Human Infants. Pediatrics, v. 107, n. 6, p. E88, jun. 2001.

MONTEIRO, C. A. et al. Narrowing socioeconomic inequality in child stunting: the Brazilian experience, 1974-2007. Bulletin of the World Health Organization, v. 88, n. 4, p. 305-311, abr. 2010.

MONTEIROII, V. Tendência secular da amamentação no Brasil. Rev Saúde Pública, v. 47, n. 6, p. 1205-8, 2013.

NEWBY, P. K.; TUCKER, K. L. Empirically derived eating patterns using factor or cluster analysis: a review. Nutrition Reviews, v. 62, n. 5, p. 177-203, maio 2004.

NORTHSTONE, K.; EMMETT, P. M. Are dietary patterns stable throughout early and mid-childhood? A birth cohort study. The British Journal of Nutrition, v. 100, n. 5, p. 1069-1076, nov. 2008.

OLIVEIRA, L. P. M. DE et al. Complementary feeding in the first two years of life. Revista de Nutrição, v. 18, n. 4, p. 459-469, ago. 2005. 
OLIVEIRA, M. G. O. A. DE et al. Factors associated with breastfeeding in two municipalities with low human development index in Northeast Brazil. Revista Brasileira de Epidemiologia, v. 16, n. 1, p. 178-189, mar. 2013.

ORGANIZAÇÃO PANAMERICANA DE SAÚDE. PLAN DE ACCIÓN PARA LA PREVENCIÓN DE LA OBESIDAD EN LA NIÑEZ Y LA ADOLESCENCIA, 2014.

PARIZOTO, G. M. et al. Tendência e determinantes do aleitamento materno exclusivo em crianças menores de 6 meses. J Pediatr, v. 85, n. 3, p. 201-8, 2009.

PATEL, A.; BANERJEE, A.; KALETWAD, A. Factors associated with prelacteal feeding and timely initiation of breastfeeding in hospital-delivered infants in India. Journal of Human Lactation: Official Journal of International Lactation Consultant Association, v. 29, n. 4, p. 572-578, nov. 2013.

BEMFAN. Pesquisa Nacional de Demografia e Saúde. , 1997. Disponível em: <http://dhsprogram.com/pubs/pdf/FR77/FR77.pdf>

PIWOZ, E. G. et al. Potential for misclassification of infants' usual feeding practices using 24-hour dietary assessment methods. The Journal of Nutrition, v. 125, n. 1, p. 57-65, jan. 1995.

PORTELLA, M. B.; MORAIS, T. B. DE; MORAIS, M. B. DE. Excess sodium and insufficient iron content in complementary foods. Jornal de Pediatria, v. 86, n. 4, p. 303-310, ago. 2010.

PRIOR, E. et al. Breastfeeding after cesarean delivery: a systematic review and meta-analysis of world literature. The American Journal of Clinical Nutrition, v. 95, n. 5, p. 1113-1135, maio 2012.

PRYER, J. A.; ROGERS, S. Dietary patterns among a national sample of British children aged 1 1/2-4 1/2 years. Public Health Nutrition, v. 12, n. 7, p. 957-966, jul. 2009.

RAYKOV, T.; MARCOULIDES, G. A. An introduction to applied multivariate analysis. [s.I.] Routledge, 2012.

REA, M. F. The Brazilian National Breastfeeding Program: a success story. International Journal of Gynaecology and Obstetrics: The Official Organ of the International Federation of Gynaecology and Obstetrics, v. 31 Suppl 1, p. 79-82; discussion 83-84, 1990.

ROBERTS, T. J.; CARNAHAN, E.; GAKIDOU, E. Can breastfeeding promote child health equity? A comprehensive analysis of breastfeeding patterns across the developing world and what we can learn from them. BMC Medicine, v. 11, n. 1, p. 254, 4 dez. 2013.

ROUX, A. V. D. A glossary for multilevel analysis. Journal of Epidemiology and Community Health, v. 56, n. 8, p. 588-594, 1 ago. 2002.

SALDIVA, S. et al. Influência regional no consumo precoce de alimentos diferentes do leite materno em menores de seis meses residentes nas capitais brasileiras e Distrito Federal. Cad Saúde Pública, v. 27, n. 11, p. 2253-62, 2011.

SANTO, L. C. DO E.; DE OLIVEIRA, L. D.; GIUGLIANI, E. R. J. Factors associated with low incidence of exclusive breastfeeding for the first 6 months. Birth, v. 34, n. 3, p. 212-219, set. 2007.

SIGULEM, D. M.; TUDISCO, E. S. Aleitamento natural em diferentes classes de renda no município de São Paulo. Archivos latinoamericanos de nutricion, 1980.

SILVA, L. M. P.; VENÂNCIO, S. I.; MARCHIONI, D. M. L. Complementary feeding practices in the first year of life and associated factors. Revista de Nutrição, v. 23, n. 6, p. 983-992, dez. 2010. 
SMITHERS, L. G. et al. Associations between dietary patterns at 6 and 15 months of age and sociodemographic factors. European Journal of Clinical Nutrition, v. 66, n. 6, p. 658-666, jun. 2012.

STAM, J.; SAUER, P. J.; BOEHM, G. Can we define an infant's need from the composition of human milk? The American Journal of Clinical Nutrition, v. 98, n. 2, p. 521S-528S, 1 ago. 2013.

StataCorp. 2013.Stata 13 Base Reference Manual. College Station, TX: Stata Press

TUMA, R. C. F. B.; COSTA, T. H. M. DA; SCHMITZ, B. DE A. S. Dietary and anthropometric assessment of three pre-schools from Brasilia, Federal District, Brazil. Revista Brasileira de Saúde Materno Infantil, v. 5, n. 4, p. 419-428, dez. 2005.

UNICEF. Introduction to interpreting area graphs - For Infant and Young Child Feeding, [s.d.]. Disponível em: <http://www.unicef.org/nutrition/files/Area_graphs_introduction_SinglePg.pdf>

UNIVERSITY OF BRISTOL. Leckie, G. Learning Environment for Multilevel Methodology and Applications (LEMMA). Module 5: Introduction to multilevel modelling. Stata Practical. Disponível em: < http://www.bristol.ac.uk/cmm/learning/online-course/index.html>. Acesso em: 2 jan. 2015.

VENANCIO, S. I. et al. The Baby-Friendly Hospital Initiative shows positive effects on breastfeeding indicators in Brazil. Journal of Epidemiology and Community Health, v. 66, n. 10, p. 914-918, out. 2012.

VENANCIO, S. I. et al. Secular trends in breastfeeding in Brazil. Revista de Saúde Pública, v. 47, n. 6, p. 1205-1208, dez. 2013.

VENANCIO, S. I.; MONTEIRO, C. A. A tendência da prática da amamentação no Brasil nas décadas de 70 e 80. Revista Brasileira de Epidemiologia, v. 1, n. 1, p. 40-49, abr. 1998.

VENANCIO, S. I.; MONTEIRO, C. A. Individual and contextual determinants of exclusive breast-feeding in São Paulo, Brazil: a multilevel analysis. Public Health Nutrition, v. 9, n. 1, p. 40-46, fev. 2006.

VICTORA, C. G. et al. Evidence for protection by breast-feeding against infant deaths from infectious diseases in Brazil. Lancet, v. 2, n. 8554, p. 319-322, 8 ago. 1987.

VICTORA, C. G. et al. Worldwide timing of growth faltering: revisiting implications for interventions. Pediatrics, v. 125, n. 3, p. e473-480, mar. 2010.

VICTORA, C. G. et al. Maternal and child health in Brazil: progress and challenges. The Lancet, v. 377, n. 9780, p. 1863-1876, 2011.

VIEIRA, T. O. et al. Determinants of breastfeeding initiation within the first hour of life in a Brazilian population: cross-sectional study. BMC Public Health, v. 10, n. 1, p. 760, 9 dez. 2010.

WEN, X. et al. Sociodemographic differences and infant dietary patterns. Pediatrics, v. 134, n. 5, p. e1387-1398, nov. 2014.

WORLD HEALTH ORGANIZATION. Equity, social determinants. Health and nutrition of children: equity, social determinants and public health programmes, 2010. Disponível em: <http://whqlibdoc.who.int/publications/2010/9789241563970_eng.pdf>

WORLD HEALTH ORGANIZATION. 2010 Countdown to 2015 Decade Report (2000-2010). Disponível em: <http://www.who.int/pmnch/knowledge/topics/2010countdown_decadereport/en/>. Acesso em: 2 jan. 2015. 
WORLD HEALTH ORGANIZATION. Complementary feeding of young children in developing countries. 1998. Disponível em:

<http://www.who.int/nutrition/publications/infantfeeding/WHO_NUT_98.1/en/>. Acesso em: 20 out. 2014b.

WORLD HEALTH ORGANIZATION. Complementary feeding: family foods for breastfed children. 2000. Disponível em:

<http://www.who.int/nutrition/publications/infantfeeding/WHO_NHD_00.1/en/>. Acesso em: 2 jan. 2015.

WORLD HEALTH ORGANIZATION. Effect of breastfeeding on infant and child mortality due to infectious diseases in less developed countries: a pooled analysis. WHO Collaborative Study Team on the Role of Breastfeeding on the Prevention of Infant Mortality. Lancet, v. 355, n. 9202, p. 451-455, 5 fev. 2000.

WORLD HEALTH ORGANIZATION. Global Strategy for Infant and Young Child Feeding. 2003a.

Disponível em: <http://www.who.int/nutrition/topics/global_strategy/en/>. Acesso em: 3 fev. 2015.

WORLD HEALTH ORGANIZATION. Guiding principles for complementary feeding of the breastfed child. 2003b. Disponível em:

<http://www.who.int/maternal_child_adolescent/documents/a85622/en/>. Acesso em: 3 fev. 2015.

WORLD HEALTH ORGANIZATION. Indicators for assessing infant and young child feeding practices. 2008. Disponível em:

<http://www.who.int/maternal_child_adolescent/documents/9789241596664/en/>. Acesso em: 2 jan. 2015a.

WORLD HEALTH ORGANIZATION. Long-term effects of breastfeeding: a systematic review. 2013a. Disponível em:

<http://www.who.int/maternal_child_adolescent/documents/breastfeeding_long_term_effects/en/ >. Acesso em: 3 fev. 2015.

WORLD HEALTH ORGANIZATION. Short-term effects of breastfeeding: a systematic review on the benefits of breastfeeding on diarrhoea and pneumonia mortality. 2013b Disponível em:

$<$ http://www.who.int/maternal_child_adolescent/documents/breastfeeding_short_term_effects/en />. Acesso em: 3 fev. 2015.

WIJNDAELE, K. et al. Determinants of early weaning and use of unmodified cow's milk in infants: a systematic review. Journal of the American Dietetic Association, v. 109, n. 12, p. 2017-2028, dez. 2009.

ZANARDO, V. et al. Early lactation failure and formula adoption after elective caesarean delivery: cohort study. Archives of Disease in Childhood. Fetal and Neonatal Edition, v. 98, n. 1, p. F37-41, jan. 2013. 


\section{ANEXO 1}

Descrição das principais características do plano amostral nas três pesquisas nacionais de demografia e saúde. Brasil, 1986-2006.

\begin{tabular}{|c|c|c|c|}
\hline & \multicolumn{3}{|c|}{ Anos das pesquisas } \\
\hline Aspectos descritos & 1986 & 1996 & 2006 \\
\hline Nome da pesquisa & $\begin{array}{l}\text { Pesquisa Nacional sobre } \\
\text { Saúde Materno-Infantil e } \\
\text { Planejamento Familiar }\end{array}$ & $\begin{array}{l}\text { Pesquisa Nacional sobre } \\
\text { Demografia e Saúde } \\
\text { (PNDS 1996) }\end{array}$ & $\begin{array}{lll}\text { Pesquisa } & \text { Nacional } & \text { de } \\
\text { Demografia e Saúde da } & \text { da Sca e da Mulher: } \\
\text { Criança } & \text { da MNDS }\end{array}$ \\
\hline $\begin{array}{ll}\text { Instituição } & \text { responsável } \\
\text { pela Pesquisa } & \end{array}$ & 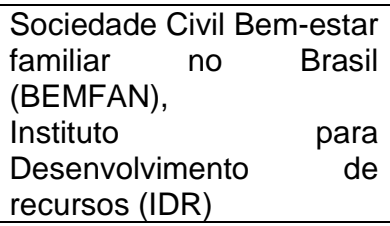 & 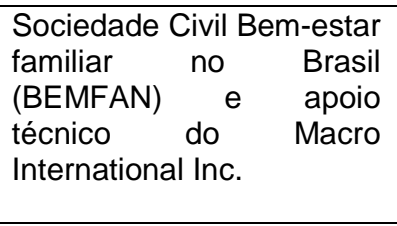 & $\begin{array}{l}\text { Centro Brasileiro de } \\
\text { Análise e Planejamento } \\
\left(\text { CEBRAP) }{ }^{*}\right.\end{array}$ \\
\hline $\begin{array}{lll}\text { Fase } & \text { Projeto } & \text { MESUARE } \\
\text { DHS } & & \\
\end{array}$ & Fase I & Fase III & Fase V \\
\hline Público alvo & $\begin{array}{l}\text { Mulheres entre } 15 \text { e } 44 \\
\text { anos }\end{array}$ & $\begin{array}{l}\text { Mulheres entre } 15 \text { e } 49 \\
\text { anos }\end{array}$ & $\begin{array}{l}\text { Mulheres entre } 15 \text { e } 49 \\
\text { anos }\end{array}$ \\
\hline Amostragem & Probabilística complexa & Probabilística complexa & $\begin{array}{l}\text { Probabilística complexa } \\
\text { (cada amostra das } \\
\text { macrorregiões será obtida } \\
\text { por meio de AAS por } \\
\text { conglomerado em dois } \\
\text { estágios) }\end{array}$ \\
\hline Número de estágio & Dois & Dois & Dois \\
\hline Pesquisa base da amostra & $\begin{array}{l}\text { Subamostra dos setores } \\
\text { censitários da PNAD } 1984\end{array}$ & $\begin{array}{l}\text { Subamostra dos setores } \\
\text { censitários da PNAD } 1995\end{array}$ & \begin{tabular}{llr} 
Amostra & \multicolumn{2}{c}{ independente, } \\
sendo utilizados os & odo \\
setores censitários do \\
Censo 2000.
\end{tabular} \\
\hline Domínios da amostra & $\begin{array}{l}\text {-Seis regiões da PNAD; } \\
\text {-Regiões rural e urbana } \\
\text { do Nordeste, São Paulo, } \\
\text { Minas Gerais e Rio de } \\
\text { Janeiro(autoponderadas). }\end{array}$ & 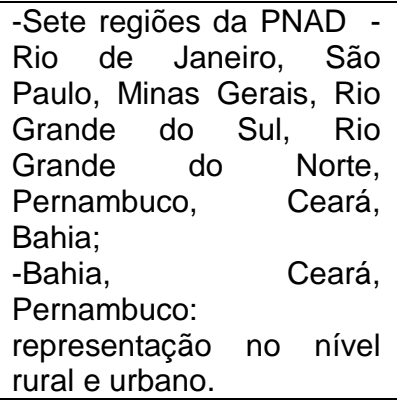 & $\begin{array}{ll}\text {-Dez } & \text { macrorregiões } \\
\text { brasileiras } & \end{array}$ \\
\hline Estratos (Marco amostral) & 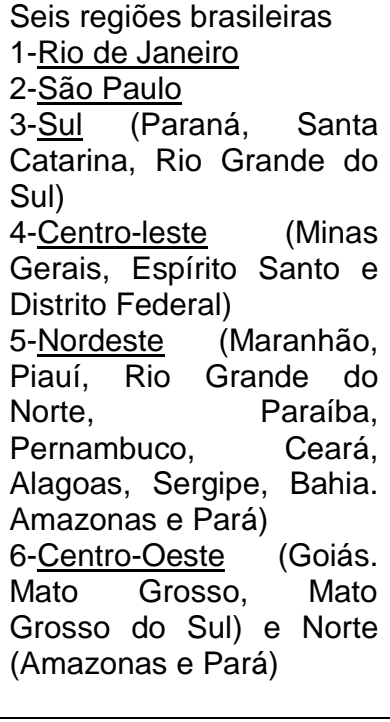 & 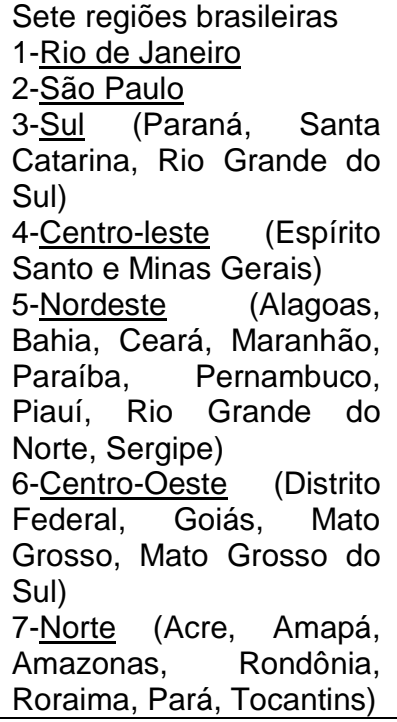 & $\begin{array}{l}\text { Dez macrorregiões } \\
\text { brasileiras: } \\
\text { 1-Norte rural } \\
\text { 2-Norte urbano } \\
\text { 3-Nordeste rural } \\
\text { 4-Nordeste urbano } \\
\text { 5-Centro-Oeste rural } \\
\text { 6-Centro-Oeste urbano } \\
\text { 7-Sudeste rural } \\
\text { 8-Sudeste urbano } \\
\text { 9-Sul rural } \\
\text { 10-Sul urbano }\end{array}$ \\
\hline $\begin{array}{l}\text { Situação do } \\
\text { (rural/urbano) }^{\star \star}\end{array}$ & $\begin{array}{l}\text { Domínio rural e urbano } \\
\text { para região Nordeste }\end{array}$ & $\begin{array}{l}\text { Domínio rural e urbano } \\
\text { para Pernambuco, Bahia } \\
\text { e Ceará }\end{array}$ & $\begin{array}{l}\text { Domínio rural e urbano } \\
\text { para dez macrorregiões }\end{array}$ \\
\hline excluídas & Áreas rurais das regiões & Área rural da região Norte & ------- \\
\hline
\end{tabular}




\begin{tabular}{|c|c|c|c|}
\hline amostra & $\begin{array}{l}\text { Norte e Centro-oeste, } \\
\text { Estados Acre, Roraima, } \\
\text { Rondônia e Amapá (5\% } \\
\text { da população brasileira - } \\
\text { Censo 1980) }\end{array}$ & $\begin{array}{l}\text { (com exceção de } \\
\text { Tocantins) }\end{array}$ & \\
\hline $\begin{array}{l}\text { Unidade primária de análise } \\
\text { (UPA) }\end{array}$ & Setores censitários & Setores censitários & Setores censitários \\
\hline Critério de seleção (UPA) & $\begin{array}{l}\text { Amostragem proporcional } \\
\text { ao tamanho do número de } \\
\text { domicílios }\end{array}$ & $\begin{array}{l}\text { Amostragem sistemática } \\
\text { com probabilidade } \\
\text { proporcional ao tamanho } \\
\text { do número de domicílios } \\
\text { em cada setor. }\end{array}$ & $\begin{array}{lr}\text { Amostragem } & \text { aleatória } \\
\text { simples } & \text { por } \\
\text { conglomerado }^{1} & \end{array}$ \\
\hline $\begin{array}{l}\text { Unidade secundária de } \\
\text { análise (USA) }\end{array}$ & Domicílios privados & Domicílios privados & Domicílios privados \\
\hline Critério de seleção (USA) & $\begin{array}{l}\text { Amostragem sistemática } \\
\text { (consideração da } \\
\text { probabilidade de seleção } \\
\text { e no dos setores } \\
\text { censitários da PNDS e no } \\
\text { setores censitários da } \\
\text { PNAD e sua fração } \\
\text { amostral por região } \\
\text { (domínio amostral). }\end{array}$ & $\begin{array}{l}\text { Amostragem sistemática } \\
\text { (o número de domicílios a } \\
\text { serem selecionados em } \\
\text { cada setor foi definido de } \\
\text { forma a manter a fração } \\
\text { amostral uniforme para } \\
\text { cada domicílio em cada } \\
\text { região). A sistematização } \\
\text { adotada foi específica } \\
\text { para área urbana e rural. } \\
\text { Estimou-se o número de } \\
\text { domicílios por unidade da } \\
\text { federação que seriam } \\
\text { necessários para garantir } \\
\text { que fossem encontradas e } \\
\text { entrevistadas } \\
\text { aproximadamente } 13600 \\
\text { mulheres de } 15 \text { a } 49 \text { anos } \\
\text { (este numero foi estimado } \\
\text { na pesquisa da BEMFAN } \\
\text { de } 1991 \text { realizada no } \\
\text { nordeste) }\end{array}$ & $\begin{array}{l}\text { Amostragem inversa (para } \\
\text { cada setor foi fixado um } \\
\text { número de } 12 \text { entrevistas } \\
\text { do questionário completo). } \\
\text { Exigência de pelo menos } \\
1 \text { mulher elegível no } \\
\text { domicílio). }\end{array}$ \\
\hline $\begin{array}{l}\text { № de setores censitários } \\
\text { entrevistados }\end{array}$ & 346 & 842 & 1088 \\
\hline 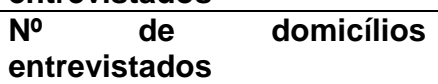 & 8519 & 13283 & 14617 \\
\hline $\begin{array}{ll}\text { Mulheres } & \text { elegíveis } \\
\text { entrevistadas } & \end{array}$ & 5892 & 12612 & 15575 \\
\hline $\begin{array}{l}\text { Crianças } \\
\text { avaliadas }\end{array}$ & 3305 & 4817 & 4818 \\
\hline
\end{tabular}

${ }^{*}$ Parceria com Unicamp - Núcleo de Estudos de Populações (NEPO) e Departamento de Medicina Preventiva da Faculdade de Ciências médicas e USP: Núcleo de Pesquisas em Nutrição e Saúde (FSP) e Laboratório de Nutrição (Depto de Clínica Médica FMRP)

${ }^{* *}$ Como situação urbana consideram-se as áreas correspondentes às cidades (sedes municipais), às vilas (sedes distritais) ou às áreas urbanas isoladas. A situação rural abrange toda a área situada fora desses limites. Este critério é, também, utilizado na classificação da população urbana e rural. 


\section{ANEXO 2}

Descrição da configuração das variáveis utilizadas no estudo conforme categorias originais e categorias recodificadas para as análises realizadas.

\begin{tabular}{|c|c|c|}
\hline Variáveis & $\begin{array}{c}\text { Categorias originalmente } \\
\text { disponíveis }\end{array}$ & Codificação utilizada \\
\hline \multicolumn{3}{|l|}{ Variáveis referentes à criança } \\
\hline Sexo & $\begin{array}{l}\text { 1: masculino } \\
\text { 2: feminino }\end{array}$ & $\begin{array}{l}\text { 1: masculino } \\
\text { 2: feminino }\end{array}$ \\
\hline $\begin{array}{l}\text { Ocorrência de diarréia (últimos } 15 \\
\text { dias) }\end{array}$ & $\begin{array}{l}\text { 0: não } \\
1: \operatorname{sim}\end{array}$ & $\begin{array}{l}\text { 0: não } \\
1: \operatorname{sim}\end{array}$ \\
\hline $\begin{array}{l}\text { Ocorrência de tosse (últimos } 15 \\
\text { dias) }\end{array}$ & $\begin{array}{l}0: \text { não } \\
1: \operatorname{sim}\end{array}$ & $\begin{array}{l}0: \text { não } \\
1: \operatorname{sim}\end{array}$ \\
\hline $\begin{array}{l}\text { Ocorrência de febre (últimos } 15 \\
\text { dias) }\end{array}$ & $\begin{array}{l}0: \text { não } \\
1: \operatorname{sim}\end{array}$ & $\begin{array}{l}0: \text { não } \\
1: \operatorname{sim}\end{array}$ \\
\hline $\begin{array}{l}\text { Ocorrência de doenças (últimos } \\
15 \text { dias)* }\end{array}$ & $\ldots$ & $\begin{array}{l}\text { 0: nenhuma } \\
\text { 1: } 1 \text { doença } \\
\text { 2: } 2 \text { doenças } \\
\text { 3: } 3 \text { doenças }\end{array}$ \\
\hline Número de crianças no domicílio & $\frac{\text { Variável discreta }}{1 \text { a } 6}$ & $\begin{array}{l}\text { Variável categórica: } \\
1: 1 \text { criança } \\
2: 2 \text { crianças } \\
3: \geq 3 \text { (união das categorias } 4,5 \text { e } 6 \text { ) }\end{array}$ \\
\hline $\begin{array}{l}\text { Peso ao nascer (baixo peso ao } \\
\text { nascer) }\end{array}$ & Variável contínua (gramas) & $\begin{array}{l}\text { Variável categórica: } \\
\text { Presença de baixo peso } \\
0: \text { não } \\
1: \operatorname{sim}\end{array}$ \\
\hline \multicolumn{3}{|l|}{ Variáveis referentes à mãe } \\
\hline Idade materna ao nascimento & $\begin{array}{l}\text { Variável contínua } \\
\text { 1986: } 14 \text { a } 45 \text { anos } \\
\text { 1996: } 12 \text { a } 48 \text { anos } \\
\text { 2006: } 12 \text { a } 47 \text { anos }\end{array}$ & $\begin{array}{l}\text { Variável categórica: } \\
1:<20 \text { anos } \\
2: 20 \text { a } 29 \text { anos } \\
3: 30 \text { a } 45 \text { anos }\end{array}$ \\
\hline $\begin{array}{l}\text { Idade materna atual (no momento } \\
\text { da entrevista) }\end{array}$ & $\begin{array}{l}\text { Variável contínua } \\
1986: 15 \text { a } 44 \text { anos } \\
\text { 1996-2006: } 15 \text { a } 49 \text { anos }\end{array}$ & $\begin{array}{l}\text { Variável categórica: } \\
1:<20 \text { anos } \\
2: 20 \text { a } 29 \text { anos } \\
3: 30 \text { a } 45 \text { anos }\end{array}$ \\
\hline Estado civil & $\begin{array}{l}\text { Variável categórica } \\
0: \text { Solteira } \\
\text { 1: Casada } \\
\text { 2: União estável } \\
\text { 3: Viúva } \\
\text { 4: Divorciada } \\
\text { 5: Não vive com } \\
\text { companheiro }\end{array}$ & $\begin{array}{l}\text { Variável categórica: } \\
0: \text { sem companheiro (categorias } \\
0,3,4,5) \\
1: \text { com companheiro } \\
\text { (categorias } 1,2 \text { ) }\end{array}$ \\
\hline Paridade (primípara) & $\frac{\text { Variável categórica }}{1 \text { a } 15 \text { filhos }}$ & $\begin{array}{l}\text { Variável categórica } \\
0: \text { não (mais de um filho) } \\
1: \operatorname{sim}(1 \text { filho })\end{array}$ \\
\hline Mãe ouve rádio & $\begin{array}{l}0: \text { não } \\
1: \operatorname{sim}\end{array}$ & $\begin{array}{l}0: \text { não } \\
1: \operatorname{sim}\end{array}$ \\
\hline Mãe assiste televisão & $\begin{array}{l}0: \text { não } \\
1: \operatorname{sim}\end{array}$ & $\begin{array}{l}\text { 0: não } \\
1: \operatorname{sim}\end{array}$ \\
\hline Mãe lê jornal/revista & $\begin{array}{l}0: \text { não } \\
1: \operatorname{sim}\end{array}$ & $\begin{array}{l}\text { 0: não } \\
1: \operatorname{sim}\end{array}$ \\
\hline $\begin{array}{l}\text { Principal fonte de informação } \\
\text { para a mãe* }\end{array}$ & $\ldots$ & $\begin{array}{l}\text { Variável categórica } \\
0: \text { nenhuma } \\
\text { 1: rádio } \\
\text { 2: televisão } \\
\text { 3: jornal/revista }\end{array}$ \\
\hline Realização de pré-natal & $\begin{array}{l}0: \text { não } \\
1: \operatorname{sim}\end{array}$ & $\begin{array}{l}0: \text { não } \\
1: \operatorname{sim}\end{array}$ \\
\hline
\end{tabular}




\begin{tabular}{|c|c|c|}
\hline Variáveis & $\begin{array}{c}\text { Categorias originalmente } \\
\text { disponíveis }\end{array}$ & Codificação utilizada \\
\hline $\begin{array}{l}\text { Tempo em que realizou a } 1^{\underline{a}} \\
\text { consulta }\end{array}$ & $\frac{\text { Variável discreta }}{0 \text { a 9o mês }}$ & $\begin{array}{l}\text { Variável categórica: } \\
0: \text { após } 3^{\circ} \text { mês } \\
\text { 1: antes do } 3^{\circ} \text { mês }\end{array}$ \\
\hline Número de consultas & $\frac{\text { Variável discreta }}{0 \text { a } 20 \text { consultas }}$ & $\begin{array}{l}\text { Variável categórica: } \\
0 \text { : inferior a } 6 \text { consultas } \\
1 \text { : igual ou superior a } 6 \text { consultas }\end{array}$ \\
\hline Realização de consulta pós-natal & $\begin{array}{l}0: \text { não } \\
1: \operatorname{sim}\end{array}$ & $\begin{array}{l}0: \text { não } \\
1: \operatorname{sim}\end{array}$ \\
\hline Escore pré-natal $^{*}$ & $\ldots$ & $\begin{array}{l}\text { 0: nenhum procedimento } \\
\text { 1: } 1 \text { procedimento } \\
\text { 2: } 2 \text { procedimentos } \\
3: 3 \text { procedimentos } \\
4: 4 \text { procedimentos }\end{array}$ \\
\hline Tipo de parto & $\begin{array}{l}\text { 0: parto normal } \\
\text { 1: parto cesáreo }\end{array}$ & $\begin{array}{l}\text { 0: parto normal } \\
\text { 1: parto cesáreo }\end{array}$ \\
\hline Local do parto & $\begin{array}{l}\text { 1: em casa } \\
\text { 2: hospital/maternidade } \\
\text { públicos (SUS) } \\
\text { 3: centro de saúde ou casa } \\
\text { de parto } \\
\text { 4: hospital/maternidade } \\
\text { (convênio) } \\
\text { 5: hospital/maternidade } \\
\text { particular } \\
\text { 6: INAMPS e previdência } \\
\text { municipal ou estadual (1986) }\end{array}$ & $\begin{array}{l}\text { 0: hospital público (categorias: } 1,2,3 \text { ) } \\
\text { 1: hospital privado (categorias: } 4,5,6 \text { ) }\end{array}$ \\
\hline \multicolumn{3}{|l|}{ Variáveis socioeconômicas } \\
\hline Escolaridade materna & $\begin{array}{l}\text { Variável discreta: } \\
0 \text { a } 19 \text { anos }\end{array}$ & $\begin{array}{l}3 \text { categorias: } \\
1: 0 \text { a } 3 \text { anos } \\
2: 4 \text { a } 7 \text { anos } \\
3: 8 \text { a } 11 \text { anos } \\
4: \geq 12 \text { anos }\end{array}$ \\
\hline $\begin{array}{l}\text { Escolaridade do chefe do } \\
\text { domicílio }\end{array}$ & $\begin{array}{l}\text { Variável discreta: } \\
0 \text { a } 19 \text { anos }\end{array}$ & $\begin{array}{l}3 \text { categorias: } \\
1: 0 \text { a } 3 \text { anos } \\
2: 4 \text { a } 7 \text { anos } \\
3: 8 \text { a } 11 \text { anos } \\
4: \geq 12 \text { anos }\end{array}$ \\
\hline Trabalho materno atual & $\begin{array}{l}0: \text { não trabalha } \\
\text { 1: trabalha }\end{array}$ & $\begin{array}{l}0: \text { não trabalha } \\
\text { 1: trabalha }\end{array}$ \\
\hline Situação do trabalho materno & $\ldots$ & $\begin{array}{l}\text { 0: não trabalha } \\
\text { 1: trabalho informal } \\
\text { 2: trabalho formal }\end{array}$ \\
\hline Macrorregiões brasileiras' ${ }^{1}$ & $\begin{array}{l}\text { 1996: } \\
\text { 1: Rio de Janeiro } \\
\text { 2: São Paulo } \\
\text { 3: Sul } \\
\text { 4: Centro-leste } \\
\text { 5: Nordeste } \\
\text { 6: Norte } \\
\text { 7: Centro-oeste }\end{array}$ & $\begin{array}{l}\text { 1996 e 2006: } \\
\text { 1: Norte } \\
\text { 2: Nordeste } \\
\text { 3: Centro-oeste } \\
\text { 4: Sudeste } \\
\text { 5: Sul }\end{array}$ \\
\hline Situação do domicílio & $\begin{array}{l}\text { 1: Urbano } \\
\text { 2: Rural }\end{array}$ & $\begin{array}{l}\text { 1: Urbano } \\
\text { 2: Rural }\end{array}$ \\
\hline Índice de riqueza* & $\ldots$ & $\begin{array}{l}\text { 1: } 1^{\circ} \text { quintil } \\
2: 2^{\circ} \text { quintil } \\
\text { 3: } 3^{\circ} \text { quintil } \\
\text { 4: } 4^{\circ} \text { quintil } \\
5: 5^{\circ} \text { quintil }\end{array}$ \\
\hline $\begin{array}{l}\text { Bens utilizados no calculo do } \\
\text { índice de riqueza (descrição } \\
\text { dos bens para os três }\end{array}$ & & \\
\hline
\end{tabular}




\begin{tabular}{|c|c|c|}
\hline inquéritos) & & \\
\hline Fonte da água para beber & $\begin{array}{l}\text { Fontes: } \\
\text { 1: água encanada (cozinha) } \\
\text { 2: água encanada (quintal) } \\
\text { 3: poço } \\
\text { 4: torneira pública } \\
\text { 5: açude } \\
\text { 6: rio ou riacho } \\
\text { 7: olho d'água/mina } \\
\text { 8: outro }\end{array}$ & $\begin{array}{l}\text { Classificacão da fonte de água } \\
\text { quanto à potabilidade } \\
\text { 0: inadequado (categorias } 6 \text { a 8) } \\
\text { 1: adequado (categorias } 1 \text { e } 5 \text { ) }\end{array}$ \\
\hline Tipo de esgotamento sanitário & $\begin{array}{l}\text { Fontes: } \\
\text { 1: Rede de esgoto } \\
\text { 2: Fossa séptica } \\
\text { 3: Fossa rudimentar } \\
\text { 4: Vala aberta } \\
\text { 5: Qualquer lugar } \\
\text { 6: Direto no rio/mar } \\
\text { 7: Outro }\end{array}$ & $\begin{array}{l}\text { Classificacão do tipo de esgotamento } \\
\text { sanitário }{ }^{2} \\
0: \text { inadequado (categorias } 3 \text { a } 7 \text { ) } \\
\text { 1: adequado (categorias } 1 \text { e } 2 \text { ) }\end{array}$ \\
\hline Televisão & $\begin{array}{l}\text { Presença no domicílio } \\
0 \text { a } 4\end{array}$ & $\begin{array}{l}\text { Presença no domicílio } \\
0: \text { não } \\
1: \operatorname{sim} \text { (categorias } 1 \text { a } 4 \text { ) }\end{array}$ \\
\hline Rádio & $\frac{\text { Presença no domicílio }}{0 \text { a } 5}$ & $\begin{array}{l}\text { Presença no domicílio } \\
0: \text { não } \\
1: \operatorname{sim} \text { (categorias } 1 \text { a } 5 \text { ) }\end{array}$ \\
\hline Banheiros & $\begin{array}{l}\text { Presença no domicílio } \\
0 \text { a } 6\end{array}$ & $\begin{array}{l}\text { Presença no domicílio } \\
0: \text { não } \\
1: \operatorname{sim} \text { (categorias } 1 \text { a } 6 \text { ) }\end{array}$ \\
\hline Automóvel & $\frac{\text { Presenca no domicílio }}{0 \text { a } 5}$ & $\begin{array}{l}\text { Presenca no domicílio } \\
0: \text { não } \\
1: \operatorname{sim} \text { (categorias } 1 \text { a } 5 \text { ) }\end{array}$ \\
\hline Empregada doméstica & $\begin{array}{l}\text { Presença no domicílio } \\
0 \text { a } 5\end{array}$ & $\begin{array}{l}\text { Presença no domicílio } \\
0: \text { não } \\
1: \operatorname{sim} \text { (categorias } 1 \text { a } 5 \text { ) }\end{array}$ \\
\hline Aspirador de pó & $\frac{\text { Presença no domicílio }}{0 \text { a } 1}$ & $\begin{array}{l}\text { Presenca no domicílio } \\
0: \text { não } \\
1: \operatorname{sim}\end{array}$ \\
\hline Máquina de lavar roupa & $\frac{\text { Presenca no domicílio }}{0 \text { a } 1}$ & $\begin{array}{l}\text { Presença no domicílio } \\
0: \text { não } \\
1: \operatorname{sim}\end{array}$ \\
\hline Vídeo cassete & $\frac{\text { Presenca no domicílio }}{0 \text { a } 5}$ & $\begin{array}{l}\text { Presença no domicílio } \\
0: \text { não } \\
\text { 1: sim (categorias } 1 \text { a 5) }\end{array}$ \\
\hline Eletricidade & $\begin{array}{l}\text { Presença no domicílio } \\
0 \text { a } 1\end{array}$ & $\begin{array}{l}\text { Presença no domicílio } \\
\text { : não } \\
1: \text { sim }\end{array}$ \\
\hline Refrigerador & $\frac{\text { Presença no domicílio }}{0 \text { a } 1}$ & $\begin{array}{l}\text { Presença no domicílio } \\
0: \text { não } \\
1: \text { sim }\end{array}$ \\
\hline Telefone & $\begin{array}{l}\text { Presença no domicílio } \\
0 \text { a } 1\end{array}$ & $\begin{array}{l}\text { Presença no domicílio } \\
0: \text { não } \\
1: \operatorname{sim}\end{array}$ \\
\hline Computador & $\frac{\text { Presença no domicílio }}{0 \text { a } 1}$ & $\begin{array}{l}\text { Presença no domicílio } \\
0: \text { não } \\
1: \operatorname{sim}\end{array}$ \\
\hline
\end{tabular}

...ausência de dado; *Variáveis criadas para o estudo, 1: Em 1986 não foi possível recompor as 5 macrorregiões brasileiras em função da diferença de estratificação adotada na amostragem. A recodificação foi realizada em 1996 para ser compatível com 2006. 2: WHO/UNICEF Joint Monitoring Programme (JMP) for water supply and sanitation (Fonte: http://www.wssinfo.org/definitions-methods/watsan-categories/) 


\section{ANEXO 3}

Variáveis utilizadas para o cálculo do índice de riqueza segundo ano do inquérito e características da análise do índice de riqueza, definido à partir de análise de principais componentes.

\begin{tabular}{|c|c|c|}
\hline \multicolumn{3}{|c|}{ Ano do inquérito } \\
\hline 1986 & 1996 & 2006 \\
\hline Fonte de água para beber & Tipo de esgotamento sanitário & Tipo de esgotamento sanitário \\
\hline Tipo de esgotamento sanitário & Televisão & Televisão \\
\hline Televisão & Rádio & Banheiro \\
\hline Rádio & Banheiro & Carro \\
\hline Banheiro & Carro & Empregada doméstica \\
\hline Empregada doméstica & Empregada doméstica & Aspirador de pó \\
\hline Aspirador de pó & Aspirador de pó & Máquina de lavar roupa \\
\hline Máquina de lavar roupa & Máquina de lavar roupa & Vídeo cassete \\
\hline $\begin{array}{l}\text { Escolaridade do chefe do } \\
\text { domicílio }\end{array}$ & Eletricidade & Refrigerador \\
\hline & Refrigerador & Computador \\
\hline & Vídeo cassete & Telefone \\
\hline & $\begin{array}{llll}\begin{array}{l}\text { Escolaridade do chefe } \\
\text { domicílio }\end{array} & & \\
\end{array}$ & $\begin{array}{l}\begin{array}{l}\text { Escolaridade do chefe } \\
\text { domicílio }\end{array} \\
\end{array}$ \\
\hline Características da análise de & incipais componentes & \\
\hline $\begin{array}{l}\text { \% variância explicada no } 1^{\circ}= \\
\text { componente: } 39 \%\end{array}$ & $\begin{array}{l}\% \text { variância explicada no } 1^{\circ} \\
\text { componente: } 37 \%\end{array}$ & $\begin{array}{l}\% \text { variância explicada no } 1^{\circ}= \\
\text { componente: } 31 \%\end{array}$ \\
\hline KMO: 0,87 & KMO: 0,89 & KMO: 0,88 \\
\hline
\end{tabular}




\section{ANEXO 4}

Manuscrito: Breastfeeding measures: can retrospective mother recall fits median length as accurately as current status?

\section{Submetido para o periódico: Maternal and Child Nutrition}

Autores: Ana Elisa Madalena Rinaldi Wolney Lisboa Conde

Abstract

Background: Usually, indicators of breastfeeding practices are based on current data as provided by the World Health Organization. Our aim is to compare exclusive breastfeeding (EBF) and breastfeeding (BF) median using current status and retrospective recall data in different breastfeeding patterns across countries. Methods: Data was from seven pooled Demographic Health Surveys, including 55,670 infants under age of 36 months. EBF and BF median based on current status were calculated using current status estimator and logistic regression; medians based on retrospective mother recall data were estimated using survival analysis. Results: EBF and BF median using current status estimator ranged from 0.8 to 5.5 and 9.1 to 29.4 months across countries; using logistic regression, they ranged from 1.5 to 3.9 and 11.5 to 29.9 months; and using survival analysis, they ranged from 0.02 to 5.0 and 9.0 to 30.0 months, respectively. EBF medians estimated using survival analysis produced the highest values compared to the current status estimator and logistic regression. BF medians estimated by logistic regression produced the highest values. The EBF and BF medians calculated using current status estimator and survival analysis were more similar than medians calculated using logistic regression. The difference between EBF and BF median between current status estimator and survival analysis was correlated with the number of censored children. Conclusion: Retrospective recall data as recalled by the mother is a reliable estimate of EBF and BF and provides data to investigate effects of breastfeeding policies for surveillance and for modeling individual determinants at a proximal level.

Keywords: breastfeeding, nutritional epidemiology, breastfeeding duration, child public health, child feeding, research methodology 


\section{Background}

The use of current status indicators for infant feeding practices was defined by a panel of experts coordinated by the World Health Organization Working Group on Infant Feeding (WHO)("WHO I Indicators for assessing breastfeeding practices," n.d.). Current status data is characterized by the single information about whether the event has succeeded or not and it can be right censored with respect to the exact time of occurrence(Shiboski, 1998). To analyze breastfeeding data, current status indicators rely on four main assumptions: a) current status data represents that the present situation and the proportions of breastfeeding children can only change in one direction; b) current status classify breastfeeding condition as yes or not at day of survey; c) current status data can be compared with the age range column of the actuarial life table d) current status data represents essentially the sum of qualitative status information, and therefore, is analyzed only as an aggregated indicator.

The current status indicator is recommended for a population estimate, working better with large samples of infants, and is always analyzed using a descriptive population perspective ("WHO I Indicators for assessing infant and young child feeding practices," n.d.). Besides, this indicator converts monthly aggregated data into unity of analysis and therefore cannot be used to evaluate the effects on individuals. Nowadays, current status is the frequently used indicator to estimate the prevalence or length of breastfeeding across countries.

Breastfeeding length data is sometimes gathered as mothers' retrospective recall information. This kind of data relies on assumptions that the mother is a good informant and changes in child feeding patterns are remarkable events to mothers. That data could be used advantageously in estimates for an individual perspective. Arguments against using recall data posit recall bias and heaping of data at certain age values because they are recalled as integers number("WHO | Indicators for assessing infant and young child feeding practices," n.d.).

An accurate evaluation of breastfeeding is complex and it can be measured broadly by combining indicators expressed by proportions and durations. There is no best single indicator to measure breastfeeding. The best indicator depends on the objective and analytical purpose of the study(Greiner, 2014).

Breastfeeding estimates have to overcome some challenges. Children at breastfeeding age can be divided into two groups-one group following WHO feeding recommendations and another group that does not. Current status and mothers' retrospective recall deal in different ways with information that 
comes from the two groups. An additional statistical issue is how to deal with a skewed distribution. The group of infants in agreement with WHO recommendations brings up the issue of estimating the median in survival data: in a skewed distribution, is the time span of the group beyond the median determined in the same way as that in the group behind median? (Gould, 1985) The median, in a mixed expose distribution, depends on a prescribed set of circumstances, and therefore, the survival time will differ according to the treatment group. If we accept these assumptions, we will need some adjustment to estimate the actual time span of the infant cohort following WHO recommendations.

The study was designed to calculate the breastfeeding and exclusive breastfeeding median using current status data and retrospective recall data using three different statistical analysis and to compare them across countries.

\section{Participants and methods}

\section{Data source}

The data are from seven national demographic health surveys supported by the DHS Measure Program (Macro International): Bolivia, Brazil, Colombia, Egypt, India, Kenya, and Rwanda (available at: http://www.measuredhs.com/data/available-datasets.cfm). The selection of countries was based on different breastfeeding patterns and on the availability of retrospective recall data in databases. These data were obtained from each published final report and the DHS Program STAT compiler website (http://www.statcompiler.com/). Eligible infants were those younger than 36 months, alive on the interview date, and who had lived with the mother or respondent. The data about breastfeeding and feeding were available for the last child in the birth history index. The last child coped with $85 \%-$ $90 \%$ of all children under 36 months in the birth history index.

\section{Breastfeeding indicators}

Breastfeeding and exclusive breastfeeding were defined as proposed by the World Health Organization ("WHO | The optimal duration of exclusive breastfeeding," n.d.). The BF and EBF indicators for current status were based on information from the previous day and retrospective recall indicators were based on mothers' report of breastfeeding duration-time from birth until current age. The BF indicator for current status was a binary variable representing the status of breastfeeding based on the previous day (0: BF, 1: non-BF), and for retrospective recall data, the indicator was a continuous variable representing the length of BF. The EBF indicator for current status was a binary 
variable representing the status of food intake and breastfeeding on the previous day (0: EBF, 1: nonEBF). EBF was set for infants who did not have any food intake the previous day. The EBF based on retrospective recall data was a continuous variable representing the length of EBF. Retrospective data was recorded in two different ways. In Brazil, the mother was asked to recall directly the number of months since birth when the infant has received only breast milk. In other countries, the mother was asked for recalling the month at which infants had received any liquid, semi-solid, and solid foods for the first time. The percentage of infants who had never breastfed and who breastfed only for one day was estimated for each country.

\section{Data analysis}

The BF and EBF median were calculated using three statistical methods: a) current status, for which the median corresponds to the three-group moving average interval, where 50 percent of infants were still breastfeeding, b) logistic regression (logit) considering as dependent variable, the status of breastfeeding (yes or no) on the previous day (current status) and as independent variable, the current infant age, and c) survival analysis with the Kaplan-Meier method using retrospective recall data .

Using current status data indicator, BF and EBF median were calculated according to WHO/Macro recommendations("WHO | Indicators for assessing infant and young child feeding practices," n.d.). Infants who received breast milk the previous day were classified as "breastfed." Infants who did not receive any food the previous day or with missing data for all foods were classified as "exclusive breastfeeding." Infants whose mothers did not know about any food intake, who had eaten at least one food item the previous day and who had never received breast milk were categorized as "nonexclusive breastfed." The BF and EBF median were determined by linear interpolation of the proportion of infants classified as BF and EBF by two-month age groups below 0.5 and the previous group's percentage("WHO | Indicators for assessing infant and young child feeding practices," n.d.). To standardize the estimate, we recalculated all BF and EBF medians for each country, adopting the same rules and inclusion/exclusion criteria.

The current status data was used to estimate the median using logistic regression. In this analysis the BF and EBF probabilities were estimated for each age from logistic function. The median of BF and EBF matched the mean age were the probability was to breastfeed was $50 \%$. 
For retrospective recall data, we performed adjustments to keep the sample and estimates matched with current status data, such as: a) assignment of value $0.0164(0.5$ day/30.44) when data was missing data, "do not know" answers, or length of BF and EBF was only one day; b) assignment of a symbolic value ( 0.000001 month) to avoid zeroes for infants who had never been breastfed, and $\mathrm{c}$ ) assignment of current age as breastfeeding length for infants who were still breastfeeding (exclusive and not exclusive). The BF median was estimated considering children under 36 months and EBF was calculated considering infants under 6 months.

The BF and EBF median were calculated using the Kaplan Meier (KM) survival function. The infants who were receiving breast milk (exclusive and not exclusive) were considered as right-censored cases because the failure time is equal to or greater than the present time on interview day. Correlation among variables was estimated using Pearson estimator $(r)$. We took into account complex sampling design for all estimates. Statistical analysis was performed in Stata version 13.1. This study was exempt from ethical approval because it used data from publically available datasets.

\section{Results}

The total number of infants selected from the data pool was 55,670. The prevalence of infants who had been breastfed was higher than 95 percent, levering from $95.5 \%$ in Colombia to $99.8 \%$ in Rwanda. The BF and EBF medians calculated using the current status estimator were similar to official results. The highest difference for EBF was 0.3 in India, and for BF, the 1.5 value in Rwanda (Table 1). Differences among official and recalculated prevalence are not associated with breastfeeding length. In Colombia and Kenya, the EBF median estimated by current status represented a statistical imputation value because in all age ranges, the percentage of EBF infants was lower than $50 \%$.

All BF and EBF medians estimated using logistic regression were higher than the current status estimator, except in Egypt for BF. The lowest and the highest median difference between these two estimators were in Kenya and Rwanda, respectively. It was not possible to estimate the EBF median using logistic regression because the mean age corresponding to $50 \%$ of breastfeeding children was lower than 1 month in Colombia and Kenya or higher than 5 months in Rwanda.

The EBF medians were higher using retrospective recall data. The highest increment for EBF occurred in Bolivia (+1.7 months), and for BF, in India (+0.9 months). In Bolivia and Brazil, BF median estimated 
using retrospective recall data were lower than the current status-mainly in Brazil (-1.9 months). Infants breasted only one day ranged from $0.4 \%$ to $4.5 \%$ and those exclusively breastfed ranged from $5.5 \%$ to $74.4 \%$ among the surveyed countries. The percentage of censored data for $\mathrm{BF}$ ranged from $34.9 \%$ to $80.1 \%$, and for EBF, ranged from $6.7 \%$ to $80.8 \%$ in Colombia and Rwanda, respectively. The number of censored children was correlated positively with $\operatorname{EBF}(r=0.98)$ and $\mathrm{BF}(\mathrm{r}=0.99)$ median.

The difference between the current status estimator and the retrospective recall estimator was correlated with the percentage of censored child $(r=0.64)$ for BF and for EBF $(r=0.77)$ and inversely correlated with the number of child breastfed only one day for BF $(r=-0.81)$ and for EBF $(r=-0.77)$.

\section{Discussion}

Our results highlight three main issues: 1) EBF median was slightly higher for retrospective recall data than for the current status, and for BF median, the result was inverse, except for India and Rwanda; 2) EBF and BF medians calculated for current status data were higher using logistic regression; 3) The difference between BF and EBF medians using current status and retrospective recall data were correlated with the number of child that were breastfed at interview time.

Differences among official and recalculated median can be explained by the distinct number of infants included for each analysis or by rounding adjustments in median values. For example, in India and Bolivia, there were differences of +0.2 and +0.3 month, respectively, in the final report prepared by each country and the results from the STAT Compiler available in the DHS website.

The difference in EBF medians for population and individual perspective is related to the number of infants who have been breastfed only one day. From a population perspective, EBF length is estimated of a ratio between infants who follow WHO recommendations versus the total number of infants in each age group. The sample of infants under six months can be large enough to use this method, mainly to assess the effectiveness of public policies. The power size of sample can be insufficient to show the effect of these strategies(Hector, 2011). From an individual perspective, EBF length in days is used to estimate the median and infants who have been breastfed only one day have no value in order to be included in the calculation. For these infants, we assigned a time value of 0.0164 to perform a balanced comparison between different calculations and we retained the same number of infants throughout the analysis. KM estimate is inversely proportionate to the number of infants breastfed only one day while that number does not affect the current status estimation. 
The first critical issue in current status is how much breastfeeding status of the previous day describes a typical day. Some evidence indicates that the previous day as used in current status does not represent feeding practices for infants receiving other foods than breast milk for the first time(Agampodi et al., 2011),(van Beusekom et al., 2013),(Barbosa et al., 2012),(Piwoz et al., 1995). If that is the situation, the current status would underestimate the actual number of EBF infants.

In fact, a key issue remains on the table: how long will the EBF and BF length of infants surveyed today last? If we presume that EBF and BF infants today will probably be breastfed the next day at least, the current status will underestimate the actual EBF and BF length to some extent. Taking into account all of the premises and evidence, we should provide some adjustments to converge the EBF and BF estimate to the actual and unknown values.

The estimates of EBF and BF median using logistic regression were similar to the current status estimator. This statistical method can estimate the probability of one child as being in EBF or BF at a specific age and can be defined as a descriptive use of this method. The median is determined at $50 \%$. The use of logistic regression for breastfeeding estimate is based on the assumption of "singular point of development" or "milestone." One "singular point of development" is defined as a specific moment of a process that an individual experiences and it only happens once during the entire lifetime. This point determines an important period in our lives. This assumption is similar to the current status and it is possible to compare both estimates and the results were similar. Indeed, logistic analysis takes into account only information from a fraction of children following WHO recommendations-same as what the current status does.

The censorship applied in survival analysis allows consideration of the breastfeeding length regardless of the situation at the time of interview. This is based on the premise that an EBF and BF infant should be not labeled at any step of the calculation, so they will be counted at the next age range. This procedure adds one time unit to each EBF infant. Such an adjustment provides more elevated values in our analysis, except in the case of Kenya. This adjustment was influenced only by the prevalence of infants breastfed only one day, which is a feature of survival analysis and was not related to the adjustment itself. 
The major impact in breastfeeding median using retrospective recall data was verified in countries with three common characteristics: largest EBF medians, lowest percentage of infants who received breast milk during one day, and larger than $40 \%$ of infants in EBF (Bolivia, Brazil, and Rwanda). In Kenya, the percentage of infants breastfed only one day is high (68.3\%) and the percent of EBF infants is low (11.2\%); therefore, the adjustments did not modify the median value.

The survival analysis enables us to use all the information available from EBF and non EBF infant cohorts. The censorship mechanism provided an improved median estimation and has no effect at the individual data level. Survival analysis with censure allowed estimating an EBF median that was as good as the current status. The mothers' retrospective recall data can be used as a valid output in conventional models to estimate effects from individual determinants of breastfeeding and the impacts of action and policies that are pro-breastfeeding. The surveillance and monitoring breastfeeding situation in eleven surveys are based on the retrospective recall data(Chapman and Perez-Escamilla, 2009).

The incentive for using maternal retrospective recall data and the adjustments proposed in our study are explained by the complexity during incorporating covariates in current status methods for the assessment of public policies. Parametric and nonparametric models were previously tested with the current status data. For the parametric model, all infants were considered exposed to breast milk in the probabilistic model, and for younger infants, the breastfeeding median was underestimated, and for the older ones, the median was overestimated. For the nonparametric model, the failure rate was negative because the current status data distribution was not monotonic in series. For spline fitting, the results were suitable mainly because the exclusive breastfeeding length was related to age. However, the knots in the spline models were specific to each country(Grummer-strawn, 1993). The generalized additive models for the current status enables incorporation of covariates, but these variables can only be available at the same time as the current status variables. Some covariates referring to past exposure can be incompatible with the current status data of breastfeeding. ${ }^{2}$ The Markov models can be applied to longitudinal breastfeeding analysis to incorporate possible status changes (non-EBF and EBF) for infants who received food for the first time(Chola et al., 2013).

The strengths of this study are the selection of countries with different breastfeeding profiles that allowed researchers to analyze the behavior of two kind of data in median calculation (retrospective data and current status); the similarity of questions about foods consumed the 
previous day (current status) in all countries, and the standardization of the treatment for both types of data in the analyzes. Besides the above, selection of infants under six months improves the probability of weaning, which can be virtually simultaneous to the mothers' reporting. Mothers who practiced EBF were able to recall the length of breastfeeding practices accurately. Furthermore, the maternal recall for BF duration is accurate and reliable until 36 months $(\mathrm{Li}$ et al., 2005) and the recall for breastfeeding in particular is higher than the specific age of food introduction (Li et al., 2005),(Launer et al., 1992).

The two main limitations of our studies were due to the source of available data. There were differences among retrospective recall questions on breastfeeding and/or the age of food introduction. In Brazil, the question was about "the length of exclusive breastfeeding" while for all other countries, the questions was about the age of introduction of liquids/solid foods. The accuracy of reporting the exact age of food introduction was lower than that which reported the duration of breastfeeding(Barbosa et al., 2012),(Launer et al., 1992),(Li et al., 2005),(Cupul-Uicab et al., 2009) and the EBF. One possible explanation for this effect is that breastfeeding is an important and single event when compared to the age of food introduction. One study in Guatemala, which provided information about feeding practices—current status and retrospective recall—was accurate. The use of these questions implied attempts to standardize and to refine them in order to avoid the bias introduced by some differences. Recall bias must be considered in epidemiological studies, but there are other important factors that contributed to the decrease in the validity of the retrospective recall data, such as appropriate questions and practice of the interviewer in applied questions (Agampodi et al., 2011).

The length of breastfeeding is the main source of heterogeneity among studies on breastfeeding and health outcomes. The accumulative effects of breastfeeding can be underestimated if the source of information is based on the proportion of infants that are or not breastfed("WHO | Long-term effects of breastfeeding," n.d.). The time unit of variables for breastfeeding or the age of food introduction provided in the data sets is a matter of concern. Usually, the unit is recorded in integer months in all countries. A more accurate register could avoid, for example, the heaping of values in specific months, which can affect the median calculation.

Finally, the purpose of Ted Greiner to use two types of information-one that reflects the proportion of infants under six months receiving exclusive breast milk and another that reflects the length of 
exclusive breastfeeding—should be combined because they are complementary(Greiner, 2014). In this study, conversely, the estimate of exclusive breastfeeding could be underestimated by using the current status indicator, mainly in countries where mothers traditionally exclusively breastfed infants for longer periods.

A final relevant issue remains: our results suggest adjustments are necessary to estimate breastfeeding accurately. If we select only EBF data from countries with actual calculations, all modelling or adjustments move exclusive breastfeeding length to the right, i.e., increasing the time-a strong evidence of underestimation by current status estimation. Moreover, all alternatives here presented are conventional center parameter estimations.

Indeed, if breastfeeding is a phenomenon in which some groups have a more favorable beginning than others, then the median is not sensitive to the same determinants in both groups. Thus, our challenge is to find the best way to estimate its output properly. This vision is relevant for studies analyzing the effective progress of breastfeeding policies within countries. In that analysis, we need to investigate individual responses to actions; therefore, groups presenting different determinants need to be treated as different.

Until then, we need more evidence to make a point about different possible cohorts in a survey on breastfeeding analysis. Different cohorts can have different determinants. Thus, the only approach to analyze this in cross-section studies is by using individual data as that provided in the mothers' information about infant breastfeeding patterns.

\section{Conclusions}

The BF and EBF medians using current data and retrospective recall data are similar. The difference between them is mainly about the number of children who undergo breastfeeding. Retrospective recall data as recalled by mothers is a reliable estimate of breastfeeding length and provides data to investigate effects from breastfeeding policies, for surveillance and for modeling individual determinants at the proximal level. Our results have showed positive perspectives by using recalled mother information for both objectives: to analyze individual determinants of breastfeeding and to estimate regional or national medians for breastfeeding length.

\section{Key messages}


- Usually, exclusive breastfeeding and breastfeeding median are estimated from current status information;

- The number of infants and children under breastfeeding at interview day is one the main reasons for the difference between EBF and BF median based on current status and retrospective recall data;

- The retrospective recall data can capture and assess the EBF and BF length as accurately as current status estimator;

- The retrospective recall data should be used in an advantageous way at the individual level to evaluate public policies.

\author{
Abbreviations \\ BF: breastfeeding \\ DHS: Demographic Health Survey \\ EBF: exclusive breastfeeding \\ KM: Kaplan Meier \\ LR: Logistic regression
}

\title{
Competing interests
}

The authors declare that they have no competing interests.

\section{Authors' contributions}

AEMR contributed to conception, to configure all datasets, to performer the statistical analysis, to write the manuscript. WLC contributed to conception, to design the statistical analysis and to review final version of manuscript. All authors read and approved the final manuscript.

\section{Acknowledgement}

We appreciated the Full Professor Jose Maria Pacheco de Souza from School of Public Health (University of Sao Paulo) to discuss about the statistical analysis. We also appreciated the graduate student Vanessa Manfre from School of Public Health (University of Sao Paulo) to configure three datasets. 


\section{References}

Agampodi, S.B., Fernando, S., Dharmaratne, S.D., Agampodi, T.C., 2011. Duration of exclusive breastfeeding; validity of retrospective assessment at nine months of age. BMC Pediatr. 11, 80. doi:10.1186/1471-2431-11-80

Barbosa, R.W., Oliveira, A.E., Zandonade, E., Neto, S., Dos, E.T., 2012. Mothers' memory about breastfeeding and sucking habits in the first months of life for their children. Rev. Paul. Pediatr. 30, 180-186. doi:10.1590/S0103-05822012000200005

Chapman, D.J., Perez-Escamilla, R., 2009. US National Breastfeeding Monitoring and Surveillance: Current Status and Recommendations. J. Hum. Lact. Off. J. Int. Lact. Consult. Assoc. 25, 139-150. doi:10.1177/0890334409332437

Chola, L., Fadnes, L.T., Engebretsen, I.M.S., Tumwine, J.K., Tylleskar, T., Robberstad, B., PROMISE EBF Study Group, 2013. Infant feeding survival and Markov transition probabilities among children under age 6 months in Uganda. Am. J. Epidemiol. 177, 453-462. doi:10.1093/aje/kws254

Cupul-Uicab, L.A., Gladen, B.C., Hernández-Avila, M., Longnecker, M.P., 2009. Reliability of reported breastfeeding duration among reproductive-aged women from Mexico. Matern. Child. Nutr. 5, 125137. doi:10.1111/j.1740-8709.2008.00159.x

Gould, S.J., 1985. The median isn't the message. Discover 6, 40-42.

Greiner, T., 2014. Exclusive breastfeeding: measurement and indicators. Int. Breastfeed. J. 9, 18. doi:10.1186/1746-4358-9-18

Grummer-strawn, L.M., 1993. Regression analysis of current-status data: an application to breastfeeding. J. Am. Stat. Assoc. 88, 758-765.

Hector, D.J., 2011. Complexities and subtleties in the measurement and reporting of breastfeeding practices. Int. Breastfeed. J. 6, 5. doi:10.1186/1746-4358-6-5

Launer, L.J., Forman, M.R., Hundt, G.L., Sarov, B., Chang, D., Berendes, H.W., Naggan, L., 1992. Maternal recall of infant feeding events is accurate. J. Epidemiol. Community Health 46, 203-206.

Li, R., Scanlon, K.S., Serdula, M.K., 2005. The validity and reliability of maternal recall of breastfeeding practice. Nutr. Rev. 63, 103-110.

Piwoz, E.G., Creed de Kanashiro, H., Lopez de Romaña, G., Black, R.E., Brown, K.H., 1995. Potential for misclassification of infants' usual feeding practices using 24-hour dietary assessment methods. J. Nutr. 125, 57-65.

Shiboski, S.C., 1998. Generalized Additive Models for Current Status Data. Lifetime Data Anal. 4, 29 50. doi:10.1023/A:1009652024999

Van Beusekom, I., Vossenaar, M., Montenegro-Bethancourt, G., Doak, C.M., Solomons, N.W., 2013. Estimates of exclusive breastfeeding rates among mother-infant dyads in Quetzaltenango, Guatemala, vary according to interview method and time frame. Food Nutr. Bull. 34, 160-168.

WHO | Indicators for assessing breastfeeding practices [WWW Document], n.d. WHO. URL http://www.who.int/maternal_child_adolescent/documents/cdd_ser_91_14/en/ (accessed 10.6.14).

WHO | Indicators for assessing infant and young child feeding practices [WWW Document], n.d. WHO. URL http://www.who.int/maternal_child_adolescent/documents/9789241596664/en/ (accessed 1.2.15a).

WHO | Indicators for assessing infant and young child feeding practices [WWW Document], n.d. WHO. URL http://www.who.int/maternal_child_adolescent/documents/9789241599290/en/ (accessed 1.2.15b). 
WHO | Long-term effects of breastfeeding: a systematic review [WWW Document], n.d. WHO. URL http://www.who.int/maternal_child_adolescent/documents/breastfeeding_long_term_effects/en/ (accessed 2.3.15).

WHO | The optimal duration of exclusive breastfeeding [WWW Document], n.d. WHO. URL http://www.who.int/nutrition/publications/infantfeeding/WHO_NHD_01.08/en/ (accessed 1.2.15).

Table 1. Exclusive breastfeeding and breastfeeding median estimated by current status, logistic regression and survival analysis in seven countries.

\begin{tabular}{|c|c|c|c|c|}
\hline & \multicolumn{3}{|c|}{ Current status data } & \multirow{2}{*}{$\begin{array}{c}\text { Retrospective } \\
\text { recall data }\end{array}$} \\
\hline $\begin{array}{c}\text { Countries } \\
\text { (infant number) }^{1}\end{array}$ & $\begin{array}{l}\text { Publishes } \\
\text { results }^{2}\end{array}$ & $\begin{array}{l}\text { Current } \\
\text { status }\end{array}$ & Logit & \\
\hline $\begin{array}{c}\text { Exclusive } \\
\text { breastfeeding }\end{array}$ & \multicolumn{4}{|c|}{ Median } \\
\hline Bolivia (863) & 3.5 & 3.3 & 3.9 & 5.0 \\
\hline Brazil (494) & 1.4 & 1.5 & 1.5 & 2.0 \\
\hline Colombia (359) & 0.5 & $0.8^{*}$ & $\ldots$ & 0.02 \\
\hline Egypt (827) & 1.8 & 1.6 & 2.3 & 2.0 \\
\hline India (6599) & 1.4 & 1.1 & 1.9 & 2.0 \\
\hline Kenya (582) & 0.5 & $0.8^{*}$ & $\ldots$ & 0.02 \\
\hline Rwanda (578) & 5.4 & 5.5 & $\ldots$ & 6.0 \\
\hline Breastfeeding & \multicolumn{4}{|c|}{ Median } \\
\hline Bolivia (5017) & 18.8 & 18.7 & 19.8 & 18.0 \\
\hline Brazil (2877) & 14.0 & 13.9 & 14.7 & 12.0 \\
\hline Colombia (2233) & 9.0 & 9.1 & 11.5 & 9.0 \\
\hline Egypt (4772) & 19.1 & 19.1 & 18.8 & 19.0 \\
\hline India (34418) & 24.4 & 25.1 & 27.0 & 26.0 \\
\hline Kenya (3347) & 21.1 & 22.3 & 22.1 & 22.0 \\
\hline Rwanda (3006) & 27.9 & 29.4 & 29.9 & 30.0 \\
\hline
\end{tabular}




\section{ANEXO 5}

Efeito do desenho do estudo das variáveis sociodemográficas, de saúde maternoinfantil, de aleitamento materno e da alimentação infantil segundo ano do inquérito. Brasil, 1986-2006.

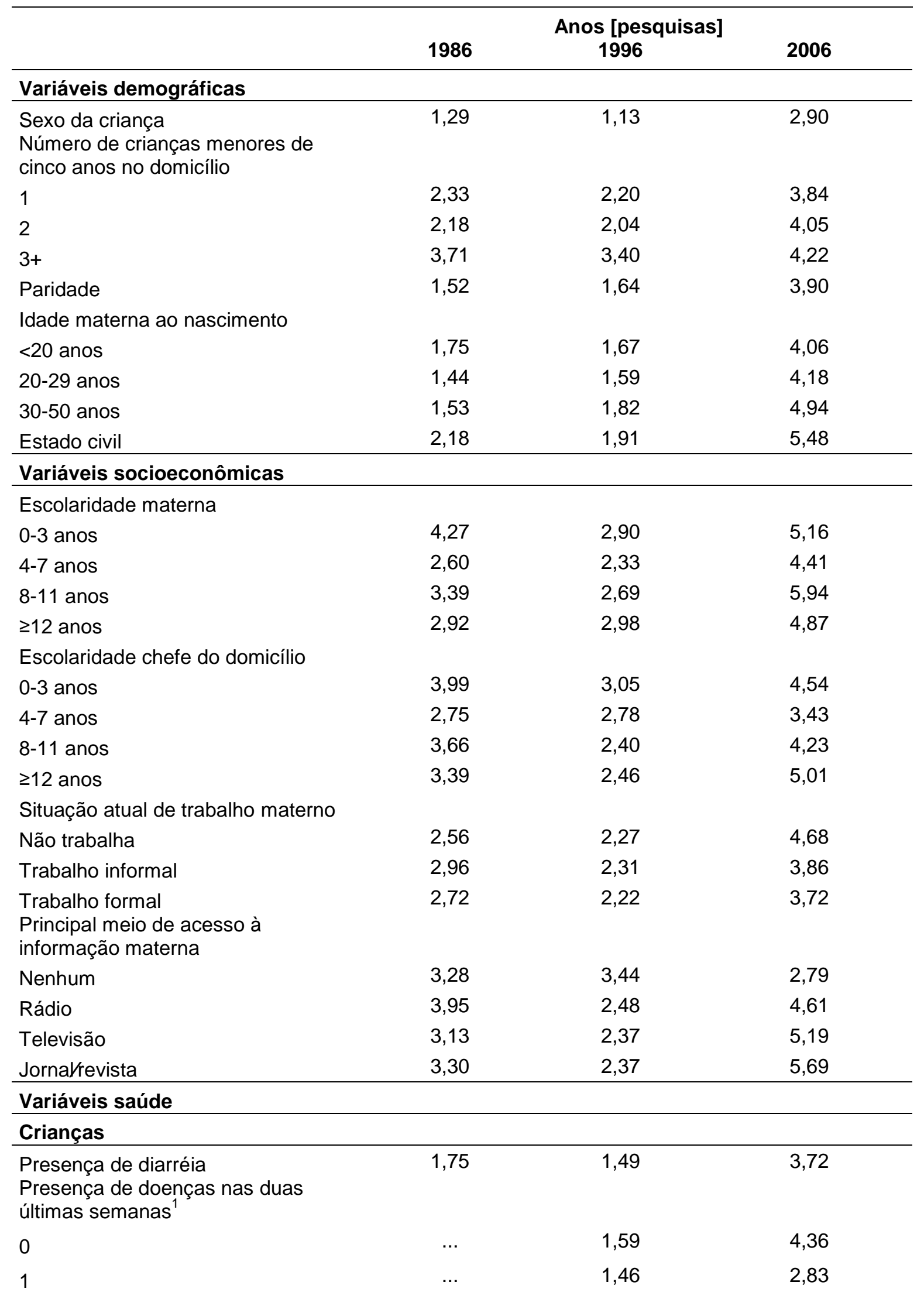




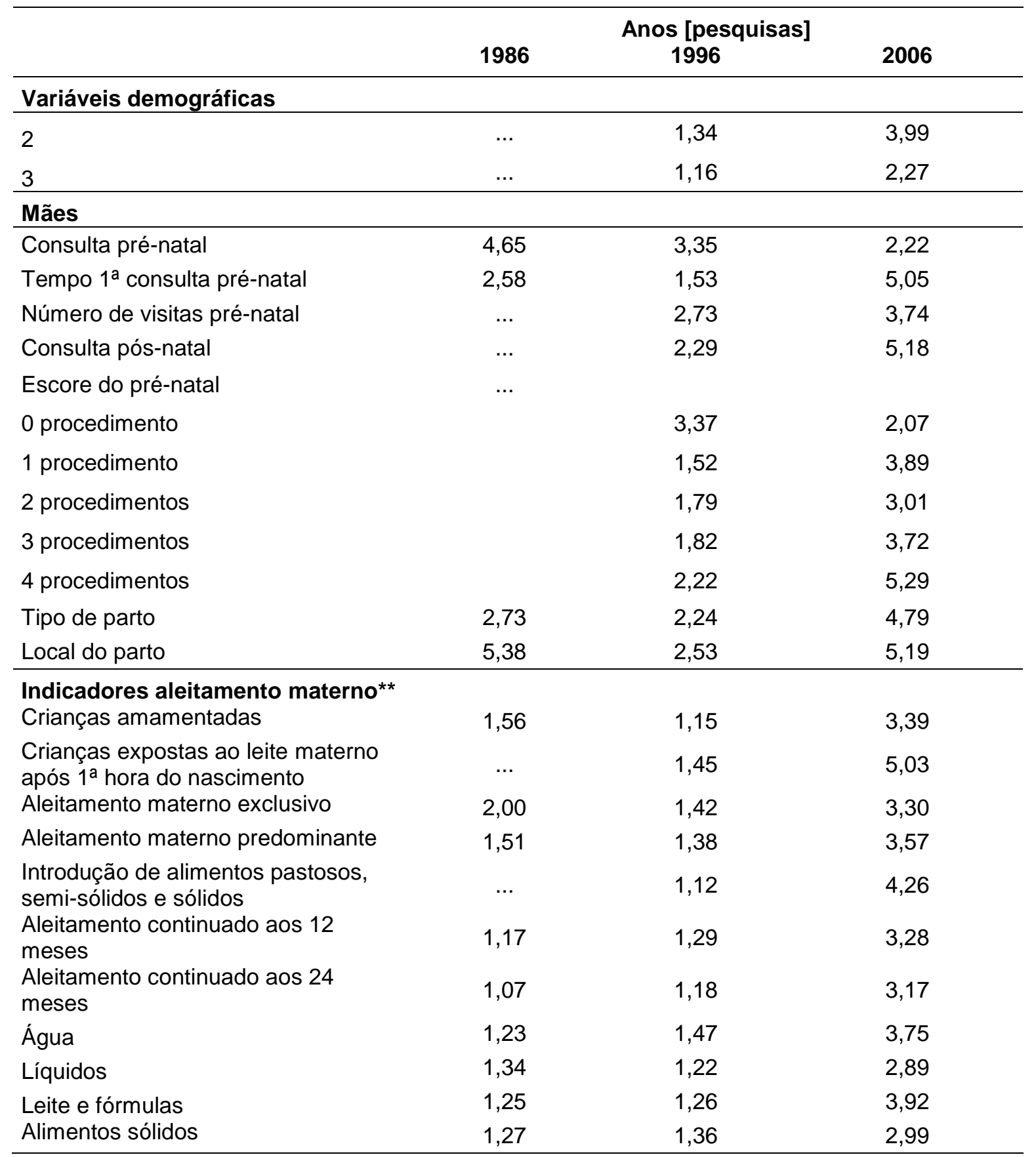

*Variáveis indisponíveis no inquérito de 1986

**Todas as estimativas de aleitamento materno e alimentação infantil foram estimadas para crianças menores de 24 meses, com exceção de aleitamento materno predominante e exclusivo (crianças menores de seis meses) 


\section{ANEXO 6}

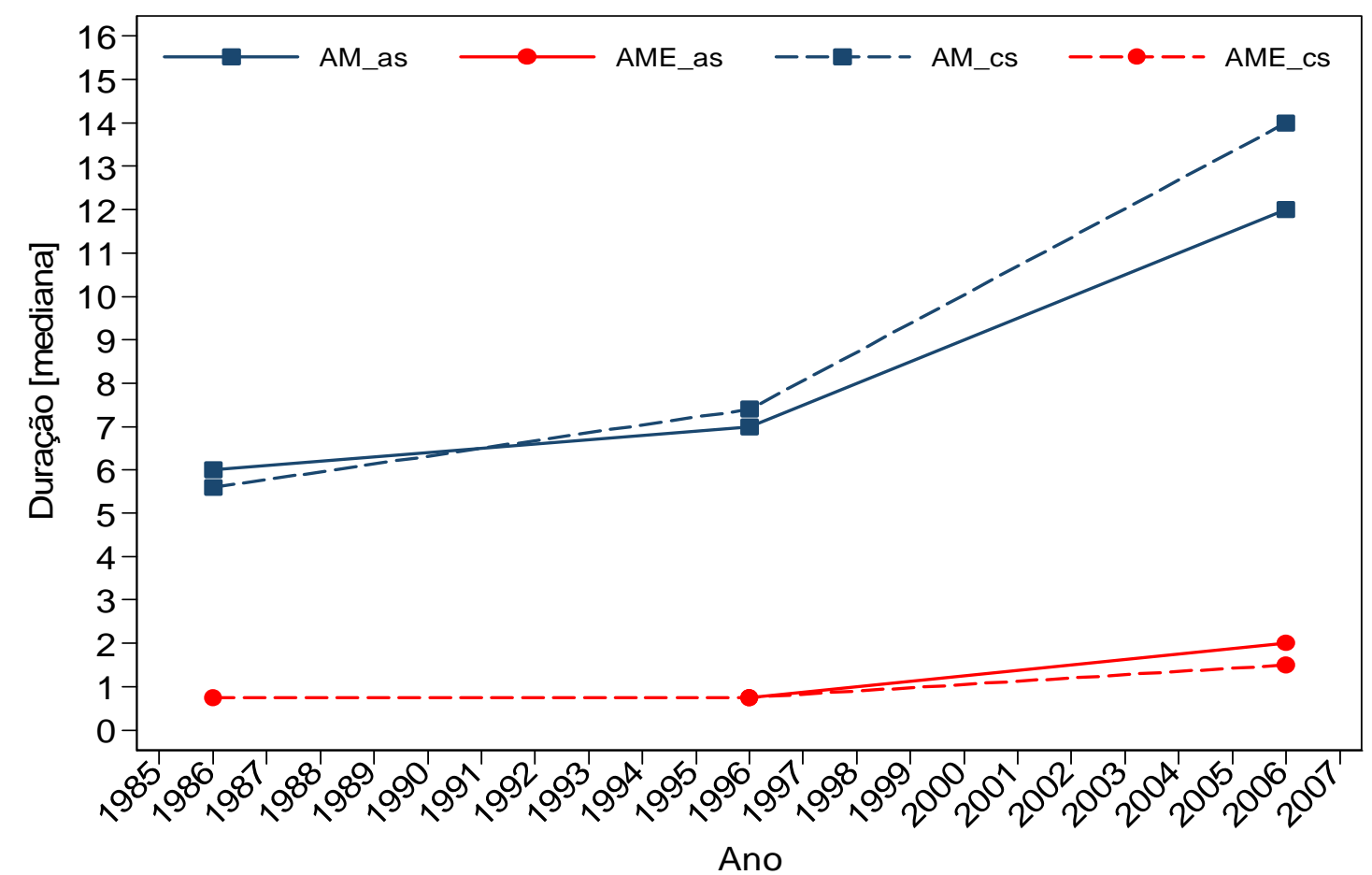

Análise de sobrevida: método de Kaplan Meier; Current status: médias móveis (recomendação Organização Mundial da Saúde) Figura. Duração mediana do aleitamento materno e aleitamento materno exclusivo nas três últimas décadas estimada por análise de sobrevida (as) e current status (cs). Brasil, 1986-2006.

\section{Current status}

Neste método, o cálculo da mediana é realizado pela interpolação linear da proporção de crianças classificadas em aleitamento materno exclusivo por faixa etária (bimestral) que estão imediatamente acima e abaixo de $50 \%$ dos valores. As informações detalhadas e os fundamentos do método estão disponíveis em manuais específicos (WHO, 2006; Macro, 2005)

Referências:

World Health Organization. Indicators for assessing infant and Young child feeding practices, 2006. Disponível em: http://www.who.int/maternal_child_adolescent/documents/9789241596664/en/

Rutstein, S.O.; Rojas, G. MEASURE DHS/ICF International. Guide to DHS Statistic, 2006. Disponível em: http://dhsprogram.com/pubs/pdf/DHSG1/Guide_to_DHS_Statistics_29Oct2012_DHSG1.pdf 


\section{CURRICULUM LATTES}

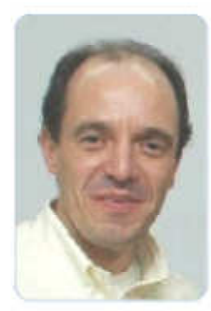

\section{Wolney Lisboa Conde}

Endereço para acessar este CV: http://attes.cnpq.br/3019128679501921

úlima atualzaçăo do curriculo em 05/06/2014

possui graduação em Nutrição pela Universidade Federal do Pará (1991) e doutorado em Saúde Pública pela Universidade de São Paulo (2004). Atualmente é professor doutor da Universidade de São Paulo, atuando no curso de graduação em Nutrição e no curso de pós-graduação em Nutrição em Saúde Pública. Tem experiência na área de Saúde Coletiva, com ênfase em Nutrição, atuando principalmente nos seguintes temas: epidemiologia nutricional, transição nutricional, obesidade, determinantes do estado nutricional e antropometria. (Texto informado pelo autor)

Identificação

Nome Wolney Lisboa Conde

Nome em citaçôes bibliográficas CONDE, W. L;; Popkin, Barry M.;Conde, Wolney L.;de Assis, M. A. A.

Endereço

Endereço Profissional Universidade de São Paulo, Faculdade de Saúde Pública, Departamento de Nutriçāo.

Av. Dr. Amaldo, 715 , Laboratório de Avaliaçāo Nutricional de Populaçōes

Cerqueira César

01246-904 - Sao Paulo, SP - Brasil

Telefone: (11) 30667705

Fax: (11) 30667762

URL da Homepage: http://www.fsp.usp.br/

Formação acadêmica/titulação

\begin{tabular}{|c|c|}
\hline \multirow[t]{2}{*}{$2000-2004$} & $\begin{array}{l}\text { Doutorado em Saúde Pública (Conceito CAPES 6). } \\
\text { Universidade de São Paulo, USP, Brasil. } \\
\text { Titulo: DESENVOLVIMENTO E APLICAÇÃO DE SISTEMA CLASSIFICATÓRIO PARA } \\
\text { AVALIAÇÃO DO ESTADO NUTRICIONAL. DE CRIANÇAS E ADQLESCENTES } \\
\text { BRASILEIROS BASEADO NO ÍNDICE DE MASSA CORPORAL, Ano de obtenção: } \\
2004 .\end{array}$ \\
\hline & $\begin{array}{l}\text { Orientador: (1) Carlos Augusto Monteiro. } \\
\text { Palavras-chave: adolescente; IMC; padrão; crianç; método; tendência secular. } \\
\text { Grande área: Gências da Saúde / Área: Saúde Coletiva / Subárea: Epidemiologia } \\
\text { / Especialidade: Nutrição. } \\
\text { Setores de atividade: Nutrição e Alimentação. }\end{array}$ \\
\hline $1992-1992$ & $\begin{array}{l}\text { Especialização em Fipam. } \\
\text { Universidade Federal do Pará, UFPA, Brasil. } \\
\text { Titulo: O Complexo Agoindustrial e o Desenvolvimento Regional. } \\
\text { Orientador: José Marcelino. } \\
\text { Bolsista do(a): Coordenação de Aperfeiçoamento de Pessoal de Nivel Superior, } \\
\text { CAPES, Brasil. }\end{array}$ \\
\hline $1985-1991$ & $\begin{array}{l}\text { Graduação em Nutrição. } \\
\text { Universidade Federal do Pará, UFPA, Brasil. } \\
\text { Titulo: A Porta da Cozinha. } \\
\text { Orientador: Maria Angélica Mota-Maués. }\end{array}$ \\
\hline
\end{tabular}




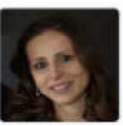

Ana Elisa Madalena Rinaldi

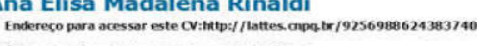

Uttine attualizactoo do curricido en 63/02/2015

Resumo informado pelo autor

Nutricionista pela Universidade Estadual Paulista Jülio de Mesquita Filho (2004). Possui aprimoramento profissional em Bioquínica Nutricional e Dietética pela Faculdaude de Medicina de Botucatu. Mestre em Nutricäo Humana Aplicada (PRONUTI-USP). Professora Assistente da Unuersidade Federal de Uberlandia (UFU). Atua principaimente nos seguintes temas: aleitamento materno e alimentação infantil, avaliação do consumo alimentar $\mathbf{e}$ avaliação do estado nutricional.

(Texto informado pelo autor)

Dados pessoais

Nome Ana Elisa Madaiena Rinacic

Fillaçaco Jose Nelison Rennaldi E Odere Madalena Rinace

Nascimento 17/02/1982- Jau/SP - Bras

Carteira de $303007229 \mathrm{SSP}-\mathrm{SP}-1301 / 2004$
Identidade

CPF $303012258 \cdot 18$

Passporte FGe06041

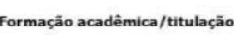

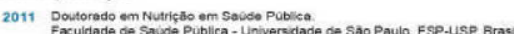

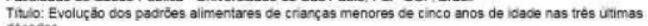
Onentasor Woingy Lisboa Conde (6)

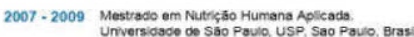

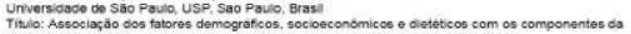

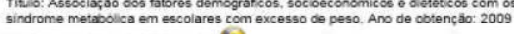
Onentasor: Roserno carlos Bumn (t)

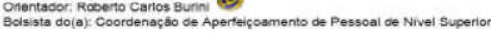

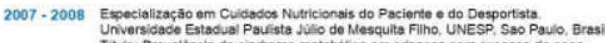

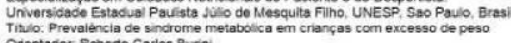

$2000-2004$ Graduaçă am Nutriçă

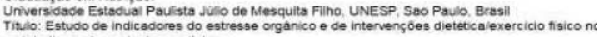

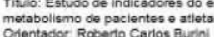

Bdestas do(a) Canseho Nacional dia Desenvovimento Cientinco e Techologico

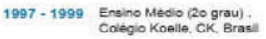

1989 - 1996 Ersino Fundamental (10 grau)

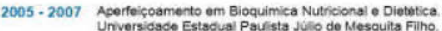

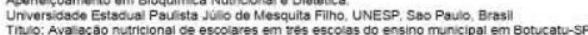

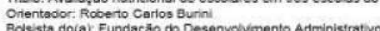

Formaçầ complementa

2004-2004 Nutriço Clinica no Gan

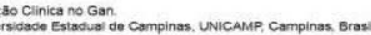

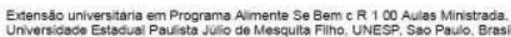

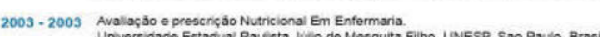

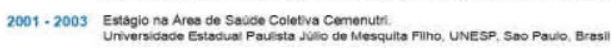

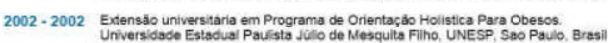

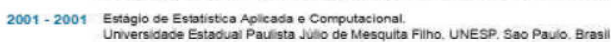

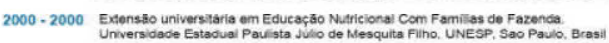

Atuaçāo profissional

1. Universidade Federal de Uberiandila - UFU

Vinculo
instutucional

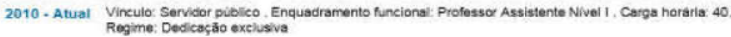

Atividades

06/2010 - Atual Extensdo Universtaria, Faculdade de Medicina

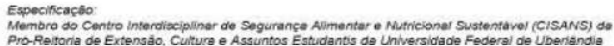

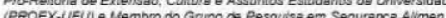

2. Universidade Estadual Paulista Jülio de Mesquita Filho - UNESP

Vinculo
institucional

2009-2009 Vireulo: Professor subettuto, Enquastramento Aneiona: CLT, Carga herdis: 12, Ragime: Parcial

3. Faculdade de Medicina de Botucatu - FMB 